University of San Diego

Digital USD

1997-05-01

\title{
Role Expectation of Chief Nurse Executive Officers in Integrated Healthcare Systems Located in Highly Managed Care Markets
}

Daniel L. Gross DNSc

University of San Diego

Follow this and additional works at: https://digital.sandiego.edu/dissertations

Part of the Nursing Commons

\section{Digital USD Citation}

Gross, Daniel L. DNSc, "Role Expectation of Chief Nurse Executive Officers in Integrated Healthcare Systems Located in Highly Managed Care Markets" (1997). Dissertations. 264.

https://digital.sandiego.edu/dissertations/264

This Dissertation: Open Access is brought to you for free and open access by the Theses and Dissertations at Digital USD. It has been accepted for inclusion in Dissertations by an authorized administrator of Digital USD. For more information, please contact digital@sandiego.edu. 
ROLE EXPECTATIONS OF CHIEF NURSE EXECUTIVE OFFICERS IN INTEGRATED HEALTHCARE SYSTEMS LOCATED IN HIGHLY MANAGED CARE MARKETS

$$
\text { by }
$$

Daniel L. Gross

\begin{abstract}
A dissertation presented to the
FACULTY OF THE PHILIP Y. HAHN SCHOOL OF NURSING UNIVERSITY OF SAN DIEGO
\end{abstract}

In partial fulfillment of the

requirements for the degree

DOCTOR OF NURSING SCIENCE

May 1997

Dissertation Committee

Janet Harrison, EdD, RN, Chair

Mary Jo Clark, PhD, RN

Susan Zgliczynski, PhD 


\section{ABSTRACT}

The healthcare industry is undergoing radical transformation. Healthcare's transformation is characterized by new patterns of organization, alliance, management, administration, and governance. Traditional fee-for-senice reimbursement strategies are rapidly dissolving and managed health care is proliferating. Managed care and managed competition are forcing hospitals and healthcare providers to reduce expenses and identify improved methods for healthcare delivery. Integrated healthcare delivery systems (IDSs) and networks are at the center of healthcare reform. Chief Nurse Executive Officers (CNEOs) are increasingly finding themselves in roles within complex IDSs located within highly managed care markets (HMCMs). This new work environment is altering old and mandating new CNEO role expectations. The purpose of this study was to identify present-day and future role expectations for CNEOs employed in IDSs located within HMCMs and determine the level of consensus between CNEOs and CNEO supervisors on present-day and future CNEO role expectations.

The research methodology employed was a Delphi process. A 25 member expert panel, 15 CNEOs and 10 CNEO supervisors, completed three iterative survey rounds. The panel retention rate was $83 \%$. The panel reached consensus on 59 present-day and 59 identical future role expectations for CNEOs working in IDSs in HMCMs. Three major categories of CNEO role expectations were identified: leadership role expectations, clinical role expectations, and system/organizational improvement expectations. Mean importance ratings for the CNEO role expectations revealed all but one present-day and two future CNEO role expectations to be important. Stratification of CNEO role expectations by CNEO and CNEO supervisor sub-groups revealed a high level of consensus between CNEOs and CNEO supervisors on present-day CNEO role expectations and a moderately high level of consensus on future CNEO role 
expectations.

Study implications relate to successful CNEO role enactment; increased CNEO job satisfaction; decreased CNEO turnover, and development of graduate curricula, educational offerings, position descriptions, and performance standards. Further study was recommended to validate study findings, explore more fully future CNEO role expectations, and determine how study findings are communicated, operationalized, and evaluated in the work setting. 
(c) Copyright by Daniel L. Gross 1997

\section{ALL RIGHTS RESERVED}




\section{DEDICATION}

This dissertation is dedicated to the expert panelists who took time from their busy work schedules to make this study a reality and to my wife, Cathy, who provided ongoing assistance and commitment throughout this endeavor. 


\section{ACKNOWLEDGEMENTS}

I would like to begin by acknowledging and thanking two individuals who truly made this academic journey possible. I thank Dr. Jan Stichler for introducing me to the doctoral program at the University of San Diego and the gentle nudging provided which motivated me to embark upon my doctoral studies. A heartfelt respect and thank-you is extended to Marian Hubbard for her generous scholarship which financially supported my studies.

I am most appreciative of a wonderful and talented dissertation committee led by Dr. Janet Harrison. Jan's leadership and support has been remarkable not only throughout this study but throughout my entire doctoral program-thank you! I am also grateful for the guidance and wisdom provided by Dr.'s Mary Jo Clark and Susan Zgliczynski. I am exceedingly appreciative of my dissertation committee for their responsiveness to requests for meetings and timely reviews of manuscripts and their commitment to my learning. Unquestionably, my positive dissertation experience and feelings of accomplishment are directly related to the support I have received from Dr.'s Harrison, Clark, and Zgliczynsiki; I am indebted.

The support of friends and colleagues during this educational journey has been extraordinary. I thank June Andrea for her friendship and unwavering support and motivation. I thank Julie Lucas for her perseverance, calmness, and ability to balance my unbelievable work and study schedule for four long years. Willa Fields, Nancy Saks, Dale Glaser, Lorie Thomas, and Barbara Riegal-thank you. And to all of the school and work colleagues who have supported me by providing insight and undying encouragement I am grateful; to name a few Sandy Noon, Judy Fix, Marian Furlong, Paul and Susan Murray, Dr.'s Rita Snyder-Halpern and Julie Erickson.

Finally, to my wife-l love and thank you! You truly made it possible! 


\section{TABLE OF CONTENTS}

DEDICATION $\ldots \ldots \ldots \ldots \ldots \ldots \ldots \ldots \ldots \ldots \ldots \ldots \ldots \ldots \ldots \ldots \ldots \ldots \ldots \ldots \ldots$

ACKNOWLEDGEMENTS $\ldots \ldots \ldots \ldots \ldots \ldots \ldots \ldots \ldots \ldots \ldots \ldots \ldots \ldots \ldots \ldots \ldots \ldots$

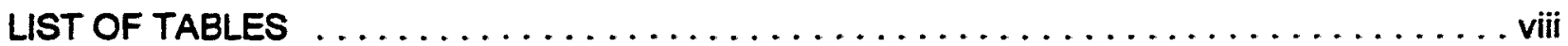

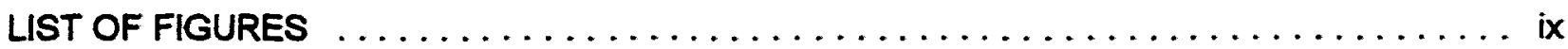

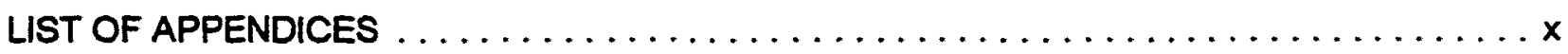

CHAPTERI INTRODUCTION $\ldots \ldots \ldots \ldots \ldots \ldots \ldots \ldots \ldots \ldots \ldots \ldots \ldots \ldots \ldots$

Statement of Issue $\ldots \ldots \ldots \ldots \ldots \ldots \ldots \ldots \ldots \ldots \ldots \ldots \ldots$

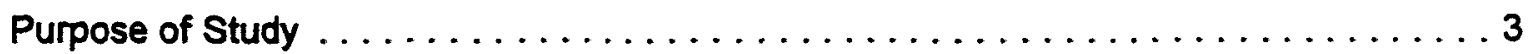

Research Questions $\ldots \ldots \ldots \ldots \ldots \ldots \ldots \ldots \ldots \ldots \ldots \ldots \ldots$

Theoretical Framework $\ldots \ldots \ldots \ldots \ldots \ldots \ldots \ldots \ldots \ldots \ldots \ldots \ldots$

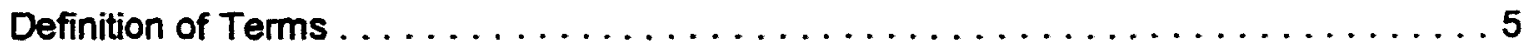

Significance of the Study $\ldots \ldots \ldots \ldots \ldots \ldots \ldots \ldots \ldots \ldots \ldots \ldots \ldots$

Assumptions and Limitations $\ldots \ldots \ldots \ldots \ldots \ldots \ldots \ldots \ldots \ldots \ldots$

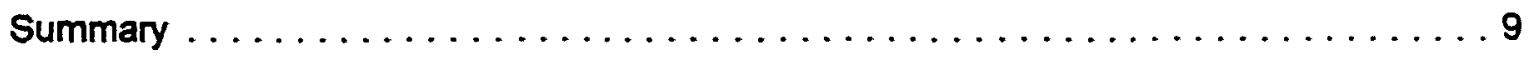

CHAPTER II REVIEW OF THE LITERATURE $\ldots \ldots \ldots \ldots \ldots \ldots \ldots \ldots \ldots \ldots \ldots \ldots$

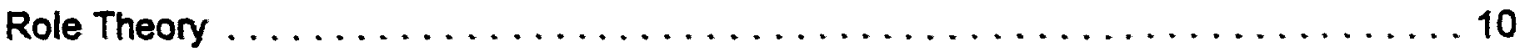

Domain/Origin/Evolution $\ldots \ldots \ldots \ldots \ldots \ldots \ldots \ldots \ldots \ldots \ldots \ldots \ldots \ldots \ldots \ldots \ldots$

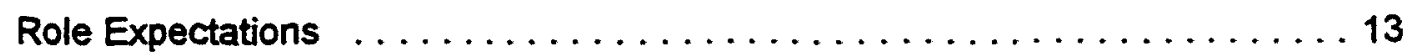

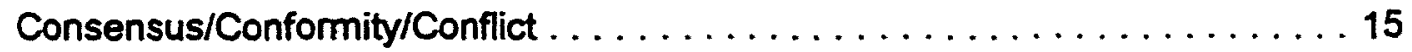

Chief Nurse Officer Role Expectations $\ldots \ldots \ldots \ldots \ldots \ldots \ldots \ldots \ldots \ldots \ldots$

iv 
Historical CNEO Role Expectations $\ldots \ldots \ldots \ldots \ldots \ldots \ldots \ldots \ldots \ldots$

Traditional CNEO Role Expectations $\ldots \ldots \ldots \ldots \ldots \ldots \ldots \ldots \ldots$

Research-based CNEO Role Expectations . . . . . . . . . . . . . 19

Transformational CNEO Expectations $\ldots \ldots \ldots \ldots \ldots \ldots \ldots \ldots \ldots$

Managed care and integrated healthcare delivery systems $\ldots \ldots \ldots 24$

CNEO role expectations $\ldots \ldots \ldots \ldots \ldots \ldots \ldots \ldots \ldots \ldots$

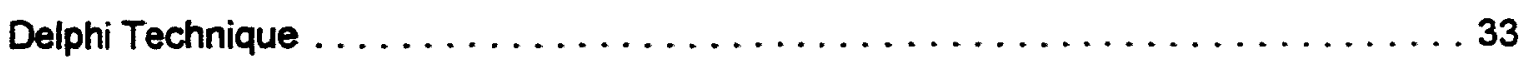

Characteristics/Strengths $\ldots \ldots \ldots \ldots \ldots \ldots \ldots \ldots \ldots \ldots \ldots \ldots$

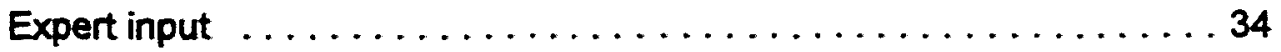

Anonymity of panel and response $\ldots \ldots \ldots \ldots \ldots \ldots \ldots \ldots$

Iteration with controlled feedback $\ldots \ldots \ldots \ldots \ldots \ldots \ldots$

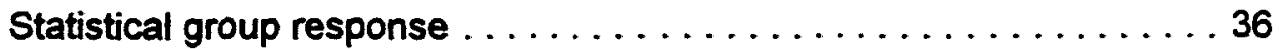

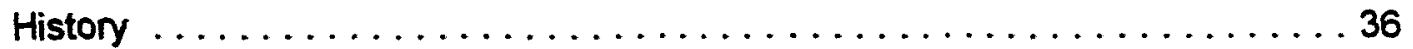

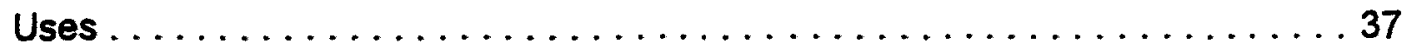

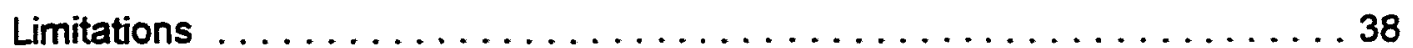

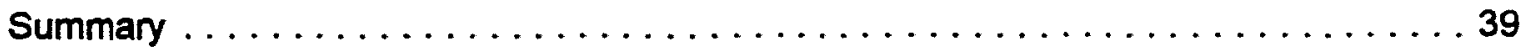

CHAPTER III METHODOLOGY $\ldots \ldots \ldots \ldots \ldots \ldots \ldots \ldots \ldots \ldots \ldots \ldots \ldots \ldots \ldots \ldots$

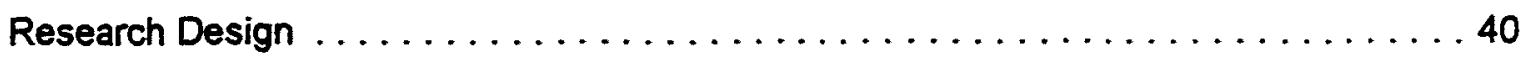

Research Design Limitations: Delphi Method $\ldots \ldots \ldots \ldots \ldots \ldots \ldots$

Consensus $\ldots \ldots \ldots \ldots \ldots \ldots \ldots \ldots \ldots \ldots \ldots \ldots \ldots \ldots \ldots \ldots \ldots \ldots \ldots$

Minority and extreme opinion $\quad 42$

Researcher bias $\ldots \ldots \ldots \ldots \ldots \ldots \ldots \ldots \ldots \ldots \ldots \ldots$

Panel attrition and subject bias $\ldots \ldots \ldots \ldots \ldots \ldots \ldots \ldots$

Expert Panel Selection $\ldots \ldots \ldots \ldots \ldots \ldots \ldots \ldots \ldots \ldots \ldots \ldots \ldots \ldots \ldots \ldots \ldots \ldots$

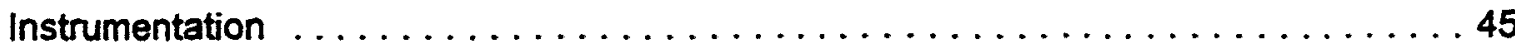

v 


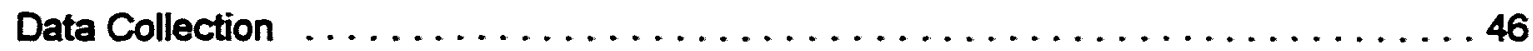

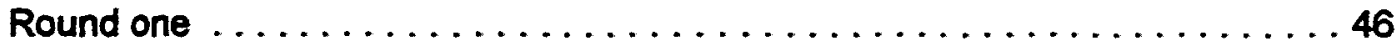

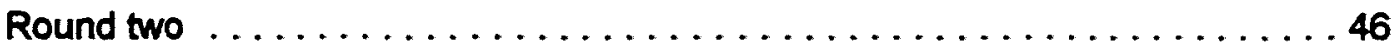

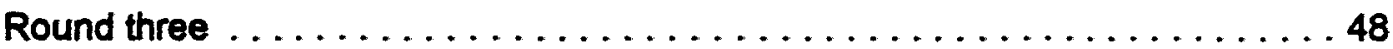

Data Analysis . . . . . . . . . . . . . . . . . . . . . . . . . 50

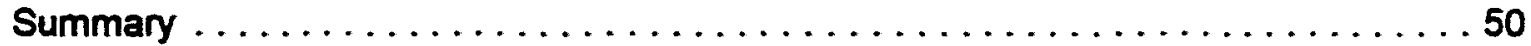

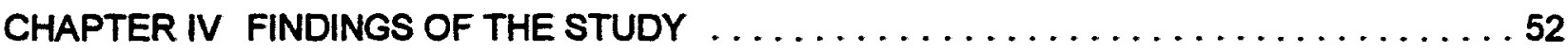

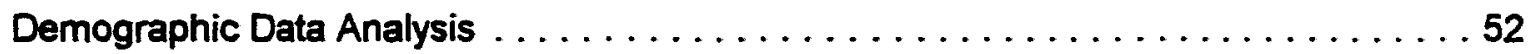

Personal Demographic Data . . . . . . . . . . . . . . . . . . . 53

Professional/role Demographic Data . . . . . . . . . . . . . . . 53

Organizational Demographic Data $\ldots \ldots \ldots \ldots \ldots \ldots \ldots \ldots \ldots \ldots \ldots \ldots \ldots \ldots$

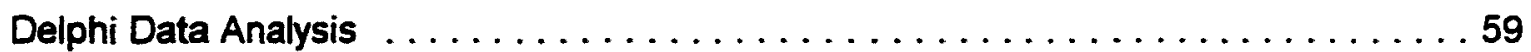

Round One Results $\ldots \ldots \ldots \ldots \ldots \ldots \ldots \ldots \ldots \ldots \ldots$

Round Two Results .......................... 59

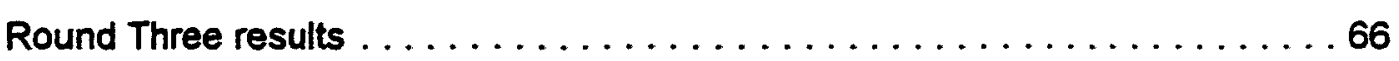

Non-consensus present-day CNEO role expectations $\ldots \ldots \ldots \ldots 66$

Additional present-day CNEO role expectations $\ldots \ldots \ldots \ldots \ldots 66$

Present-day CNEO role expectations $\ldots \ldots \ldots \ldots \ldots \ldots \ldots \ldots 68$

Future CNEO role expectations $\ldots \ldots \ldots \ldots \ldots \ldots \ldots \ldots$

Consensus between CNEOs and CNEO supervisors on present-

day CNEO role expectations $\ldots \ldots \ldots \ldots \ldots \ldots \ldots \ldots$

Consensus between CNEOs and CNEO supervisors on future

CNEO role expectations $\ldots \ldots \ldots \ldots \ldots \ldots \ldots \ldots \ldots$

Panelists' consensus on present-day and future CNEO role expectations by mean importance ratings $\ldots \ldots \ldots \ldots \ldots 84$

vi 
Future direction, importance, and evolution of the CNEO role $\ldots \ldots \ldots 84$

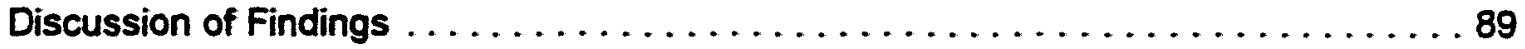

Demographic Findings $\ldots \ldots \ldots \ldots \ldots \ldots \ldots \ldots \ldots \ldots$

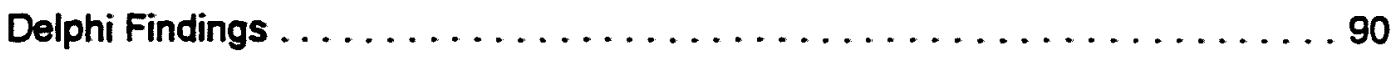

Consensus Present-day and Future CNEO Role Expectations $\ldots \ldots \ldots \ldots 90$

Leadership expectations $\ldots \ldots \ldots \ldots \ldots \ldots \ldots \ldots \ldots \ldots \ldots$

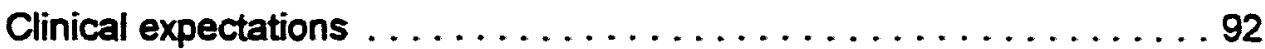

System/Organizational improvement expectations $\ldots \ldots \ldots \ldots \ldots .93$

Consensus Between CNEOs and CNEO Supervisors on Present-

day and Future CNEO Role Expectations $\ldots \ldots \ldots \ldots \ldots \ldots$

Future Direction, Importance, and Evolution of the CNEO Role . . . . . . . . 95

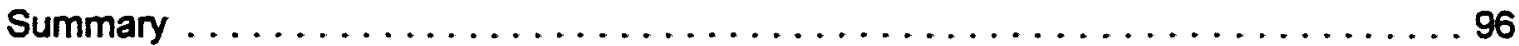

CHAPTER $V$ SUMMARY, CONCLUSIONS, AND RECOMMENDATIONS $\ldots \ldots \ldots \ldots .97$

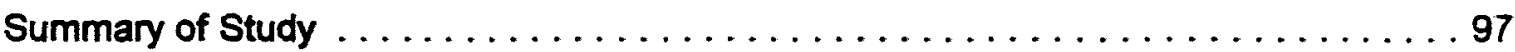

Statement of the Issue $\ldots \ldots \ldots \ldots \ldots \ldots \ldots \ldots \ldots$. . . . . . . . . .

Purpose of the Study $\ldots \ldots \ldots \ldots \ldots \ldots \ldots \ldots \ldots \ldots \ldots$

Methodology . . . . . . . . . . . . . . . . . . . . . 98

Results ................................ 99

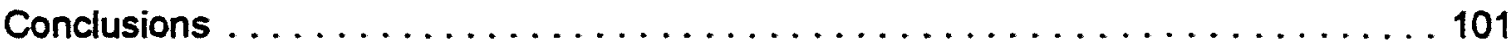

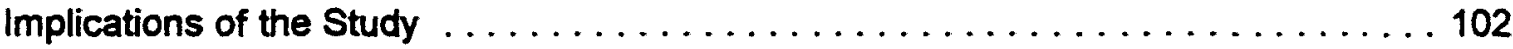

Recommendations for Further Research $\ldots \ldots \ldots \ldots \ldots \ldots \ldots \ldots . \ldots \ldots$

Strengths of the Study . . . . . . . . . . . . . . . . . . . . . . 104

Weaknesses of the Study . . . . . . . . . . . . . . . . . . 104

Recommendations for Further Study $\ldots \ldots \ldots \ldots \ldots \ldots \ldots \ldots \ldots \ldots$

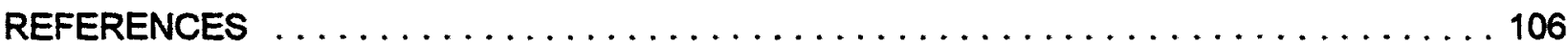

vii 


\section{LIST OF TABLES}

TABLE

PAGE

1. Round One: Panelist Identified Present-day Role Expectations for CNEOs

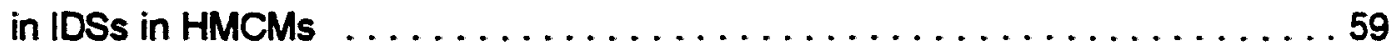

2. Round Two: Non-Consensus Present-day CNEO Role Expectations . . . . . 65

3. Round Two: Additional Present-day CNEO Role Expectations $\ldots \ldots \ldots \ldots 67$

4. Present-day and Future Role Expectations for CNEOs in IDSs in HMCMs . . . 69

5. Shared and Non-shared Extremely Important Present-day Role Expectations

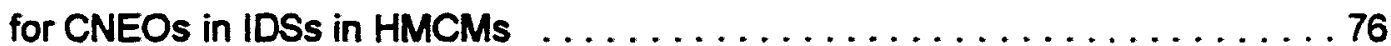

6. Shared and Non-shared Extremely Important Future Role Expectations

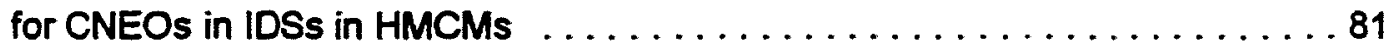

7. Consensus Present-day Role Expectations for CNEOs in IDSs in HMCMs . . . 86

8. Consensus Future Role Expectations for CNEOs in IDSs in HMCMs . . . . . 88 


\section{LIST OF FIGURES}

FIGURE

PAGE

1. Delphi study rounds and related process activities $\ldots \ldots \ldots \ldots \ldots \ldots \ldots \ldots$

2. Panelists' highest earned academic degree by CNEO and CNEO

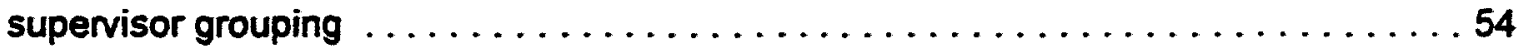

3. Years in an administrative role by CNEO and CNEO supervisor grouping $\ldots \ldots \ldots 55$

4. Percent of contracted and capitated managed care reimbursement received by CNEO and CNEO supervisor hospitals $\ldots \ldots \ldots \ldots \ldots \ldots \ldots \ldots \ldots \ldots$

5. Continuum of care services provided by panelists' IDSs $\ldots \ldots \ldots \ldots \ldots \ldots \ldots$

6. Numerical breakdown of shared and non-shared extremely important present-day CNEO role expectations by CNEO and CNEO supervisor sub-groups $\ldots \ldots \ldots \ldots .80$

7. Numerical breakdown of shared and non-shared extremely important future CNEO role expectations by CNEO and CNEO supervisor sub-groups $\ldots \ldots \ldots \ldots 85$ 


\section{LIST OF APPENDICES}

$\begin{array}{ll}\text { APPENDIX PAGE } & \text { PAX }\end{array}$

A Invitation to Participate in Study ........................... 120

B Demographic Questionnaire . . . . . . . . . . . . . . . . . 122

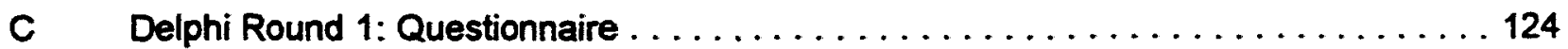

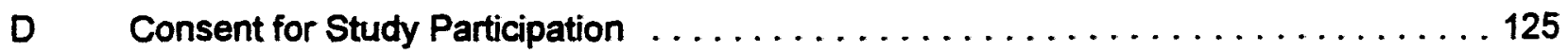

E Follow-Up Invitation to Participate in Study . . . . . . . . . . . . 127

F Cover Letter. Round Two . . . . . . . . . . . . . . . 128

G Delphi Round 2: Questionnaire . . . . . . . . . . . . . . . . 129

H Cover Letter: Round Three $\ldots \ldots \ldots \ldots \ldots \ldots \ldots \ldots \ldots \ldots \ldots \ldots \ldots \ldots \ldots$

I Delphi Round 3: Questionnaire . . . . . . . . . . . . . . 134 


\section{Chapter I \\ INTRODUCTION \\ Statement of Issue}

Soaring health care costs, increased hospital competition, technological innovation, proliferation of physician and health maintenance organizations, employer demands for costefficient healthcare, and consumer mandates for quality care are transforming the health care industry. Today's healthcare transformation is characterized by new patterns of organization, alliance, management, administration, and govemance. Traditional fee-for-service reimbursement strategies are dissolving and managed health care is proliferating. The number of people enrolled in managed care has tripled in the past decade (Stachura, 1995) and is predicted to grow by nine percent each year through the remainder of the decade (Coile, 1994). Managed care and managed competition are forcing hospitals and healthcare providers to control costs and identify new methods of healthcare delivery (Grimaldi, 1995; Stahl, 1995).

Integrated healthcare delivery systems and networks are at the center of healthcare reform. By the year 2000 , it is predicted that three out of every four hospitals will belong to a multi-hospital network, alliance, or system and integrated delivery systems will dominate (Coile, 1994). Integrated healthcare delivery systems provide or arrange to provide for a coordinated continuum of services for defined patient populations. Integrated delivery systems focus on health promotion, wellness, disease prevention and non-hospital services such as sub-acute, long-term, rehabilitation, and hospice care. Hospitals are rapidly becoming cost centers as opposed to traditional revenue centers and patient care is moving from hospitals to out-patient care centers (Shortell, 1993; Sovie, 1995). 
This metamorphosis of health care is placing new demands and expectations upon hospital leaders. Perhaps no individual is confronted more with new role expectations than the hospital Chief Nurse Executive Officer (CNEO); leader of the single largest clinical discipline in the hospital setting (Fralic, 1993). Chief Nurse Executive Officers are increasingly finding themselves in roles within complex integrated health care delivery systems in highly managed care markets. This new work environment is altering old and mandating new role expectations (Andrica, 1995; Sovie, 1995). Within the new paradigm, CNEO responsibilities are extending beyond hospitals and single discipline leadership (O'Grady, 1995). As managed care and integrated healthcare delivery systems proliferate, CNEOs will be confronted with the challenges of building delivery systems across multiple settings, securing patient populations, effectively managing health care, and delivering patient care in varied sites (Curran, 1995; Shortell, 1995). More and more, CNEOs will focus on reducing hospital costs, improving clinical outcomes, and enhancing patient satisfaction (Sovie, 1995).

In the decade ahead, CNEOs will be confronted with a sicker patient population, a decline in the permanent nursing workforce, an increase in temporary workers, and a struggle to develop organizational commitment from all workers. CNEOs will need to be become flexible, strategic thinkers who develop inclusive models which bring nurses and a new contingency workforce into partnership with the organization (Wyld, 1996). CNEO role expectations are likely to include those of internal consultant, advocate, special projects manager, spokesperson, and affiliate opportunity analyst (Davidson, 1996). Role expectations evolve and change as members of a profession strive to meet new goals and standards for professional practice. In today's changing healthcare environment one of the CNEOs most pressing concerns is that of role definition and expectation clarification.

As integrated healthcare delivery systems in highly managed care markets have grown, so has the anecdotal literature predicting CNEO role changes. Unfortunately, the anecdotal 
CNEO literature is rarely authored by individuals currently enacting such roles. Professional practice and role expectations are best identified by the individuals performing the role and the organizational members who influence or establish work expectations; unfortunately, this is not what the literature reflects (Bible \& McComas, 1966; Carey, Craighead, \& Netzel, 1988).

Noticeably absent within the literature are research investigations addressing CNEO role expectations within integrated healthcare delivery systems in highly managed care markets. Research on the topic of CNEO role expectations, especially from the perspective of expert role definers, is greatly needed. This research study, using the Delphi method, employed expert opinion to examine CNEO role expectations within integrated healthcare delivery systems in highly managed care markets.

\section{Purpose of the Study}

The purpose of this study was to obtain expert opinion on CNEO role expectations within the growing context of integrated healthcare delivery systems in highly managed care markets. Both present-day and future CNEO role expectations were identified. Addtionally, the level of consensus among experts on identified CNEO role expectations was examined. The specific research aims were as follows:

1. Obtain expert opinion on present-day CNEO role expectations within integrated healthcare systems in highly managed care markets. Experts will identify and determine the importance of present-day CNEO role expectations.

2. Obtain expert opinion on future CNEO role expectations in integrated healthcare systems in highly managed care markets. Experts will identify and determine the importance of future CNEO role expectations.

3. Determine the level of consensus between expert panel members (CNEOs and CNEO supervisors) on present-day CNEO role expectations in integrated healthcare systems in highly 
managed care markets.

4. Determine the level of consensus between expert panel members (CNEOs and CNEO supervisors) on future CNEO role expectations in integrated healthcare systems in highly managed care markets.

\section{Research Questions}

The research questions answered by this study were:

1. What are the present-day role expectations for CNEOs employed in integrated healthcare systems in highly managed care markets?

2. What are future role expectations for CNEOs employed in integrated healthcare systems in highly managed care markets?

3. What is the level of consensus between CNEOs and CNEO supervisors on identified present-day role expectations for CNEOs employed in integrated healthcare systems in highly managed care markets?

4. What is the level of consensus between CNEOs and CNEO supervisors on identified future role expectations for CNEOs employed in integrated healthcare systems in highly managed care markets?

\section{Theoretical Framework}

Contingency theory for the administrative role provided the theoretical framework for this study. Contingency theory posits that executive behavior is contingent upon the demands imposed by organizational situations (Stodgill, 1974). Contingency theory seeks to define organizational situations, identify common dimensions within the situation, and then identify causal relationships between the situation and executive behavior (Wright, 1995). Organizational situations are influenced by numerous external and internal environmental forces (Jaco, Price, \& 
Davidson, 1994) which ultimately shape executive behavior as executives adapt to their changing environments. As a result, CNEO role expectations and behaviors are contingent upon the many external and internal forces which confront today's healthcare organizations.

External environmental influences encompass people, objects, and ideas originating outside of the organization. Health care customers (e.g. patients, physicians, government and non-government reimbursors), business entrepreneurs, the corporatization of healthcare, new technology and delivery systems, and innovative reimbursement strategies are all examples of external influences affecting healthcare and healthcare executives (Johns, 1996; Sullivan \& Decker, 1992; Wyld, 1996).

Organizational members, goals and expectations, competition and conflict, and financial constraints all serve as internal environmental situational variables. Shrinking bottom-lines, work and role re-design, development of integrated healthcare delivery systems, mergers and affiliations, and competition for limited resources all illustrate contemporary internal environmental influences (Stahl, 1995).

Contingency theory provided an excellent framework from which to view and study CNEO role expectations as CNEO role expectations are unquestionably and inexorably linked to the organizations' situation. Presently, and in the years ahead, external and internal environmental factors will require healthcare organizations to develop integrated healthcare delivery systems within highly managed care environments (Shortell, 1995; Sovie, 1995).

\section{Definition of Terms}

For the purposes of this study, the following definitions were used:

Chief Nurse Executive Officer. A licensed registered nurse assigned responsibility for directing nursing services within an acute care hospital. Synonyms for CNEO include: VicePresident of Patient Care Services and Director of Nursing Services. 
Chief Nurse Executive Officer Supervisor: An individual who directly supervises and evaluates the role performance of the CNEO. Synonyms for CNEO supervisor include: Chief Executive Officer, Chief Operating Officer, and Senior Vice President of Hospital Operations.

Present-day CNEO Role Expectations: Current behavioral expectations required of CNEOs. Behavioral expectations are comprised of the duties and obligations of any occupant in a social position (Gross, Mason, \& McEachern, 1958; Sarbin \& Allan, 1968).

Future CNEO Role Expectations: Behavioral expectations anticipated for CNEOs five years from now. Behavioral expectations are comprised of the duties and obligations of any occupant in a social position (Gross, Mason, \& McEachern, 1958; Sarbin \& Allan, 1968).

Integrated Healthcare Delivery System: A network of organizations that provides or arranges to provide a coordinated continuum of services to a defined population and is clinically and fiscally accountable for the outcomes and the health status of a specific population (Shortell, 1993).

Highly Managed Care Market: Highly managed care markets are communities which are Stage III or IV markets where HMO plans usually control approximately $31 \%$ or more of a hospital's inpatient admissions. Within these markets, health care buyers/organizations (insurance, employers, and government) actively manage costs and utilization of health services for their beneficiaries. (Coile, 1993, Sovie, 1995).

Expert Panel: Participants in a Delphi study selected based upon their knowledge and experience. For this study, experts were hospital CNEOs and CNEO supervisors working within integrated healthcare delivery systems in highly managed care markets for a minimum of one year.

Panel Consensus: Agreement of at least $80 \%$ of the panelists to retain items on the Delphi instrument. 


\section{Significance of the Study}

This study has relevance and significance for increasing the knowledge of CNEO role expectations employed in integrated healthcare delivery systems in highly managed care markets. Knowledge gained from this study will support effective CNEO role preparation and implementation. A meaningful contribution will also be made to the nursing and health care administration literature.

Successful CNEO role enactment and performance depends largely upon clearty defined, articulated, and shared (subordinate and superior) role expectations (Biddle, 1979; Sarbin \& Allen, 1968). Unclear and disparate role expectations produce CNEO role ambiguity and conflict, power imbalances, inadequate role implementation, job dissatisfaction, and, often times, CNEO resignation or termination (Biddle, 1979; Weaver, 1988). These outcomes are detrimental to both the CNEO and the organization, resulting in a loss of time, money, and productivity (Kippenbrock, 1995).

The most serious consequence of confusion in CNEO role expectations is CNEO resignation or termination. CNEO tumover leads to organizational instability; changes in organizational values, philosophies, and strategies; operational inefficiencies; a nursing service without voice and direction; and powerless, insecure, and uncertain staff nurses. Chief Nurse Executive Officer and CEO role disagreement has been found to be a leading cause of CNEO turnover (Kippenbrock, 1995; Kippenbrock \& May, 1994; 1995; Weaver, 1988).

Present-day and future integrated healthcare delivery systems are dependent upon executive leaders who are knowledgeable of their role expectations and prepared to implement them (Adams, 1994). Findings from this study will provide role expectation clarity for CNEOs and CNEO supervisors who are currently experiencing or struggling with role transformation as well as provide guidance to prepare CNEOs who have yet to experience the changing environment for healthcare. Identification of present-day and future CNEO role expectations will also assist 
educators in developing graduate curricula for CNEO role preparation.

Insight into CNEO role expectation consensus among CNEOs and CNEO supervisors is essential in ensuring that shared role expecations exist between superior and subordinate. If shared CNEO role expectations do not exist between CNEOs and CNEO supervisors, superior/subordinate role conflict, dissonance, and tumover is likely (Adams, 1994; Kippenbrock, 1995). Additionally, this study will be instrumental in moving CNEO role expecation exploration from anecdotal thoughts and experiences into the realm of scientific qualitative inquiry. Perhaps most imporantly, this study attempts to ensure that leaders of the single largest clinical discipline in health care gain knowledge about their changing role within a rapidly changing healthcare industry.

\section{Assumptions and Limitations}

Assumptions. The following assumptions were identified for this study:

1. A relevant and accurate set of role expectations can be identified for CNEOs when environmental contexts are identified.

2. CNEO role expectations are generalizable and meaningful to CNEOs in similar work environments.

3. CNEOS and CNEO supervisors are the most qualified experts to identify CNEO role expectations.

4. Managed care and integrated healthcare delivery systems will continue to proliferate and define the roles of those employed within the industry.

Limitations. The following limitations were identified for this study:

1. Expert panelists may be influenced by other panelists who have marginal capabilities and competencies; unequal panelist expertise (Grant, 1992).

2. Future CNEO predictions may be questionable as the future cannot be predicted with 
complete accuracy (Vela, 1989).

3. Researcher and subject bias may exist secondary to the qualitative nature of the Delphi technique (Williams \& Webb, 1994).

4. Extreme opinion of panel experts may be lost during the consensus building process (Henry, Moody, Pendergast, O'Donnell, Hutchinson, \& Skully, 1987).

5. Panel member attrition may threaten the study's validity (Goodman, 1987).

\section{Summary}

The healthcare industry is undergoing transformation and is characterized by integrated healthcare delivery systems and highly managed care markets. As a result, traditional CNEO role expectations are being altered and new expectations mandated. Awareness and understanding of CNEO role expectations are critical to ensure successful CNEO role preparation and enactment. This study, using the Delphi technique, addressed present-day and future CNEO role expectations and the level of consensus between CNEOs and CNEO supervisors on identified CNEO role expectations. 


\section{Chapter II}

\section{REVIEW OF THE LITERATURE}

This review of the literature served as the foundation for this research study. A comprehensive review of the role theory literature is first presented. The concept of role expectation was central to this study and emanates from role theory underpinnings. Next, an examination of the CNEO literature tracing the CNEO role over the past 100 years is undertaken. Historical, traditional, research-based, and transforming CNEO role expectations are addressed. The contextual variables of integrated healthcare delivery systems and managed care markets are examined in relationship to transforming CNEO role expectations. The review of the literature concludes with a discussion of the Delphi method.

\section{Role Theory}

Role theory has been extensively explored and researched by a variety of professional disciplines and provides an excellent theoretical framework for exploration of CNEO role expectations. The domain, origin and evolution of role theory; the concept of role expectations; and the related concepts of role expectation consensus, conflict, and conformity are presented. Domain/Origin/Evolution

Role theory addresses social life and resultant characteristic behavior patterns commonly referred to as roles. Roles are explained by presuming that persons are members of social positions (a set of persons) who hold expectations for the behavior of self and others. As a science, role theory attempts to describe, explain, and predict contextualized characteristic behavior patterns of individuals (Biddle, 1986). 
Persons and characteristic behavior patterns are often conceptualized and studied differently within the broad domain of role theory. Anthropologists embrace role theory by focusing on humanity, cultural variation, and societal diversity. Psychologists concentrate on individuals and how they respond to their environment, phenomenon experiences, and one's own unique history of socialization. Sociologists view persons as products of their social world (family, community, social class, occupation) and are concerned with socially conforming and functionally linked behaviors which are necessary for accomplishment of tasks. Although the orientations of the aforementioned groups are different, common to all is the concern and interest in patterned human behaviors or roles. (Biddle, 1979).

Role theory dates back to the late 1920's and early 1930's and the writings of several social theoreticians. J. L. Moreno, a German psychiatrist, was one of the first leaders in the field of role theory. Moreno became known for the dramaturgical perspective of role theory as he established the innovative therapy of psychodrama. Psychodrama therapy employed role-playing as a psychiatric treatment to assist with sociocultural reintegration of mentally disturbed patients (Biddle, 1979; Hardy \& Conway, 1988). Many of the terms subsequently used by role theorists reflect the dramaturgical influence or metaphor: role enactment, role-taking, role-making, coaching, performance, and mask (Biddle \& Thomas, 1966). Other pioneers in the field of role theory included Mead, Kuhn, Parsons, and Linton (Hardy \& Conway, 1988).

Biddle (1986) identified five distinct role theory perspectives that have emerged over the past 80 years: functional, symbolic interactionist, structural, organizational, and cognitive. The functional role theory perspective focuses on the roles and functions of individuals who occupy social positions within stable systems. Of interest is the shared normative role expectations held for individuals and the effect of conformity and non-conformity upon both the individual and social system.

Symbolic interactionists concentrate on individuals in reciprocal social interaction who 
actively construct and create their environment through self-reflexive interaction (Hardy \& Conway, 1988). Roles are constructed through social interaction and reflect norms, contextual demands, and evolving definitions of situations as understood by actors (Biddle, 1986).

Structuralists address social structures within organizations versus norms or expectations for conduct. Social structures are conceived as stable organizations, sets of persons who share the same patterned behaviors that are directed toward others within the organizational structure. Social networks, kinships, exchange relationships, and economic behaviors become the object of study. Structuralists employ mathematically expressed axiomatic theory as a means to describe structured role relationships (Biddle, 1986; Hardy \& Conway, 1988).

Organizational theorists deal with social systems that are pre-planned, task-oriented, and hierarchical (Biddle, 1986). A great deal of research has been conducted from this perspective exploring role conflict, role conflict resolution, role transition, and the effects of hierarchy (Gross, Mason, \& MacEachern, 1958; Kahn, Wolfe, \& Quinn, 1964).

The fifth role theory perspective is cognitive role theory. Social psychologists employ the cognitive perspective to study role expectations and behavior. Four subfields have developed within this perspective: role playing, group norms for the roles of leaders and followers, anticipatory role expectations, and role taking (Biddle, 1986).

Each of the five role theory perspectives provides a view or lens from which CNEO role expectations may be explored, analyzed, or researched. Studies by Carey, Craighead, and Netzel (1988), Monahan (1968), Poulin (1984), and Tubbesing (1977) have addressed CNEO role expectations from functional and organizational perspectives. These studies have provided some insight into the normative shared role expectations of CNEOs (e.g. personnel responsibilities, administrative responsibilities, behaviors, and traits).

Today, exploration of CNEO role expectations from functional, structural, and organizational role theory perspectives should be conducted cautiously. Each of these 
perspectives focuses on normative role expectations within stable social systems. Presently, healthcare institutions are far from stable social systems as noted by ongoing acquisitions, mergers, affiliations, and down-sizing. Simultaneously, ongoing organizational restructuring and work reengineering are altering roles and present-day shared role norms.

Investigation of the CNEO role from a symbolic interactionist or cognitive social theory perspective may be most beneficial. Symbolic interactionism would support CNEO role analysis by examining the current social interactions of the CNEO with organizational members. Symbolic interactionists believe roles are shaped by contemporary norms, attitudes, contextual demands, negotiations, and evolving definition of the situation as understood by the actors (Biddle, 1986). Symbolic interactionism closely mirrors contingency theory which originates from the leadership domain. Contingency theory, like symbolic interactionism, posits that behavior results from relationships and internal and external forces. Cognitive social theory also focuses less on normative expectations and more on beliefs about conduct and role taking. Cognitive theory gives attention to social conditions that give rise to expectations, roles of leaders and followers, and the impact of expectations upon behavior. Both perspectives may prove beneficial to gain insight into the CNEO role during a period of social change.

\section{Role Expectations}

Role expectations are central to all role theory investigations. Role expectations are conceptual bridges between social structure and role behavior and are comprised of rights, privileges, obligations, and fulfillment of duties (Sarbin \& Allen, 1968). Expectations are descriptive, prescriptive, proscriptive, or evaluative in nature (Biddle, 1979) and can be behavioral, attitudinal, or cognitively-oriented (Chapman, 1977). Role expectations vary in generality, specificity, extensiveness, and certainty and often define the limits or range of tolerated behavior (Sarbin \& Allen, 1968).

Numerous definitions of role expectations are found within nursing and non-nursing 
literature. Biddle (1979), Chapman (1977), and Hardy and Conway (1988) each present definitions of role expectation and in doing so they capture the essence of the term as well as the lack of conceptual clarity that has often plagued the field of role theory (Biddle, 1961; Biddle, 1979; Biddle, 1986).

Biddle (1979) provides a very broad definition of role expectations by defining them as expectations structured for positional roles within a social system. Chapman (1977) offered a more specific and limited definition of role expectations. Chapman defined role expectations as evaluative standards applied to incumbents of a particular position which are concerned with how the actor should behave in a particular role. Hardy and Conway (1988) provided perhaps the clearest, most functional definition by defining role expectations as position-specific norms that identify the attitudes, behaviors, and cognitions required and anticipated for a role occupant.

Role expectations take many forms. They can be overt, covert, written, individual, shared, personal, and/or positional. Expectations can also possess modality by being prescriptive, cathectic, or descriptive. Exploration of the various types of role expectations is essential to fully understand the concept of role expectation.

Overt expectations are those which are publically communicated. Overtly expressed expectations (enunciations) take form in testimony about past, present and future events; expressed demands for behavior; or evaluative remarks concerning behavior. Written expectations (inscriptions) are overt expectations exemplified in position descriptions, laws, and commandments (Biddle, 1979). Covert expectations are those expectations that are never communicated. Covert expectations are envisioned as mental conceptions or hypothetical constructs.

Individual expectations are expectations held by an individual subject while shared expectations are those held by several subjects. Another distinction related to expectations is whether or not the expectation is personal or positional. Personal expectations are those held for 
loved ones or family members whereas positional expectations are held for individuals who hold a specific position (e.g., professors, doctors). Individual and shared expectations can also be personal or positional (Biddle, 1979).

Expectations also express reaction and direction. Prescriptive expectations communicate norms, demands, or requests (e.g., "Mary Ann, you should attend the national symposium for nurse executives"). Cathectic expectations convey evaluations, values, or preferences (e.g., "Mary Ann, I am disappointed in the way you present yourself at the Medical Executive Committee"). Descriptive expectations represent beliefs, anticipations, opinions, or cognitions (e.g., Mary Ann, I believe the CNEO should sit on the Board of Trustees") (Biddle, 1979).

Role expectation literature highlights various and numerous types of role expectations amenable to investigation. CNEO investigations have typically focused on shared overt, written, positional expectations. Unexplored within the nursing literature are covertly held and overtly expressed/non-written role expectations. CNEO role expectation modality has also not been addressed.

\section{Consensus/Conformity/Conflict}

Key concepts associated with role expectations are consensus, conformity, and conflict. Each of these concepts has been explored extensively within the literature and emphasizes the importance of clear and specific role expectation identification. Role consensus refers to the degree of commonality, identicalness, or agreement in role expectations held among a specific group of role definers. Consensus is believed to be necessary to ensure social stability (integration and interaction), human association, cooperation and role adjustment (Bible \& McComas, 1966). Research questions of interest to role theorists are plentiful: What factors influence consensus? How is consensus measured? Does role consensus prevent role conflict? What is the relationship between consensus and role performance? Is social integration enhanced when consensus is present among organizational members? ( Biddle, 1996; Bible \& 
McComas, 1966).

Gross, Mason, and MacEachem (1958) studied interposition and intraposition role expectation consensus among superintendents and school board members relative to the superintendent's role. Findings revealed a high degree of intraposition consensus within both groups and low interposition consensus. Other studies have revealed that role consensus is high when persons hold easily identifiable positions within society at large and among small groups when long-lasting relationships have been established (Deux, 1984; Hollandar, 1985). Bible and McComas (1963) determined that teacher effectiveness and job satisfaction were high in the presence of role consensus.

Role conformity connotes the degree to which role behavior conforms to or deviates from expectations that role definers apply to a role (Gross, Mean, \& MacEachem, 1958). Central to conformity research is the relationship between expectation and behavior. Role conformity questions are: How likely is it that people conform to expectations? What governs conformity? Why should individuals conform? What are the effects or outcomes of conforming to expectations? (Biddle, 1986). Hollandar (1985) and Santee and VanDerPol (1976) reported that conformity is likely when others have "power over", the possibility to accrue status is present, or when others can view behavior.

Role conflict is the degree to which role expectations are incompatible or incongruent with the reality of the role (Rizzo, House, \& Lirtzman, 1970). Role conflicts can also be classified as intra- or interrole conflicts. Intrarole conflicts are conflicts in which role performance expectations differ among two or more individuals or when there there is a conflict within the individual with regard to different aspects of a role. Interrole conflicts are conflicts between two or more individuals in regard to two different roles or within the individual with respect to performance of two different roles (Hardy \& Conway, 1988). A great deal of research has been conducted in the area of role conflict examining variables such as sex roles, malintegration, role stress, job 
satisfaction, poor performance, and tumover (Adams, 1988; Bunsey, DeFazio, Pierce, \& Jones, 1991; Deux, 1984; Lennon, 1987).

The non-nursing literature is rich with role theory, role expectation, and role consensus, conformity, and conflict information. Research reveals that: (a) social stability and role adjustment is enhanced in the presence of role consensus, (b) role conformity is prevalent when behavior is directly observed, personal status enhanced, and others possess power over the individual, and (c) roles plagued by intra- and interrole conflict result in job dissatisfaction, role stress, job turnover and other negative outcomes. Interestingly, the nursing literature provides little to no information about intra- and interrole CNEO role expectation consensus, CNEO role conformity (barriers or enhancers), or the prevalence, source, or impact of CNEO role conflict. For the most part, within the nursing literature, insight into CNEO role expectations and related role concepts derive from anecdotal experiences or descriptive narratives.

\section{Chief Nurse Officer Role Expectations}

\section{Historical CNEO Role Expectations}

Historical CNEO role expectations are expectations that evolved during the early development of the CNEO role (1880's-1920's). During this era, CNEOs were called Superintendents and had varying scopes of responsibility. Many were responsible for only nursing services, some a hospital-based nurse training school and nursing services, and others the entire hospital ("Special Course", 1904; Erickson, 1980). CNEOs were expected to provide direct patient care, conduct patient rounds with physicians, have knowledge of all patients' plans of care, and hire and discipline hospital personnel. Additionally, CNEOs were expected to plan nursing curricula, conduct lectures, and supervise and critique the work of student nurses. Oftentimes, CNEOs were expected to oversee the kitchen, maintain the laundry, purchase supplies and equipment, collect money for services rendered, maintain accounting records, and 
consult frequently with hospital trustees (Cadmus, 1903; Gladwin, 1907; Richards, 1929; Scovil, 1901; Smith, 1947).

The earty CNEO era found CNEO expectations to be multiple, broad-based, varied and frequently non-nursing focused. Extraordinary role expectations accompanied by minimal pay, long hours, and lack of preparation led to the CNEO role being very difficult to fill (Gladwin, 1907; Scovil, 1901). Most of the historical CNEO role expectations have been abandoned and replaced by new, yet equally challenging expectations.

\section{Traditional CNEO Role Expectations}

Traditional CNEO role expectations are present-day expectations which have emerged and prevailed over the past several decades (1970's-1990). In general, CNEOs are presently expected to organize and direct the delivery of high quality nursing care (Fralic, 1992; Joint Commission of Accreditation of Healthcare Organizations, 1993). This organizing/directing function, commonly known as operations management, produces CNEO role expectations of budget planning, resource allocation (material, human, and financial), annual goal setting, and development of policies, standards, and programs that support the clinical practice of nursing (American Hospital Association, 1990; Johnson, 1990; Rowland \& Rowland, 1985; Spengler 1989).

CNEOs are also responsible for developing nursing structures that support achievement of organizational and departmental goals and objectives (Joint Commission on Accreditation of Healthcare Organizations 1993; Johnson, 1990; Rowland \& Rowland, 1985; Spengler, 1989). CNEOs are expected to create a work environment characterized by caring and one that recruits and retains nurses, supports ongoing education and development, and recognizes the expertise and performance of nursing staff (American Hospital Association, 1990; Joint Commission on Accreditation of Healthcare Organizations).

Johnson (1990) identified development of quality monitoring processes and new 
programs as explicit traditional CNEO expectations. Personal characteristics such as caring, competence, commitment, and perseverance are also cited as expectations (Fralic, 1993; Spitzer, 1990).

CNEOs must be able to articulate the nursing perspective to organizational leaders, work as competent team members, recognize the interdependence of health care disciplines, and implement and evaluate patient care programs. The CNEO is also expected to cope with conflict emanating from the community, govemment, unions, doctors, and nursing staff (Gallivan, 1986; Hamil, 1969; Ikle, 1976).

In summary, traditional role expectations of the CNEO mandate that CNEOs are operations experts who establish goals for nursing service and ensure quality nursing care. The CNEO is also expected to establish positive working relationships with staff and create work environments that are conducive to recruitment and retention of nurses. Additionally, CNEOs are expected to confront and negotiate tactfully (Leininger, 1974), cope with conflict, develop and enforce nursing and organizational policy, and act as the "singular voice for nurses" (Erickson, 1980). Traditional CNEO role expectations have not been abandoned; they are, however, undergoing expansion and transformation.

\section{Research-based CNEO Role Expectations}

Research-based CNEO role expectations are expectations identified and validated through scientific investigations. Surprisingly, few studies have been conducted which explore CNEO role expectations. A comprehensive review of the literature revealed only four studies which addressed CNEO role expectations or role functions.

Monahan (1968) studied 58 Directors of Nursing (DONs) employed in community hospitals within a 50 mile radius of New York City. Hospital bed size ranged between $100-400$ beds. Questionnaires and interviews were used for data collection. The purpose of the study was to identify DON functions and determine role function appropriateness. Findings revealed that 
DONs focused predominately on personnel and patient care, communications with the hospital administrator, policies and procedure development, establishment of positive interdepartmental relationships, and program design and development. DONs addressed nursing issues versus organizational issues. Ten percent of the directors seldom or never prepared nursing budgets. Fifty percent never collaborated with the institutional medical board, governing board, or other health care agencies. DONs supported the role functions queried on Monahan's questionnaire. However, $70 \%$ of the respondents identified inappropriate DON activities not listed on the questionnaire: preparing payroll, distributing checks, releasing bodies from the morgue, dispensing drugs from the pharmacy, and checking linen supplies. Monahan's finding's have limited implications for todays CNEOs based upon the limited scope, sophistication, and age of the investigation. Perhaps today, its' greatest empirical value is as a yardstick to measure the progress or change in present-day CNEO role expectations.

Tubbesing (1977) studied DON role perception differences among DONs, staff nurses, physicians, and hospital administrators. The convenience sample came from a large metropolitan community in the southwest and was comprised of seven DONs, five physicians, five nurses and a hospital administrator associated with each of the DONs. A 40-item instrument identifying DON role expectations was constructed by the researcher and used for data collection. Role expectations were extracted from the literature and addressed four DON role dimensions: relationship to significant others, interaction with and accessibility to personnel, management style, and functions and collaboration. Face validity was established for the instrument using a panel of four DONs and one collegiate dean.

Finding's revealed that DONs should decentralize power through delegation of authority, involve themselves in hospital committees, determine salary levels and administrative policy for nurses, function predominately in the confines of nursing management versus organizational leadership, and be more clinically focused rather than management focused. Tubbesing 
concluded that perceptual differences among physicians, nurses, DONs and hospital administrators place the DON in a position of role conflict. Interestingly, Tubbesing (1977) does not support or reject her three formally stated hypotheses: (a) there will be significant differences between the perceptions of doctors and nurses regarding the DON role in the hospital, (b) there will be significant differences between the perceptions of hospital administrators and doctors regarding the DON role in the hospital, and (c) there will be significant differences between the perceptions of hospital administrators and nurses regarding the DON role in the hospital. Numerous limitations are identified within Tubbesings' study. Questionable instrument design (validity and reliability), a small non-random sample, incomplete statistical data analysis, and inferior research reporting all weaken this study's contribution to understanding CNEO role expectations.

Role functions of 12 CNEOs were examined by Poulin (1984) using a qualitative design. CNEOs were interviewed utilizing a semi-structured interview guide addressing eight areas: persons most influential to the CNEO, nursing care, personnel, education, nursing department responsibilities, responsibilities in agency administration, community, and personnel assessment. Interviews were taped and lasted approximately two hours. The non-random sample was comprised of 11 women and one man between the ages of 50-59. The typical CNEO held a masters degree, had been employed in nursing for 25 years, and had been in the current role for 5.3 years. Hospital size ranged from $400-599$ beds. Data were analyzed and sub-categories and categories were established from the substantive areas of the interview. Face validity was determined for category sets by two additional coders who independently applied the "classification scheme" (pg. 10) to two interviews; coder agreement was 95\%.

Data revealed the chief executive officer and associate directors of nursing to be individuals who most influenced CNEOs. CNEOs primary roles in nursing care were setting and implementing standards and goals, ensuring control mechanisms, provision of personnel, and 
the facilitation of staff functioning. Budget and salary scale development were priority personnel functions. Diverse CNEO educational responsibilities were identified: precepting for students, teaching classes, serving on advisory councils, promoting higher education, and providing tuition reimbursement and educational offerings for staff. All CNEOs held responsibilities for noninpatient nursing activities. Hospital responsibilities were broad and varied for the CNEO. Only four of the CNEOs studied had nursing services as their sole responsibility. Community responsibilities were non-uniform. All CNEOs reported an expectation for helping meet the health needs of the community. Personal assessment reflections depicted the CNEO as a confident and competent organizational leader whose personal strengths were acquired through education and experience. Poulin's small non-random sample limits the generalizability of her findings. Nevertheless, many of Poulin's findings are consistent with other descriptive non-researchfocused CNEO literature as described in the previous section of this paper.

Carey, Craighead, and Netzel (1988) studied DON role expectations among 144 randomly sampled DONs $(n=64)$, Assistant DONs $(n=50)$, and Associate DONs $(n=30)$. Subjects were employed in federally controlled $(n=84)$ and voluntary general hospitals $(n=60)$. Seventy-five percent of the respondents reported advanced academic preparation. Research questions addressed identification of descriptive (actual) and prescriptive (ideal) role expectations; the effect of educational preparation, work experience, and work setting upon DON role expectations; DON role expectation congruence between director and assistant/associate director, and, DON role dissonance secondary to prescriptive and descriptive role expectations. A demographic form and the Miller-Carey Work Role Inventory were used to answer research questions. The Miller-Carey Work Role Inventory was two dimensional, measuring both DON traits and behaviors. The tool contained 34 semantic differential item pairs for each dimension. Matched item pairs for DON traits consisted of one end representing a goal-directed adjective and the other an interpersonal adjective (e.g., dependent-self-sufficient). DON behaviors were 
measured using paired verbs which described role enactment (e.g., push-calm, smoothdemand). The tool was administered twice, once asking respondents to describe the DON role as practiced (descriptive) and again as it should be practiced (prescriptive).

Carey, et al. (1988) identified nine descriptive factors (four trait, five behavioral) and ten prescriptive (five trait, five behavioral) factors which defined the DON role. Factors were identified by clustering the data using the principle factor method and varimax rotation. A criterion of .40 was employed for selecting factor defining items; eigen values for factors ranged from 6.97 to .90 .

Descriptive trait factors described the DON as self-assured (e.g., assured, assertive, confident, decisive) and nurturing (e.g., gentle, supportive) with a dominating leadership approach (e.g., aggressive, competitive, tough, superior). Descriptive behavioral factors found the DON to be goal-oriented (e.g., accomplish, plan, develop, motivate), determined (e.g., challenge, demand, persist, push) and communicative (e.g., introduce, explain). Prescriptive trait factors revealed desired personality qualities (e.g., stable, sincere, objective, bright) and preferred interpersonal styles (e.g., good, tactful, decisive, competitive). Prescriptive behavioral factors suggested valued goal attainment functions as well as how they should be attained (e.g., accomplish, plan, analyze, develop, persist, preside, reinforce).

Findings revealed that DON role expectations were not shaped by educational preparation and work experience. Carey, et al. (1988) reported that work setting did significantly influence respondents perceptions of prescriptive and descriptive factors. Using t-test analysis, prescriptive expectations in voluntary hospitals were found to be "more extreme" (p. 40) than in federal agencies and descriptive expectations to be "more extreme" (p. 40) in federal agencies than voluntary hospitals.

Nineteen comparison's of DON and Assistant/Associate DONs data revealed marked role expectation consensus between DON's and Assistant/Associate DONs. Only three statistically 
significant differences were identified between the two groups; two prescriptive behavior factors and one descriptive trait factor. Statistical methodology and significance levels were not reported for comparing the DON and Assistant/Associate DON groups. Role dissonance for directors of nursing was revealed when conducting t-test comparisons of descriptive and prescriptive traits and behaviors. Significant differences between means were found on seven of ten comparisons.

Of the four studies reviewed, only Carey, et al. (1988) sought to address CNEO role expectations. Carey et al. nobly and uniquely attempted to employ much of Biddle's (1979) work to provide a theoretical foundation for their study. However, like the previous researchers, they fall short of clearly identifying and articulating CNEO role expectations. Role expectations should communicate rights, privileges, obligations, and duties (Sarbin \& Allen, 1968). Carey et al., at best, paint a generic picture of CNEO role expectations via a collage of verbs and adjectives.

Monahan (1968), Tubbesing (1977), Poulin (1984), and Carey et al. (1988) attempt to provide insight into the CNEO role. Each study has its limitations and validates the need for further study, especially in light of the transformational changes occurring in healthcare.

\section{Transformational CNEO Expectations}

Transformational role expectations are expectations which are presently evolving or anticipated for the future. Spengler (1989) stated that the CNEO role is evolving and being reshaped by a deregulated, highly competitive, complex, mature healthcare industry.Today's mature healthcare industry is resulting in the proliferation of managed care markets and integrated healthcare delivery systems which are altering old and mandating new CNEO role expectations. CNEO roles will increasingly focus on integrated healtcare networks with broader span, complexity and increased accountability to networks (Matrone, 1996).

Managed care and integrated healthcare delivery systems. No matter where a healthcare organization is located in the U.S., managed care will soon arrive, if it hasn't already. Over the past 10 years, health maintenance organization enroliment, a strong indicator of managed care 
growth, has tripled (Stachura, 1995). From 1990-1995, managed care organizations and managed care market penetration soared. During this period HMO enrollment grew $9 \%$ annually (Coile, 1994). By January of 1995, a record number of HMO's (562) provided healthcare coverage for more than 50 million Americans. Today, $21.1 \%$ of all Americans are enrolled in HMOs (Stahl, 1996) and more than 1,000 managed care organizations (MCOs) provide health insurance coverage to U.S. employers (Bostrom, 1995).

America has entered a new era. Traditional indemnity insurance and fee-for-service is all but obsolete and managed care strategies are reshaping the healthcare industry. Fee-for-service payment systems are believed to be too expensive and encourage overuse of costly physician and hospital services (Ahern, 1996). Healthcare buyers are actively seeking managed care plans which aggressively manage costs and utilization of services for their beneficiaries (Coile, 1994). Healthcare reimbursors, government and non-government alike, are aggressively attempting to reduce their healthcare costs.

Several key strategies are used by managed care organizations (MCOs) to control costs and service utilization. Primary care physicians assume "gatekeeper" roles for enrollees scrutinizing and controlling access to costly physician specialists. Primary care physicians assume total patient care responsibility for enrollees even when specialty physician services are required. This is exemplified by specialty physicians' being required to obtain primary care physician approval, prior to ordering expensive diagnostic tests or procedures. Hospital admissions require a formal authorization process for both elective and non-elective services and oftentimes pre-authorization for the provision of emergency services is attempted. Outpatient, as opposed to inpatient, procedures are provided whenever possible. Inpatient surgical procedures, when absolutely necessary, are consistently performed on the day of hospital admission. Patients no longer are allowed to be admitted the evening prior to surgery. Managed care reduces hospital inpatient utilization and moves care to outpatient, subacute, or home care 
settings (Dunn, 1996). Utilization of services is closely monitored by managed care organizations via resource utilization indicators. Common resource utilization indicators are inpatient health care costs, inpatient days per 1,000 members, average lengths of stay, inpatient days by level of care, and inpatient discharges per 1,000 members. Data clearly reveals that length of stay, hospital costs, and inpatient days per 1,000 members are consistently lower for enrollees in MCOs (Grimaldi, 1996).

Managed care reimbursement strategies vary; common to all, however, are reduced profits for hospitals and providers. Managed care organizations contract with healthcare providers for services using one of the following approaches: fixed per diem rates (e.g., $\$ 1,000 /$ day for ICU care), discounts from charges (e.g., $30 \%$ off billed charges), case rates (e.g., $\$ 2,000$ /cholecystectomy), or capitated dollar amounts for comprehensive care (e.g., $\$ 50 /$ member/month). Capitated reimbursement arrangements are the most aggressive of all reimbursement strategies and mandate MCOs to manage members' utilization of hospital care, specialty physician care, and other referral services (Grimaldi, 1996).

In order to be successful in managed care markets, especially under capitated contracting, hospitals must reduce costs, increase efficiency, adjust to serve a lower patient census, and find innovative ways to treat patients more cost-effectively. In general, hospitals must reduce patient lengths of stay, labor and supply costs, and find new methods for gaining market share and funding capital expenditures. Typical strategies include: clinical pathway development, patient care delivery redesign, aggressive supply and equipment vendor contracting, organizational right-sizing, flattening of management structures, and development of physician group relationships which increase market share and place physicians at financial risk for hospital financial performance. Hospitals are also developing quality outcome measures and joining integrated healthcare systems to successfully compete with other organizations for managed care contracts (Stahl, 1996b). 
Health care markets typically follow a five-stage evolution in response to increasing managed care penetration (Stahl, 1996a). Each stage of managed care affects employer, patient, provider, and payor interactions. Stages progress from one through five with stages three, four, and five being referred to as highly managed care markets. Stage I, an unstructured market, is characterized by independent clinicians, hospitals, and payors. Provider compensation is traditional fee-for-service and an overuse of hospital care fuels an oversupply of hospital beds. Very few physician groups exist and very little delivery system organization has occurred. Capitated reimbursement is viewed negatively and avoided. Stage II, a loose framework, finds employees shifting into HMOs and preferred provider organizations (PPOs) because traditional indemnity fee-for-service plans become too expensive. HMO and PPO enrollment increases and health plans begin to contract with physicians and hospitals for services. HMOs contract with hospitals on a case rate or discount from charges arrangement. During Stage II, hospitals usually remain profitable but profit margins and patient census decline. An oversupply of beds further promotes price discounts. Physicians begin to organize and primary physicians join large groups. Many markets within the U.S. are in Stage II ("How Markets Evolve", 1995; Shaw, 1995).

Stage III, consolidation, is exemplified by employers being extremely active in managing health benefit costs. Employee health benefit options decrease, employers shift costs to the employee, and true indemnity is replaced by prepaid health benefits. Govemment plans (e.g., Medicare) also start to enroll in managed care plans. In Stage III, hospitals recognize the increasing power of payors and respond by organizing into systems and developing continuums of care. Managed care dominates payment strategies, and providers and insurers begin to align. HMOs usually account for $30 \%$ of all hospital inpatient admissions. Hospitals begin to "rightsize", consolidate services, and reduce costs dramatically as healthcare systems develop. At this stage, physician services are usually reimbursed by health plans on a capitated arrangement. Several communities across the country are at Stage III (e.g., Milwaukee. Portland, Detroit, 
Boston, Phoenix).

Stage IV, managed competition, finds employers with a new economic power base. Employers form coalitions and purchase healthcare directly from integrated healthcare delivery systems which offer full continuums of care. Providers are organized to provide care to specific patient populations referred to as covered lives. Stage IV communities find HMO penetration to be $50 \%$ or more and hospitals engage in capitated agreements with health plans; fee-for-service reimbursement is all but extinct. Physicians who are not in large medical groups are usually pushed out of business and specialists find their fees and services reduced. Payors and integrated delivery systems aggressively market services toward the healthy senior citizens and ensure that Medicare recipients shift from traditional to managed care plans. Hospital costs are reduced and efficient operations vital ("How Markets Evolve", 1995; Shaw, 1995). San Diego, Los Angeles, Minneapolis, and Worcester are all cities which have advanced to a Stage IV managed care market.

Currently, there are no communities which have reached a managed care market Stage $V$, endgame. Stage $V$, is characterized by true provider and health plan partnering, a provider focus on individual system strength, and integrated healthcare delivery systems which manage patient populations ("How Markets Evolve", 1995).

Fundamental to managed care market evolution and hospital survival is the restructuring of health care delivery systems into locally and regionally based alliances of institutional providers, physicians, and payors (Fonner, 1996). Coile (1994) predicted by the year 2000 more than $80 \%$ of all U.S. hospitals will be part of local and regional health systems that provide continuums of health care services. Integrated health systems will be the dominant pattern for the provision of a continuum of care services to all Americans (Coile, 1994).

Integrated healthcare delivery systems will increasingly provide or arrange to provide acute, subacute, ambulatory, home, and rehabilitative care for a fixed price and be responsible 
for a defined population. Integrated delivery systems (IDSs) are poised to be successful for capitated agreements found in highly managed care markets (Stage III-V) and will have a unique competitive advantage (Dunn, 1996). However, IDSs are still in their infancy and are struggling to truly integrate clinical services and add value to both internal and external customers (Coile, 1994). Managing integration is complex, costly, and very difficult (Williams, 1992). Interestingly, people still have vastly different conceptions of what constitutes an IDS (Fonner, 1996). However, it is clear to all that the hospital is no longer the center or core of the healthcare business (Sovie, 1995). IDSs will shift the emphasis from the acute care hub to a system of interrelated and independent services spanning geographical areas serving patient populations (Gilmartin, 1996).

Key characteristics of IDSs are breadth, depth, and geographic concentration. Breadth is exemplified in the number of functions provided along the continuum of care (e.g. ambulatory, home health, rehabilitation), depth by the different operating units (e.g. number of hospitals), and geographic concentration in the distance between operating units. No specific formula for success exists for balancing these three dominant characteristics (Shortell, 1993). Shortell and associates have however identified numerous barriers to integration. These include: failure to understand the new core business, inability to overcome the hospital paradigm, inability to convince the cash cow to accept the system strategy, inability of the board to understand the new health care environment, ambiguous roles and responsibilities, inability to manage managed care, inability to execute the strategy, and lack of strategic alignment. These barriers can be overcome by developing a new management culture that emphasizes managing across boundaries, performing population-based needs assessments which ensure design and delivery of appropriate services, implementing patient care management systems which employ clinical pathways and continuous quality improvement techniques, complimenting patient care management with technology, and linking information and incentive systems (Shortell, Anderson, 
\& Gillies, 1993).

Clinical integration within IDSs is difficult but imperative to avoid costly, fragmented care delivery. Successful delivery systems integrate clinical programs by developing a common vision, emphasizing preventive services, implementing clinical pathways, consolidating services, closing marginal programs, establishing consistent medical direction, coordinating the purchase of new technology with competitive strategy, aligning staff and physician incentives, and developing information systems to support the redesign of operations ("Clinical Maneuvers", 1995). Four additional "best practices" which encourage successful IDS development include understanding what it means strategically to become an IDS, assessing whether your governance and management structures will take you where you want to go, looking closely at what you report to your board and management team and how you reward your staff, and considering carefully the role of doctors in your system ("Watch for Flying Phrases", 1995).

As competitive managed care transforms the healthcare industry and stimulates the development of integrated healthcare delivery systems, CNEOs are changing what they do and how they do it. It is indeed the CNEO who is responsible for operationalizing service delivery in integrated delivery systems in highly managed care markets (Singleton \& Hall, 1995).

CNEO role expectations. Within the new healthcare paradigm, CNEO role expectations are broader and the knowledge, skills, and techniques needed to be effective are more varied, complex, and sophisticated (Gilmartin, 1996). The environment requires CNEOs to be creative, innovative, charismatic, visionary leaders and problem-solvers (Clark, 1991; Fralic, 1992; Fralic, 1993; MCDonagh, 1991; Pappas, 1991; Spengler, 1989). CNEOs are expected to understand economic and political influences and build and manage collaborative relationships with physicians, hospital board members, the communities, and organizational colleagues (Blouin \& Brent, 1993; Borman, 1993; Flarey, 1990; Fralic, 1992; Joint Commission on Accreditation of Healthcare Organizations, 1993; Klakovich, 1994; O'Grady, 1995). Additionally, CNEOs are 
expected to be catalytic change agents skilled in dealing with conflict and ambiguity (Fralic, 1993; McDonagh, 1991). The emerging role of the CNEO is one of facilitator, coach, and mentor (Moore, Smith, Schumacher, Papke, 1996).

Perhaps the single greatest evolving CNEO expectation is that of institutional and patient care redesign. Healthcare institutions must be redesigned to become more humanistic, efficient, cost effective, and committed to quality (Spengler, 1989). Additionally, CNEOs must prepare organizational workers for new career opportunities outside of the hospital and re-allocate the workforce to other care arenas (Beyer, 1994). Managing the cost/quality equation is one of the most daunting expectations for today's CNEOs (Fralic, 1993). More and more, CNEOs will focus on reducing hospital costs, improving clinical outcomes, and enhancing patient satisfaction as managed care evolves (Singleton \& Nail-Hall, 1995; Sovie, 1995). The role of patient advocate is vital and must continue (Porter-O'Grady, 1995).

McDonagh (1991) firmly believes there are no better individuals to create the future design of health care than nurse executives. Patient care redesign requires CNEOs to redefine the role of the nurse and other health care workers (Porter-O'Grady, 1995). Redesign efforts are often taking CNEOs into new roles with responsibilities for non-nursing services such as pharmacy, social services, and laboratories (MCDonagh, 1991; Spitzer, 1991). CNEO responsibilities are extending beyond hospitals and single discipline leadership and focus on building multidisciplinary teams which support integrated and coordinated continuums of care (Beyer, 1994; Porter-O'Grady, 1995). Beyer believed that CNEOs must define the structure and process for care delivery in all settings and ensure linkages for patients through patient information systems, referrals, and clinical integration. CNEOs must design network requirements for nursing care delivery.

As managed care and integrated healthcare delivery systems proliferate CNEOs are confronted with the challenges of building delivery systems across multiple settings (ambulatory, 
acute, subacute, and rehabilitation), securing patient populations, effectively managing health care, and delivering care in varied sites (Gilmartin, 1996). CNEOs are developing product lines, case management programs, clinical pathways, and outcome measurement systems (Curran, 1995; Shortell, 1995).

CNEOs are also expected to build high performing teams, focus on research and publishing, and participate with academicians in curriculum development (Joint Commission on Accreditation of Healthcare Organizations 1993; Mateo \& Meeker, 1992; Spengler, 1989). Fralic (1993) believed that the new era CNEO is expected to be clinically-centered, credentialed, credible, composed, clairvoyant (anticipates work/need of evolving system), and confident.

CNEOs are expected to be bottom-line and outcome focused. They should be productivity oriented, knowledgeable about information systems, political wizards, and globally focused on organizational success. CNEOs must understand finance, statistics, strategic planning, and budgeting processes (Sanford, 1994). In-depth knowledge of business and organizational acquisitions, mergers, and affiliations is required. The CNEO work environment mandates a corporate business mentality with broad knowledge of healthcare planning and policy formation (Blouin \& Brent, 1993; Irurita, 1993; Wangsness, 1991).

In the decade ahead, CNEOs will be confronted with a sicker patient population, a decline in the permanent workforce, an increase in temporary workers, and struggle to develop organizational commitment from workers. CNEOs will need to be flexible strategic thinkers who develop inclusive models which bring nurses and a new contingency workforce into partnership with the organization (Wyld, 1996). CNEOs must be able to empower staff, promote individual growth, and increase nurse satisfaction and retention (Redmond, 1995). CNEOs are likely to become internal consultants, advocates, special projects managers, spokespersons, and affiliate opportunity analysts (Davidson, 1996). CNEOs will need to be skilled at negotiating, bargaining, and selling ideas (Jaco, Price, and Davidson, 1994). 
Porter- O'Grady (1997) stated that as society moves from the industrial age into a new quantum age nurse leaders will increasingly assume the role of gatherer of people and facilitator of processes. CNEO roles will become more dynamic and require a higher degree of leadership and managerial competence which are intricately linked with clinical nursing knowledge and research (Gilmartin, 1996). In the quantum age, lines of authority are more likely to become less clear for the CNEO making the transition from planning to implementation more difficult as direct authority lessens (Matrone, 1996; Porter-O'Grady, 1997).

In brief, the literature suggests that CNEOs are experiencing tremendous growth and transformation in their roles as integrated healthcare delivery systems in highly managed care markets develop. CNEOs are expected to abandon the traditional role of the singular voice of nursing (Singleton \& Nail, 1988) and assume multi-disciplinary leadership roles across the continuum of care. The CNEO is expected to have an increased emphasis on the costquality ratio and the competitive healthcare corporate culture. CNEOs are expected to develop new innovative patient care delivery models and re-engineer the workplace while maintaining a highperforming and satisfied workforce. The nurse executive has experienced a shift in focus, from administration, to management, to leadership (Feldman, 1995). CNEO leaders will be called upon to use more facilitation skills and rely less upon clear chain-of-command authority structures (Matrone, 1996).

\section{Delphi Technique}

\section{Characteristics/Strengths}

The Delphi technique is a survey method for structuring group opinion and discussion for the purpose of solving complex problems, forecasting, consensus determination, and establishing priorities (Linstone \& Turoff, 1975). The Delphi technique efficiently uses the abilities of a diverse group of experts or informed advocates to quantify variables that are often intangible 
or vague (Lindeman, 1975; Reid, 1988). The Delphi technique is relatively simple (Strauss \& Zeigler, 1975), flexible, encourages honest opinion, prevents group pressure (Williams \& Webb, 1994), promotes high quality ideas (McMurray, 1994), and is cost-effective (Sackman, 1975). The Delphi technique supports individuals from diverse backgrounds, often in remote areas, to come together to address issues in a way that would not otherwise be possible (Enzer, 1970). Four predominate features characterize the Delphi technique: expert input, anonymity of panel members and panel member response, iteration with controlled feedback, and statistical group response (Goodman, 1987; Martino, 1982).

Expert input. Experts, specialists, or informed advocates are employed in Delphi studies to provide opinion or judgement regarding social, technological, or economic issues (Williams \& Webb 1994). Individual participants within Delphi studies are collectively referred to as an expert panel. Panel size and panel member criteria vary greatly among studies. Panel sizes have been found to range from ten to almost two thousand members (Reid, 1988). Most panels are comprised of fewer than 50 individuals (Helmer, 1983). Panel size and panelist selection criteria should be established prior to starting a Delphi study (Goodman, 1987). Debate related to what constitutes expert opinion is found within the literature and is addressed by Martino (1982). Martino simplified the expert debate by stating that an expert on a topic is an individual who simply knows more than most people about the topic. Pre-established criteria for panel or expert selection strengthens the study and lessens the expert debate. Cicarelli (1984) clearly emphasized the importance of the expert panel in his statement, a "delphi is its panel" (p. 140).

Anonymity of panel and response. Panel members and their responses remain anonymous within most Delphi studies. The anonymity of the Delphi technique encourages uncensored individual opinion. The lack of face-to-face confrontation and response identification ensures that peer pressure, intimidation, and strong voices do not unduly influence responses and study results (Goodman, 1987; Lindeman 1975). Individuals are also free to change opinions 
without publically admitting they have done so. Anonymity guarantees that opinions and ideas are considered on merit versus whether or not panel members have low or high opinions of the idea originator (Martino, 1972). Helmer (1983) succinctly summarized the value of anonymity:

The method employed in the experiment appears to be more conducive to independent thought on the part of the experts and to aid them in the gradual formation of a considered opinion. Direct confrontation, on the other hand, all too often induces the hasty formulation of preconceived notions, an inclination to close one's mind to novel ideas, a tendency to defend a stand once taken or, alternatively and sometimes alternately, a predisposition to be swayed by persuasively stated opinions of others. (page 118)

Sackman (1975) offers a contrasting opinion stating that anonymity in fact leads to hasty decisions and judgements because panel members are secure in the knowledge that they will not be held accountable to others for their views.

Iteration with controlled feedback. The Delphi technique attempts to obtain reliable consensus of opinion among experts through a series of intensive questionnaires interspersed with controlled opinion feedback (Helmer, 1983). The Delphi sequence or questionnaire series is described in terms of rounds and each round is representative of one questionnaire administration. Consensus of expert opinion is typically achieved after three or four rounds.

During each round, panelists are requested to do one or all of the following: answer questions, assign importance to items, predict a future event or effect, and/or provide comment regarding individual perspectives. Panelists' opinions and comments are incorporated into subsequent questionnaires by the researcher and shared with the panelists during the next round. The feedback is controlled by the researcher to prevent the group from concentrating on 
self-chosen goals as opposed to the research objectives (Martino, 1982). Systematic control of the feedback also ensures objectivity of the research outcome (Lindeman, 1975). Feedback to the panel promotes awareness of collective group opinion and ultimately a judgement that is representative of the group (Goodman, 1987).

Statistical group response. After each round of the study, statistical summaries of individual and group responses along with minority opinion reports are provided to panel members. The statistical summary provides group and individual data which are representative of the "center" of the group and the degree of spread around the center (Martino, 1972). Individuals are provided the opportunity to see where personal opinion lies in relationship to the group (Goodman, 1987). Descriptive statistics such as mean, median, mode, and interquartile range are typically used within the statistical summary. In later study rounds, panelists are asked to reconsider answers and revise their opinions if individual answers deviate from group opinion. Additionally, panelists are asked to provide insight or rationale regarding individual opinion if they choose not to change to the group opinion (Helmer, 1983). A minority report is constructed and provided to all panel members which is reflective of why individual panelist opinion differs from group opinion. The minority opinion report may stimulate a change in individual and ultimately group opinion.

History

The earliest known utilization of the Delphi technique was in 1948 for the purpose of predicting horse race outcomes. Although the technique showed promise it received great criticism because of the nature of its use (Quade, 1967). The scientific development and use of the Delphi technique is traced to Dr. Olaf Helmer, a mathematician-philosopher, and Norman Dalkey co-founders of the Institute for the Future (Helmer, 1983; Lindeman, 1975). Helmer and Dalkey developed the Delphi technique while at the Rand corporation in the 1950's to solicit the opinions of experts on atomic warfare (Dalkey, 1969). The atomic warfare study was sponsored 
by the U.S. Air Force and used to estimate the number of A-bombs required to reduce the munitions output of the Soviets by a prescribed amount (Linstone \& Turoff, 1975). Helmer applied the name "Delphi" to technique which originates from the ancient Greek god Apollo Pythios of Delphi. Apollo was known to have great predictive powers (Goodman, 1987).

It wasn't until Gordon and Helmer (1964) conducted a later study addressing long-range trends of science and technology and their probable effects that the technique became wellknown. This study investigated topics such as population control, automation, war prevention, and space progress. Following the publication of this study, the use of the Delphi technique proliferated throughout the U.S., Europe, and the Far East (Linstone \& Turoff, 1975). The first comprehensive critique of the Delphi technique was published by Helmer in 1964. Subsequent critiques and methodological reviews have been written by Goodman (1987), McKenna (1994), Sackman (1975), and Williams and Webb (1993).

\section{Uses}

The Delphi technique has been applied to hundreds of studies in numerous fields since its development in the 1950's. Extensive use has occurred in industry and business (Campbell, 1966; Preble, 1984), education (Judd, 1972; Shepardson, 1972; Uhl, 1971), social services (Heath, Niemeyer, \& Pederson, 1988), and nursing (Duffield, 1993; Emden \& Young, 1987; McMurray, 1994; Whitman, 1990). The Delphi technique in nursing has been used to establish clinical nursing research priorities (Bartu, McGowan, Nelson, Ng, \& Robertson, 1993; Brower \& Crist, 1985; Henry, 1991; Lewandowski \& Kositsky, 1983; Lindeman, 1975; Oberst, 1978; Ventura \& Waligora-Serafin, 1981), validate nursing orders (Henney, Chrissafis, McFalane \& Crooks, 1979), identify patient and nursing education needs (Carter \& Axford, 1993; McGoldrick, Jablonski, \& Wolf, 1994), guide curriculum planning (Sullivan \& Brye, 1983), and elucidate competencies and decision support needs of CNEOs (Barton, 1994; Goodrich, 1982). Application of the Delphi technique is advocated for structuring group communication for the 
following purposes: forecasting, exposing priorities of personal values and social goals, determining consensus, developing causal relationships in complex economic or social phenomena, and distinguishing and clarifying real and perceived human motivations. It is not the nature of the application that determines it's use rather the circumstances confronting the situation. Examples of properties that support use of the Delphi are when the problem does not lend itself to precise analytical techniques and requires subjective judgement, the individuals needing to contribute to examination have strong contrasting perspectives, heterogeneity of the participants must be preserved to assure results, and time and money are limited (Linstone \& Turoff, 1975).

\section{Weaknesses}

Critiques of the Delphi technique have resulted in the identification of several potential weaknesses. Linstone and Turoff (1975) identified the following potential study problems: (a) underestimation of the demanding nature of the Delphi and subsequent lack of compensation to panel members, (b) lack of exploration of dissenting opinions resulting in panel attrition and artificial consensus, and (c) researcher imposition of preconceptions upon the panelists. Delphi studies can also be slow and time-consuming (Strauss \& Zeigler, 1975), questioned as lacking scientific rigor and merit, and open to distortions due to manipulation of opinions (Dodge \& Clark, 1977). Additional Delphi method concerns relate to consensus definition, loss of minority or extreme opinion, researcher and subject bias, and panel attrition (see Chapter III, Delphi Method) (Duffield, 1993; Henry, Moody, Pendergast, O'Donnell, Hutchinson, \& Scully, 1986; Williams, \& Webb, 1994). The validity and reliability of Delphi studies have also been questioned and addressed within the literature (Helmer, 1983; Martino, 1982; Sackman, 1975). However, reliability investigations by Dalkey (1969) and Duffield (1993) reveal positive consensus correlations when panel responses were divided into various sample sizes and the data compared. Goodman (1987) posits that content validity is obtained as long as the panel 
members are truly representative of the group or issue under study. Additionally, content validity is re-established by the panelist during each round of the study.

\section{Summany}

The literature identifies that the healthcare environment is undergoing great change and leaders within the industry must seek clarity and understanding of transforming role expectations to ensure individual and organizational success. CNEOs will increasingly assume leadership roles in integrated healthcare delivery systems in highly managed care markets. Minimal literature and no research was available which identifies CNEO role expectations; therefore, scientific inquiry into CNEO role expectations was strongly supported. The Delphi technique is a well-known research method used for forecasting, answering vague questions, building consensus, and establishing priorities in a variety of fields. The Delphi technique has numerous strengths and weaknesses and was most appropriate for exploring CNEO role expectations and performance outcomes. 


\section{Chapter III \\ METHODOLOGY}

This study examined CNEO role expectations in integrated healthcare delivery systems located in highly managed care markets. An exploratory, qualitative research design using Delphi methodology was employed to address the following research questions:

1. What are the present-day role expectations for CNEOs employed in integrated healthcare systems in highly managed care markets?

2. What are future role expectations for CNEOs employed in integrated healthcare systems in highly managed care markets?

3. What is the level of consensus between CNEOs and CNEO supervisors on presentday role expectations for CNEOs employed within integrated healthcare systems in highly managed care markets?

4. What is the level of consensus between CNEOs and CNEO supervisors on future role expectations for CNEOs employed in integrated healthcare systems within highly managed care markets?

\section{Research Design}

A qualitative research design was selected for the investigation of CNEO role expectations because very little was known about the social phenomenon of CNEO role expectations in integrated healthcare delivery systems in highty managed care markets. Qualitative designs have been recommended for exploring social phenomenon such as human behavior and functioning (Strauss \& Corbin, 1990) when little is known about the research group, individual, or phenomenon (Polit \& Hungler, 1995). Within the literature, only anecdotal 
information was found on the topic of CNEO role expectations in integrated healthcare delivery systems within highly managed care markets. Research derived CNEO role expectation information was not discovered.

The Delphi method was selected for this study because it enabled experts to come together from diverse areas of the country without having to meet face-to-face to identify, assess, and produce group consensus on present-day and future CNEO role expectations (Goodman, 1987; Lindeman, 1975; Reid, 1988; Waltz, Strickland, \& Lentz, 1991). Additionally, the Delphi method was chosen because it promoted honest opinion, prevented group pressure (Williams \& Webb, 1994), produced high quality ideas (McMurray, 1994), and was extremely flexible and cost-effective (Sackman, 1975). This study also drew heavily upon role theory literature and the Delphi method was conceptually congruent with that literature (refer to Chapter II, Review of the Literature) making the Delphi method ideal. Role theory literature posits that insight into role expectations is best obtained by expert role definers (e.g., the Delphi expert panel). Expert role definers are individuals defining, performing, and evaluating role expectations (Bible \& McComas, 1966; Carey, Craighead, \& Netzel, 1988).

\section{Research Design Limitations: Delphi Method}

Within the literature, numerous authors have addressed limitations of the Delphi method. A lack of consensus definition, loss of minority or extreme opinion, researcher and subject bias, and panel attrition are the most frequently identified potential Delphi method limitations (Duffield, 1993; Henry, Moody, Pendergast, O'Donnell, Hutchinson, \& Scully, 1987; Williams \& Webb, 1994).

Consensus. Consensus criteria vary within the literature (Williams \& Webb, 1994). Median ratings, interquartile rank, standard deviation, percentage agreement on modal and mean responses, and item stability have all been acceptable criteria for determining panel consensus (Duffield, 1993; Linstone \& Turoff, 1978; Rosenbaum, 1983; Williams \& Webb, 1994). The 
literature does not definitively advocate the use of one consensus criterion over another. Median ratings are often used when investigations address judgements about time or quantity, and the mode when opinion about desired conditions or the typical case is sought (Issac \& Michael, 1972; Rasp, 1973). Linstone and Turoff (1978) believe consensus is reached when responses to questions have no more than a $15 \%$ change between rounds. Dr. Rita Synder-Halpern (personal communication, February 15,1995$)$ stated that long-range forecasting studies in business and industry appear to most often use interquartile rank and median ratings whereas nursing and social phenomena based studies employ percentage agreement using mean and modal responses (Helmer, 1983).

In studies where percentage agreement levels have been used, the percentage level ranged from $50 \%$ to $100 \%$ and oftentimes has not been pre-established (Orton, 1981; Reid, 1988; Vela, 1989; Williams \& Webb, 1994). Williams and Webb have strongly advocated that consensus levels be pre-determined because if not, "the notion of a high level of consensus" becomes "a movable feast which is unilaterally decided upon by the researcher" ( $p .183,184)$. Grant, Kinney, and Guzzetta (1990) suggested a high percentage of agreement be established $(85 \%-90 \%)$ with a minimal acceptance level for the final Delphi round at $70 \%$. The consensus criteria for this study were percentage agreement on modal responses (yes/no) and importance rating (4-extremely important). The pre-established consensus level was $80 \%$ for all rounds and criteria.

Minority and extreme opinion. Minority or extreme opinion can be lost in Delphi studies unless comments are recorded and given back to panelists along with the statistical feedback. Panelist comments are essential in assisting panelists to evaluate and change responses on subsequent rounds. Although a goal of the Delphi technique is consensus of opinion it is important to ensure critical evaluation of opinion, even minority opinion. Minority opinion and comments were shared after Rounds One and Two of this study to support anonymous debate, 
maximum input, and the loss of extreme or minority opinions (Goodman, 1987; Martino, 1972).

Researcher bias. Researcher bias can be a potential threat when interpreting and feeding back panel member minority and extreme opinions (Murray, 1967). Researcher bias was minimized in this study by using content analysis processes outtined by Kippendorff (1980) and having a non-biased doctorally prepared nurse researcher review all content analysis activities (e.g., CNEO role expectation identification and summarization of panelist comments following each round). Panel members comments were used verbatim whenever possible for the construction of both the CNEO role expectations and minority opinion reports.

Panel attrition and subject bias. High panel attrition rates are often a concern in Delphi studies because they alter the range of opinion from round to round introducing response or subject bias and ultimately questionable study results (Williams \& Webb, 1994). The literature reveals that attrition rates for Delphi studies range from $30 \%$ to $50 \%$ (Brower \& Crist, 1984; Lindeman, 1975; Vintura \& Waligora-Serafin, 1981). To minimize panel attrition and subsequent subject bias, expert panelists were informed in writing (Appendix A) of the anticipated length of the study, time required to complete questionnaires, and the importance of minimizing panel attrition. Additionally, participants were given very long response timeframes for each questionnaire round; three to four weeks. Telephone calls were also made to panelists' offices if they did not respond within two weeks of the questionnaire mailing and encouraged to complete the study packets. Panelists were aiso provided a Starbuck's coffee coupon following Rounds One and Two to show researcher appreciation and encourage full study participation.

\section{Expert Panel Selection}

Careful panel selection is imperative for conducting quality Delphi studies (Heath, Neimeyer, \& Pederson, 1988). Cicarelli (1984) stated that a "Delphi is its panel" (p. 140). Panelists should come from active scholars and practitioners who are currently engaged in the 
discipline. Other authors describe expert panelists as informed advocates who know more than most people on a specific topic (Martino, 1972) and are willing to engage in discussion (Goodman, 1987). Few studies specify criteria for panel selection and expert status is often arbitrary (Williams \& Webb, 1994). Additionally, panelists usually vary in their level of expertise (Dalkey, 1969).

The size of expert panels ranges from ten to hundreds (Couper, 1984) with most studies having fewer than 50 (Helmer, 1983). Dalkey (1969) found that a panel size of 15 was sufficient to produce reliable data in forecasting studies. Panel member selection processes do not require random sampling of the target population but simply representation of the group under study. As long as the panelists are representative of the group or topic being studied, content validity can be assumed (Goodman, 1988).

Expert panelists for this study were CNEOs and CNEO supervisors. All CNEOs and CNEO supervisors were required to be employed in acute care hospitals within integrated healthcare delivery systems in highly managed care markets; Stage III or IV managed care markets where a minimum of $31 \%$ of inpatient admissions come from health maintenance plans or contracts. CNEOs and CNEO supervisor panel members were also required to have a minimum of one year experience within an integrated healthcare delivery system located in a highly managed care market.

The healthcare literature was used to identify potential expert CNEO and CNEO supervisor panelists. A two-step process was employed. First, highly managed care markets were identified using the Hospitals and Health Networks journal article, "How Markets Evolve" (1995). This article identified eighteen highly managed care markets (cities) within twelve states and the District of Columbia. One of the Stage IV markets was excluded from the study as the researcher was employed within that community and it was believed that panelist response would be influenced by researcher/panelist relationships. 
Next, the 1995/1996 American Hospital Association Guide was used to identify acute care hospitals within integrated health care delivery systems within the previously identified highly managed care markets. The American Hospital Association Guide revealed 37 acute care hospitals. Names of the CNEOs and their supervisors were obtained from the American Hospital Guide or by calling the administrative office at each of the acute care hospitals. Seventy-four potential panelists were identified.

\section{Instrumentation}

Two instruments were employed for this study; a demographic questionnaire and a Delphi survey instrument which was modified following each data collection round. The demographic questionnaire was designed to obtain individual panelist profile data. The demographic questionnaire was organized into three sections addressing personal (e.g., age, educational background), professional (e.g. title, experience, work history), and organizational variables (e.g. hospital size, payor mix) (Appendix B).

The initial Delphi instrument (Appendix C) was developed using the classical Delphi design, an unstructured, open-ended questionnaire format. An unstructured questionnaire promotes expert panelist opinion and prevents researcher and literature bias which often occurs when a semi-structured or structured format is used (Martino, 1982). Panelists were requested to identify five priority present-day CNEO role expectations. A maximum of five priority present-day CNEO role expectations were requested to guard against a time-consuming and lengthy data collection process for panelists (Linstone \& Turoff, 1975, Martino, 1982). Lengthy and timeconsuming data collection processes often lead to panel member attrition and ultimately questionable research findings (Williams \& Webb, 1994).

Pilot testing of the initial demographic and Delphi instruments was performed using a convenience sample of two CNEOs and their immediate supervisors. CNEOs and their 
supervisors were from the Stage IV managed care market excluded from the study; each of the pilot participants met study inclusion criteria. Instrument pilot testing resulted in two minor format and two demographic question changes on the demographic questionnaire. No changes were made to the Delphi instrument.

\section{Data Collection}

This study was comprised of one preparatory (round zero) and three data collection rounds (Figure 1.) Round Zero included demographic and Delphi instrument development, pilot testing of instruments, and identification of potential expert panelists.

Round one. Following the pilot survey and instrument modification, Round One was initiated. Each potential expert panel member received a study packet which contained: a cover letter requesting study participation (Appendix A), two study participation consent forms- one to be retained by the panelist (Appendix D), a demographic profile questionnaire (Appendix $B$ ), a Delphi questionnaire (Appendix $\mathrm{C}$ ), and a stamped self-addressed return envelope. Panel members were requested to complete the study packet within ten days. If study packets were not received within twenty days a second study packet was mailed to non-responders inclusive of a new invitation letter for study participation (Appendix E). An additional, two weeks was allowed for the return of study packets. Round One data was collected during October and November of 1996.

Thirty completed study packets were retumed by panel participants. Study packets were examined for completeness, informed consent signatures, and adherence to panelist selection criteria. All 30 panelists met study inclusion criteria and returned signed informed consent documents. Round One data was used to identify present-day priority CNEO role expectations which were then the basis of the Delphi Round 2: Questionnaire.

Round two. A study packet containing a cover letter (Appendix F) and the Delphi Round 
Fiqure 1. Delphi study rounds and related process activities.

\section{ROUND ZERO - DELPHI STUDY PREPARATION}

Performed Literature Review

Designed Initial Delphi Survey Instrument

Developed Demographic Questionnaire

Selected Potential Expert Panel Members

Conducted Pilot Survey

\section{ROUND ONE - EXPERTS FIRST OPINIONS}

Mailed Study Packet One to Potential Expert Panelists

Delphi Focus: Present-day Role Expectation Identification Confirmed Expert Panelists

Analyzed Round One Delphi Data

Modified Delphi Instrument

\section{ROUND TWO - FEEDBACKJRESPONSE}

Mailed Study Packet Two to Expert Panel

Delphi Focus: Present-day Role Expectation

Consensus and Importance Determination,

Additional Expectation Identification

Analyzed Round Two Delphi Data Modified Delphi Instrument

\section{ROUND THREE - EXPERTS' FINAL OPINIONS \\ Mailed Study Packet Three to Panel Delphi Focus: Present-day Role Expectation Consensus Building, Future Role Expectation Concensus and Importance Determination, Additional Future Role Expectation Identification \\ Analyzed Round Three Delphi Data Analyzed Demographic Data}


2: Questionnaire (Appendix $G$ ) was mailed to each of the 30 expert panelists. The Delphi questionnaire was divided into three major sections (leadership, clinical, and system/organizational improvement) with sub-headers and listed a total of 58 present-day CNEO role expectations. Panelists were asked to make a judgement as to whether or not each expectation should be retained by circling yes or no. Panelists were also asked to assign an importance value of one (not important), two (somewhat important), three (important), or four (extremely important) to each of the CNEO present-day role expectations. Panelists were invited to make comments regarding the role expectations to promote clarity and understanding of individual opinion. Panelists were also asked to modify CNEO role expectations as well as identify missing present-day CNEO expectations they felt to be missing.

Panelists were asked to retum Round two questionnaires within five to ten working days. All panelists not retuming questionnaires within 15 days had a telephone call placed to their office and their administrative assistants were requested to remind panelists to complete and retum the questionnaire at their earliest convenience. Ten additional working days were given for the return of study questionnaires. Twenty-five of the 30 panelists returned completed questionnaires. Round Two data collection occurred in December, 1996 and January, 1997.

Round Three. Round Three was the final data collection round for this study. Panelists were mailed a cover letter (Appendix H) and the Delphi Round 3: Questionnaire (Appendix I). The Delphi Round 3: Questionnaire was divided into two parts and addressed both present-day and future CNEO role expectations. Part One of the questionnaire addressed present-day CNEO role expectations and required panelists to re-evaluate five present-day CNEO role expectations that panelists did not reach consensus on during Round Two. Panelists were asked to review their previous opinion in light of aggregate panel opinion and individual panelist comment and determine whether or not the CNEO role expectation should be retained as well as assign an 
importance rating to each of the five expectations. Within Part One of the questionnaire, panelists were also asked to make judgement regarding seven new present-day CNEO role expectations which were identified during Round Two of the study.

Part Two of Delphi Round 3: Questionnaire focused on future CNEO expectations. Panelists were asked to evaluate the 65 CNEO role expectations identified in Rounds One and Two in relationship to the future (five years from today). Panelists were required to render an opinion as to whether each of the role expectations should be retained as a future expectation and rates it's importance for the future. Importance ratings, once again, were one (not important), two (somewhat important), three (important), and four (extremely important). Panelists were also provided space to identify additional future CNEO role expectations. An open ended question concluded the questionnaire which requested panelists to provide opinion regarding the future direction, importance, and/or evolution of the CNEO role.

Panelists were requested to complete Round Three in five to ten working days. After 13 days, panelists' administrative assistants were contacted asking them to remind panelists to please complete the Delphi Round 3: Questionnaire and fax the completed questionnaire to the researcher within the next five days. All 25 panelists completing Round Two of the research study completed the third and final Delphi round. Data collection for Round Three occurred during February, 1997.

Throughout the study, all panelists remained anonymous to each other. Panelists and study packets were assigned a unique two-digit identifier and all data were kept confidential. $A$ code identification sheet was maintained and kept separate from the data except during periods of study packet compilation and mailing. Study data will be kept for two years and then destroyed. 


\section{Data Analysis}

Delphi questionnaire data were analyzed after Rounds One, Two, and Three using both content analysis and descriptive statistics. Content analysis techniques were used to analyze the written comments of the expert panelists and consisted of identifying thematic (themes or meaning within the narrative) and/or syntactical units (direct use of written comments) (Kippendorff, 1980). Content analysis findings were validated by a non-biased doctorally prepared researcher and then again with dissertation committee members. Descriptive statistics were produced after Delphi Rounds Two and Three using the Statistical Package for the Social Sciences (SPSS-PC). Round Two and Three Delphi questionnaire data were analyzed using percentages, means, modes, and frequencies. At the end of Round Three, present-day and future CNEO role expectations were retained if $80 \%$ of the panel members agreed to retain the individual CNEO role expectation. Data were also analyzed to determine the level of consensus between CNEOs and CNEO supervisors on present-day and future CNEO role expectations. Consensus level between CNEO and CNEO supervisor sub-groups was examined for only the CNEO role expectations on which $80 \%$ of either panel group (CNEOs, $n=12$; CNEO supervisors, $n=8$ ) rated the role expectation as extremely important. Descriptive statistics (e.g., means, percentages, ranges) were also employed to analyze demographic questionnaire data following the completion of Round Three.

\section{Summary}

A three round qualitative research study using Delphi methodology was conducted to explore present-day and future CNEO role expectations in integrated healthcare delivery systems located in highly managed care markets. An expert panel comprised of 25 CNEOs and CNEO supervisors was employed to identify present-day and future priority CNEO role expectations. Data were collected using a demographic questionnaire and a Delphi questionnaire which was 
modified after each of the three data collection rounds. Data were analyzed using content analysis procedures and descriptive statistics. 


\section{Chapter IV}

\section{Findings of the Study}

The primary objective of this research study was to gain expert opinion on CNEO role expectations in integrated healthcare delivery systems in highly managed care markets. The research questions answered by this study were:

1. What are the present-day role expectations for CNEOs employed in integrated healthcare systems in highly managed care markets?

2. What are future role expectations for CNEOs employed in integrated healthcare systems in highly managed care markets?

3. What is the level of consensus between CNEOs and CNEO supervisors on presentday role expectations for CNEOs employed in integrated healthcare systems in highly managed care markets?

4. What is the level of consensus between the CNEO and CNEO supervisors on future role expectations for CNEOs employed in integrated healthcare systems in highly managed care markets?

\section{Demographic Data Analysis}

Personal, professional, and organizational demographic data were collected during Round One of this study using a three-part demographic survey instrument (Appendix B). Expert panelists were CNEOs and CNEO supervisors who were currently employed by integrated healthcare delivery systems (IDSs) located in highly managed care markets (HMCMs). Panelists were required to have a minimum of one year experience within IDSs and HMCMs. Demographic 
data were analyzed for the 25 expert panelists who completed all three rounds of this Delphi study.

\section{Personal Demographic Data}

Fifteen of the 25 panel members (60\%) were CNEOs and $10(40 \%)$ were CNEO supervisors. Sixty-eight percent of the Delphi panel were female, $32 \%$ male. CNEO panelists were all female and eight CNEO supervisor panelists male and two female. The mean age for the expert panel was 48.4 years. The CNEO panel members had a slightly higher mean age $(M=49.3$ years $)$ than did the CNEO supervisors $(M=46.8$ years $)$.

Figure 2 identifies panel members highest eamed academic degree by CNEO and CNEO supervisor grouping. Twenty-two (88\%) of the panelists held masters degrees, one (4\%) a doctorate, and two (8\%) bachelor degrees. Most CNEOs held masters degrees in nursing, most CNEO supervisors held masters degrees in health care administration.

\section{Professional/Role Demographic Data}

CNEO panelists reported job titles of Associate Administrator, Vice-President of Operations, Vice-President of Nursing Services, Director of Patient Care, and Chief Nurse. VicePresident of Patient Care Services was the most frequently (40\%) assigned CNEO title. Eighty percent of the CNEO supervisors held the title of Chief Executive Officer, President, or Senior Vice-President. CNEO panelists most typically reported to President/CEO/Senior Vice-President (60\%) or Chief Operating Officer $(26.7 \%)$ supervisors.

Panel participants averaged 4.2 years in their current positions. CNEO panelists averaged 5.33 years in their current roles, CNEO supervisor panelists 2.33 years. Panelists' years in current role ranged from less than one year to 16 years. Fifty-four percent of the panelists were in their current roles three years or less.

Panelists' years of experience in administrative roles are reported in Figure 3. Panel members averaged 18.5 years of experience in administrative roles. Only one panelist had 
Figure 2. Panelists' highest earned academic degree by CNEO and CNEO supervisor grouping.

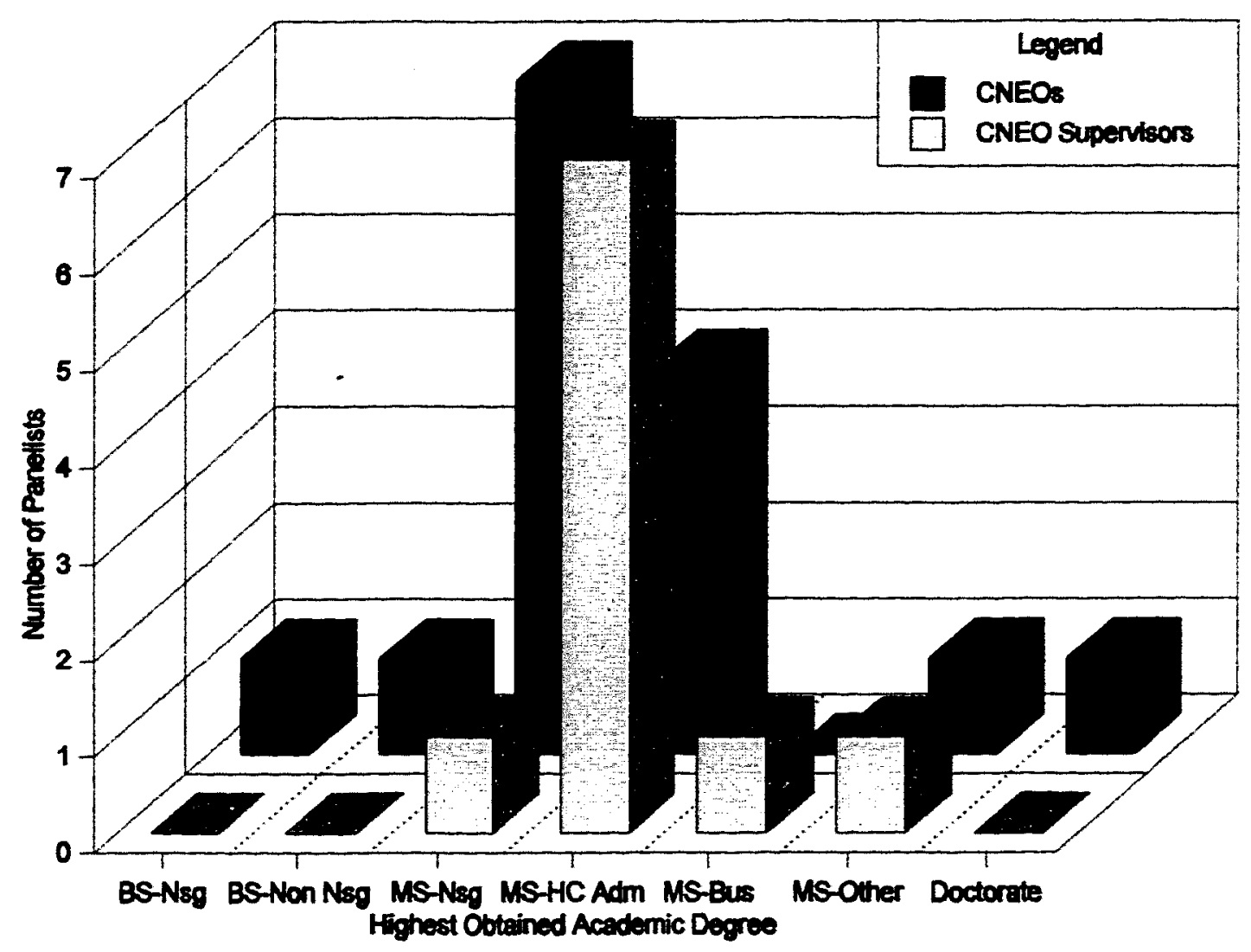


Figure 3. Years in an administrative role by CNEO and CNEO supervisor grouping.

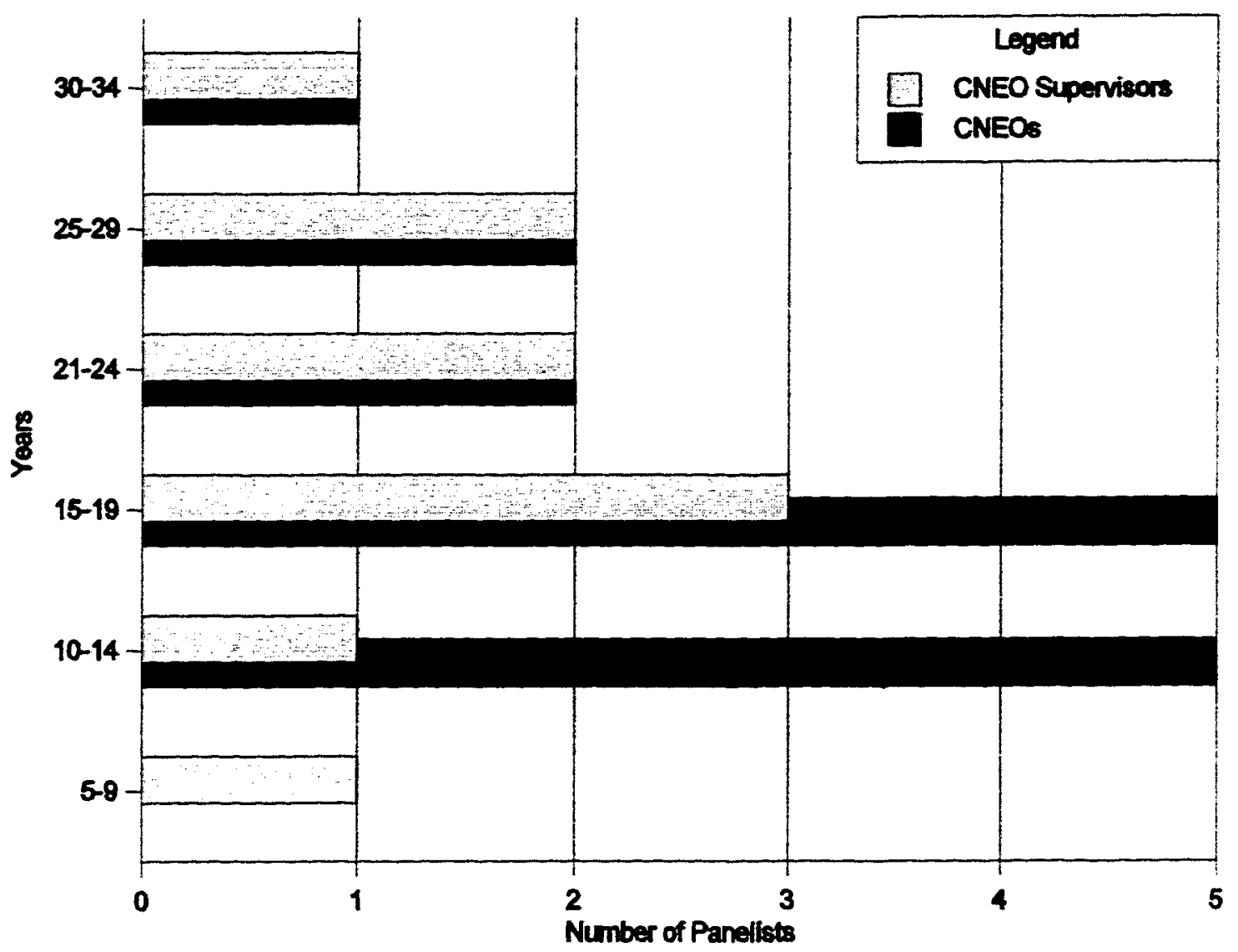


less than 10 years of administrative experience. The average number of years worked in an integrated healthcare delivery system (IDS) located within a highly managed care market (HMCM) was 6.5 years for CNEOs and 9.5 years for CNEO supervisors. Years worked in an IDS in a HMCM ranged between one and twenty-one years.

Seventy-six percent of the expert panel had continuum of care responsibilities and $76 \%$ had single hospital responsibility. CNEO and CNEO supervisor panel member differences were not found on either continuum of care or hospital responsibility data.

\section{Organizational Demographic Data}

Organizational demographic data were very similar for CNEO and CNEO supervisor panel members. All panel members were employed within not-for-profit organizations. Thirty six percent of the panelists' worked in organizations which had a bed capacity ranging between $151-300$ beds, $40 \%$ between $301-500$ beds, and $24 \%$ greater than 501 beds. The average hospital occupancy rate was $\mathbf{7 0 . 3 \%}$.

Figure 4 displays what percent of the panelists' hospital revenue comes from contracted managed care and capitated managed care reimbursement. The panel averaged $48 \%$ reimbursement from contracted managed care and $17 \%$ from capitated managed care reimbursement. The average contracted managed care reimbursement rate for CNEO panelists was $50 \%$, and $44 \%$ for CNEO supervisors. Eighty percent of both CNEO and CNEO supervisors reported that $29 \%$ or less of their hospital reimbursement comes from capitated care. One CNEO panel member reported capitated managed care reimbursement to be $80 \%$.

Organizational data revealed that panelists' systems typically provided acute, subacute, rehabilitation, and home health services. Panelists' hospitals infrequently provided psychiatric, long-term, and primary care services. Figure 5 illustrates the continuum of services provided by panelists' systems. 
Figure 4. Percent of contracted and capitated managed care reimbursement received by CNEO and CNEO supervisor hospitals.

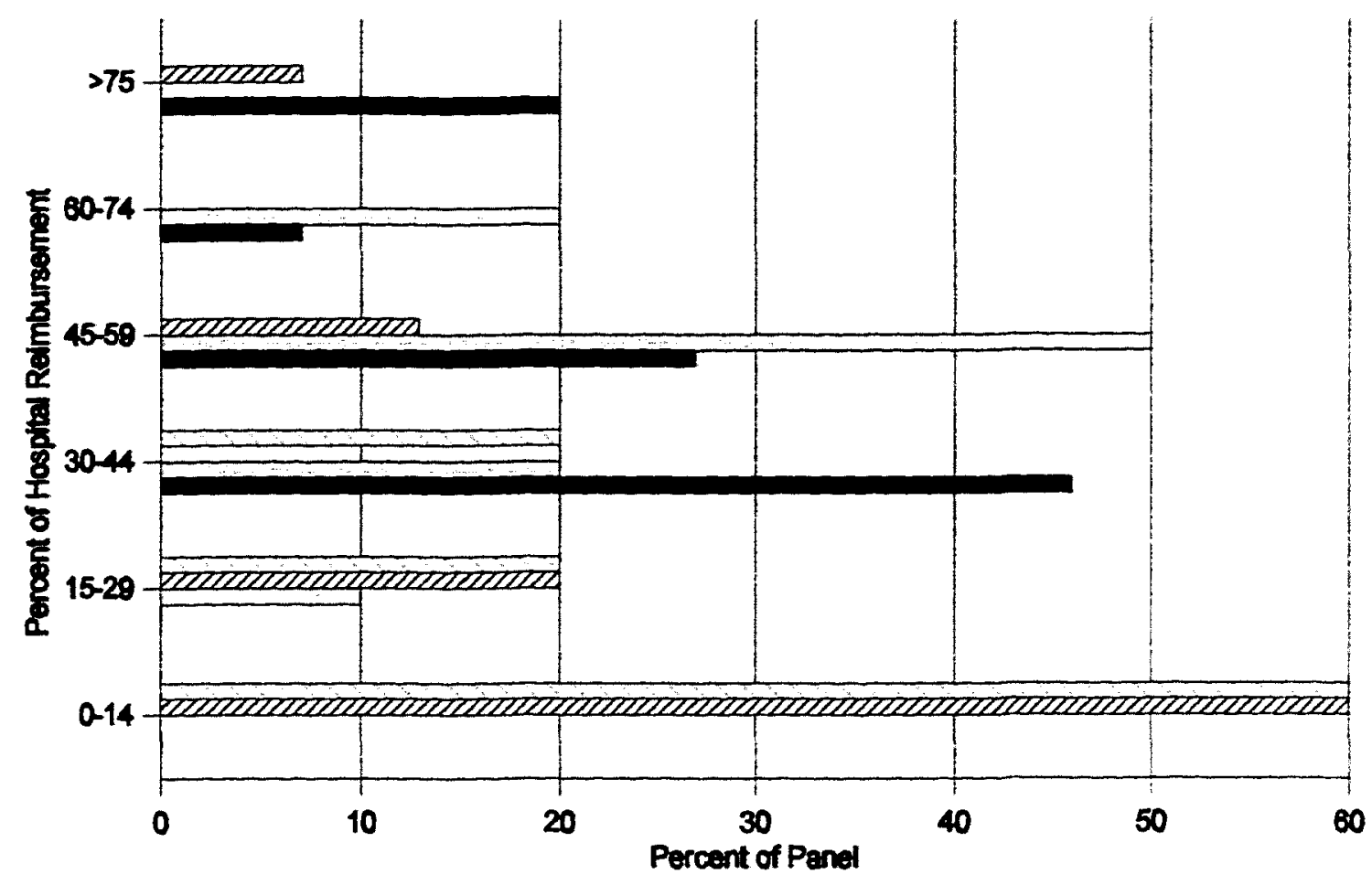

\section{Legend}

CNEO Supervisor Capltated MC Z CNEO Capitated MC CNEO SUpervisor Contracted MC CNEO Contracted MC 
Figure 5. Continuum of care services provided by panelists' IDSs.

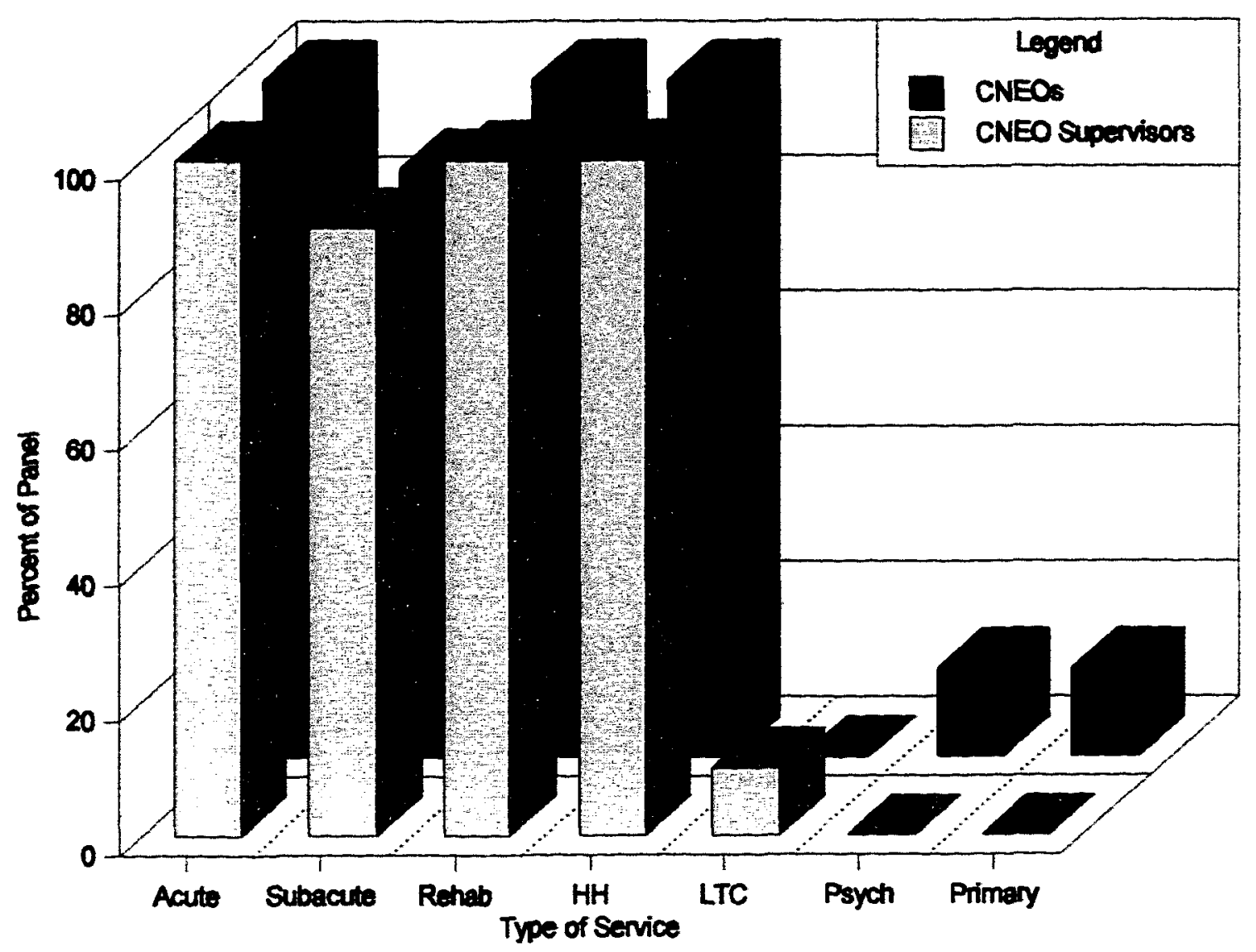




\section{Delphi Data Analysis}

\section{Round One Results}

Thirty (40\%) of the 74 invited expert panelists returned completed Delphi Round 1:

Questionnaires (Appendix C). Returned Delphi questionnaires produced 194 present-day CNEO role expectations. Duplicative present-day CNEO role expectations were consolidated resulting in the identification of $\mathbf{5 8}$ distinct and different role expectations. Thematic evaluation of the $\mathbf{5 8}$ role expectations revealed three major CNEO role expectation categories: leadership role expectations, clinical role expectations, and system/organizational improvement role expectations. Three to four sub-categories emerged for each of the major categories.

Table 1 displays the 58 present-day CNEO role expectations identified by expert panelists during Round One. Twenty-four of the present-day CNEO role expectations were leadership expectations, 17 clinical expectations, and 17 system/organizational improvement expectations.

\section{Round Two Results}

Twenty five (83\%) of the 30 Round One panelists returned Delphi Round 2: Questionnaires (Appendix G). Of the five panelists who did not respond in Round Two, four were CNEOs, one a CNEO supervisor. Using a panelist consensus criterion of $80 \%(n=20)$, data analysis revealed that panelist consensus, for role expectation retention, was reached on 53 of the 58 CNEO role expectations. The panels' mean importance rating for all but one of the retained role expectations was 3.00 or greater (4-extremely important, 3-important, 2-somewhat important, 1-not important). Forty-seven of the 58 role expectations had a mode of 4.00 (extremely important), 11 expectations a mode of 3.00 (important).

Table 2 displays the five present-day CNEO role expectations on which panelists did not reach consensus, the percent of panel members wishing to retain the expectation, and the expectations' mean importance rating. One CNEO role expectation was a leadership 
Table 1

Round One: Panelist ( $n=30$ ) Identified Present-day Role Expectations for CNEOs in IDSs in HMCMS

\section{Leadership Expectations}

\section{Scope}

1. Responsible for only nursing services.

2. Responsible for multiple clinical services (e.g., lab).

3. Responsible for product and service lines.

4. Responsible for program and project design and implementation.

Communication/Relationship-Building

1. Communicate openly with nurses, physicians, and managers.

2. Conduct routine management meetings to disseminate information and obtain input and feedback from subordinates.

3. Involve subordinates in decision-making processes.

4. Develop, coach, and mentor subordinates.

5. Foster collegial relationships across disciplines.

6. Produce highly effective work groups.

7. Acts as an organizational representative, internally and externally.

Change Facilitation

1. Lead organizational change.

2. Ensure acceptance of organizational change.

3. Act as an organizational cheerleader.

4. Intervene in organizational crises. 
Table 1

Round One: Panelist ( $n=30$ ) Identified Present-day Role Expectations for CNEOs in IDSs in HMCMS

Leadership Expectations (continued)

Change Facilitation (continued)

5. Redesign leadership roles (e.g. links service line and operations management).

6. Create an environment which breaks down barriers and supports new ways of doing business.

System Integration

1. Participate in consolidating services across the health care system.

2. Participate in organizational right-sizing.

3. Ensure that entity culture is recognized within the system.

4. Cooperate with all entities within the system.

5. Assist in integrating diverse organizations within the system.

6. Develop regional and health system alignment.

7. Share "best practices".

\section{Clinical Expectations}

Nursing

1. Ensure delivery of safe, competent, cost-effective nursing care.

2. Establish nurse delivery models reflective of appropriate skill mix and staffing levels.

3. Advance the discipline of nursing (e.g., implementation of shared governance, role maximization, professional practice).

(table continues) 
Table 1

Round One: Panelist ( $n=30$ ) Identified Present-day Role Expectations for CNEOs in IDSs in HMCMS

Clinical Expectations (continued)

Nursing (continued)

4. Develop and maintain nursing standards of care.

5. Represent the organization at state-wide nursing committees and boards.

6. Create education incentives for the nurse workforce.

7. Implement systems which support patient billing for nursing services.

Patient Care Redesign

1. Redesign patient care delivery from a patient focused, multi-disciplinary, continuum perspective.

2. Ensure patient care redesign projects improve quality and reduces costs (e.g., multi-skilled workers, patient support associates).

3. Involve physicians in patient care redesign efforts.

4. Use information systems to guide patient care redesign.

Clinical Innovation/Program Development

1. Design and implement clinical pathways.

2. Design and implement case management care models.

3. Integrate, coordinate, and facilitate clinical programs and care across the continuum (e.g., in-patient and out-patient settings).

4. Standardize policies and procedures, clinical protocols, and care guidelines across system.

(table continues) 
Table 1

Round One: Panelist ( $n=30$ ) Identified Present-day Role Expectations for CNEOs in IDSs in HMCMS

\section{Clinical Expectations (continued)}

Clinical Innovation/Program Development (continued)

5. Advance inter-disciplinary practice (e.g., daily patient rounds).

6. Merge clinical departments under an integrated leadership team.

\section{System/Organizational Improvement Expectations}

\section{Customer Satisfaction}

1. Improve patient satisfaction survey scores.

2. Utilize patient satisfaction benchmarks (system and national) to evaluate patient satisfaction performance.

3. Ensure physician satisfaction with patient care delivery processes.

\section{Quality Performance}

1. Collaborate with physicians to establish quality outcome indicators.

2. Collaborate with physicians to improve clinical outcomes (e.g., c-section rates, decubiti incidence).

3. Sponsor hospital-wide continuous quality improvement teams.

4. Implement data support systems to measure clinical pathway outcomes.

5. Implement outcome measurement to case manage across the continuum.

\section{Financial Performance}

1. Develop, monitor, and ensure compliance with organizational budgets.

2. Reduce organizational operating expenses.

(table continues) 
Table 1

Round One: Panelist ( $n=30$ ) Identified Present-day Role Expectations for CNEOs in IDSs in HMCMs

System/Oroanizational Improvement Expectations (continued)

Financial Performance

3. Implement productivity improvements.

4. Participate in clinical contract negotiations (e.g., insurance, MD, and state agencies).

5. Negotiate physician salaries and productivity levels.

Strategic Planning

1. Develop strategic plan which addresses future workforce needs, market share acquisition, and financial goal achievement.

2. Ensure that community health care needs are met.

3. Participate in setting the strategic vision for the organization.

4. Ensure that the organizations mission is met. 
Table 2

Round Two: Non-Consensus Present-day CNEO Role Expectations ( $n=25)$

\begin{tabular}{ccc}
\hline EXPECTATION & $\begin{array}{c}\text { EXPECTATION RETENTION IMPORTANCE RATING } \\
\% \text { Yes } \\
M\end{array}$ \\
\hline
\end{tabular}

\section{Leadership Expectation}

Scope

1. Responsible for only nursing service.

32

3.18

\section{Clinical Expectations}

\section{Nursing}

1. Implement systems which support patient

billing for nursing services.

Clinical Innovation/Program Development

2. Design and implement clinical pathways.

\section{System/Organizational Improvement Expectation}

Financial Performance

1. Participate in clinical contract negotiations.

2. Negotiate physician salaries and productivity levels. 
expectation, two were clinical expectations, and two were system/organizational improvement expectations.

Table 3 identifies seven additional CNEO role expectations identified by panelists during Round Two. Four of the additional present-day CNEO role expectations were clinical expectations, two leadership expectations, and one, a system/organizational improvement expectation. Three of the clinical expectations were patient care redesign focused and two technology oriented.

\section{Round Three Results}

All Round Two panelists ( $n=25$ ) completed the third and final round of this Delphi study. The three round panel retention rate was $83 \%$.

Non-consensus present-day CNEO role expectations. During Round Three panel consensus was obtained on two of the five present-day CNEO role expectations that lacked panel consensus during Round Two. Eighty-eight percent of the panel agreed the CNEO role expectation, "responsible for only nursing service", should not be retained. Eighty-eight percent of the panel acknowledged the role expectation, "design and implement clinical pathways", should be retained; mean importance rating was 3.20 , the mode importance rating 3.00 . Panelists did not reach consensus on the three remaining CNEO role expectations therefore they were not retained.

Additional present-day CNEO role expectations. Panel consensus was reached on five of the seven additional present-day CNEO role expectations identified in Round Two. The five expectations retained were: (a) ensure nursing and administration visibility through "ceremonial" activities, (b) utilize health services research principles in patient care redesign efforts, (c) use technology to complement redesign efforts, (d) demonstrate value of redesign efforts by enhancing clinical, financial, and customer service outcomes, and (e) ensure employee satisfaction levels are maintained and/or improved. The two expectations on which consensus of 
Table 3

Round Two: Additional Present-day CNEO Role Expectations ( $n=25$ )

\section{Leadership Expectations}

Scope

1. Responsible for oversight of the organizations quality program.

Communication/Relationship Building

1. Ensure nursing and administration visibility through "ceremonial" activities.

\section{Clinical Expectations}

Nursing

1. Develop electronic medical records and documentation systems.

Patient Care Redesign

1. Utilize health services research principles in patient care redesign efforts.

2. Use technology to complement redesign efforts.

3. Demonstrate value of redesign efforts by enhancing clinical, financial, and customer service outcomes.

System/Organizational Improvement Expectations

Customer Satisfaction

1. Ensure employee satisfaction levels are maintained and/or improved. 
opinion was not reached were: responsible for oversight of the organization's quality program and develop electronic medical records and documentation systems. The five retained present-day CNEO role expectations all had mean importance ratings greater than three (important), and modes of 4.00 (extremely important).

Present-day CNEO role expectations. Table 4 lists the final 59 present-day CNEO role expectations identified and retained by expert panelists. Comparison of Round One present-day CNEO role expectations (see Table 1) with the final list of present-day CNEO role expectations at the end of Round Three (see Table 4) revealed: (a) the elimination and addition of one leadership expectation, (b) elimination of one and addition of three clinical expectations, and (c) elimination of two and addition of one system/organizational improvement expectations. The number of expectations within each CNEO role expectation category changed minimally over the three Delphi rounds; leadership expectations remained at 24 , clinical expectations increased from 17 to 19 , and system/organizational improvement expectations decreased from 17 to 16 . New CNEO role expectation categories and subcategories did not emerge. All importance ratings for present-day CNEO role expectations, except one, had mean values above three (important); 46 expectations had modes of four (extremely important), 13 modes of three (important).

Future CNEO role expectations. Panel consensus was obtained on 59 of the 65 CNEO role expectations evaluated for future (five years from today) relevance and importance. The 59 future CNEO role expectations meeting consensus criterion were identical to the retained present-day CNEO role expectations. Mean importance ratings for all future CNEO role expectations, except for two, were above three (important); 47 of the expectations had modes of four and 12 expectations with modes of three. Table 4 displays consensus future CNEO role expectations along with their mean and modal values. Panelists also identified three additional future CNEO role expectations during Round Three of this study: (a) promote healthier community linkages, (b) explore options for outsourcing of services, and (c) work with schools of nursing to develop curricula that enhances flexibility. 
Table 4

Present-day and Future Role Expectations for CNEOs in IDSs in HMCMs ( $n=25$ )

\begin{tabular}{lc}
\hline EXPECTATION & IMPORTANCE RATINGS \\
$\underline{M}$ & Mode \\
Present-day / Future
\end{tabular}

\section{Leadership Expectations}

Scope

1. Responsible for multiple clinical services (e.g., lab).

$3.20 / 3.36 \quad 3.00 / 4.00$

2. Responsible for product and service lines.

$3.39 / 3.24 \quad 4.00 / 3.00$

3. Responsible for program and project design and implementation. $3.45 / 3.52 \quad 4.00 / 4.00$ Communication/Relationship-Building

1. Communicate openly with nurses, physicians, and managers. $\quad 4.00 / 3.92 \quad 4.00 / 4.00$

2. Conduct routine management meetings to disseminate information and obtain input and feedback from subordinates.

$3.80 / 3.56 \quad 4.00 / 4.00$

3. Involve subordinates in decision-making processes.

$3.84 / 3.68 \quad 4.00 / 4.00$

4. Develop, coach, and mentor subordinates.

$3.96 / 3.80 \quad 4.00 / 4.00$

5. Foster collegial relationships across disciplines.

$3.84 / 3.76 \quad 4.00 / 4.00$

6. Produce highly effective work groups.

$3.96 / 3.88 \quad 4.00 / 4.00$

7. Act as an organizational representative, internally and extemally.

$3.72 / 3.37 \quad 4.00 / 4.00$

8. Ensure nursing and administration visibility through "ceremonial" activities.

$2.76 / 2.87 \quad 3.00 / 3.00$

Change Facilitation

1. Lead organizational change.

$3.62 / 3.72 \quad 4.00 / 4.00$

4=extremely important $3=$ important $2=$ somewhat important $1=$ not important

(table continues) 
Table 4

Present-day and Future Role Expectations for CNEOs in IDSs in HMCMs ( $n=25)$

\begin{tabular}{lc}
\hline EXPECTATION & IMPORTANCE RATINGS \\
M & Mode \\
Present-day / Future
\end{tabular}

\section{Leadership Expectations (continued)}

Change Facilitation (continued)

2. Ensure acceptance of organizational change.

$3.64 / 3.56 \quad 4.00 / 4.00$

3. Act as an organizational cheerleader.

$3.32 / 3.28 \quad 3.00 / 3.00$

4. Intervene in organizational crises.

$3.56 / 3.44 \quad 4.00 / 3.00$

5. Redesign leadership roles (e.g. links service line and operations management).

6. Create an environment which breaks down barriers and supports new ways of doing business.

System Integration

1. Participate in consolidating services across the health care system.

$3.48 / 3.52 \quad 4.00 / 4.00$

2. Participate in organizational right-sizing.

$3.68 / 3.56 \quad 4.00 / 4.00$

3. Ensure that entity culture is recognized within the system.

$3.36 / 3.00 \quad 3.00 / 4.00$

4. Cooperate with all entities within the system.

$3.68 / 3.60 \quad 4.00 / 4.00$

5. Assist in integrating diverse organizations within the system.

$3.40 / 3.36 \quad 3.00 / 4.00$

6. Develop regional and health system alignment.

$3.09 / 3.20 \quad 3.00 / 4.00$

7. Share "best practices".

$3.64 / 3.64 \quad 4.00 / 4.00$

4=extremely important $3=$ important $2=$ somewhat important $1=$ not important

(table continues) 
Table 4

Present-day and Future Role Expectations for CNEOs in IDSs in HMCMs ( $n=25)$

\begin{tabular}{lc}
\hline EXPECTATION & IMPORTANCE RATINGS \\
& $\mathbf{M}$ Mode \\
Present-day / Future & \\
\hline
\end{tabular}

\section{Clinical Expectations}

Nursing

1. Ensure delivery of safe, competent, cost-effective nursing care. $\quad 3.96 / 3.91 \quad 4.00 / 4.00$

2. Establish nurse delivery models reflective of appropriate skill mix and staffing levels.

$3.84 / 3.83 \quad 4.00 / 4.00$

3. Advance the discipline of nursing (e.g., implementation of shared governance, role maximization, professional practice).

$3.68 / 3.54 \quad 4.00 / 4.00$

4. Develop and maintain nursing standards of care.

$3.76 / 3.45 \quad 4.00 / 4.00$

5. Represent the organization at state-wide nursing committees and boards.

6. Create education incentives for the nurse workforce.

\section{Patient Care Redesign}

1. Redesign patient care delivery from a patient focused, multi-disciplinary, continuum perspective.

2. Ensure patient care redesign projects improve quality and reduce costs (e.g., multi-skilled workers, patient support associates).

3. Involve physicians in patient care redesign efforts.

4. Use information systems to guide patient care redesign. 
Present-day and Future Role Expectations for CNEOs in IDSs in HMCMS ( $n=25)$

EXPECTATION

IMPORTANCE RATINGS

M

Mode

Present-day / Future

\section{Clinical Expectations (continued)}

Patient Care Redesign (continued)

5. Utilize health services research principles in patient care redesign efforts.

$3.16 / 3.37 \quad 4.00 / 4.00$

6. Use technology to compliment redesign efforts.

$3.12 / 3.36 \quad 3.00 / 3.00$

7. Demonstrate value of redesign efforts by enhancing clinical, financial, and customer service outcomes.

$3.68 / 3.80 \quad 4.00 / 4.00$

Clinical Innovation/Program Development

1. Design and implement clinical pathways.

$3.24 / 3.48 \quad 3.00 / 3.00$

2. Design and implement case management care models.

$3.28 / 3.48 \quad 4.00 / 4.00$

3. Integrate, coordinate, and facilitate clinical programs and

care across the continuum (e.g., in-patient and out-patient settings).

$3.68 / 3.54 \quad 4.00 / 4.00$

4. Standardize policies and procedures, clinical protocols, and care guidelines across system.

5. Advance inter-disciplinary practice (e.g., daily patient rounds). $\quad 3.00 / 3.16 \quad 3.00 / 3.00$

6. Merge clinical departments under an integrated leadership team. $3.18 / 3.52 \quad 3.00 / 3.00$

$4=$ extremely important $3=$ important $2=$ somewhat important $1=$ important

(table continues) 
Table 4

Present-day and Future Role Expectations for CNEOs in IDSs in HMCMs ( $n=25$ )

EXPECTATION
IMPORTANCE RATINGS

M Mode

Present-day / Future

\section{System/Oroanizational Improvement Expectations}

\section{Customer Satisfaction}

1. Improve patient satisfaction survey scores.

$3.88 / 3.64 \quad 4.00 / 4.00$

2. Utilize patient satisfaction benchmarks (system and national) to evaluate patient satisfaction performance.

$3.80 / 3.80 \quad 4.00 / 4.00$

3. Ensure physician satisfaction with patient care delivery processes. $3.64 / 3.50 \quad 4.00 / 4.00$

4. Ensure employee satisfaction levels are maintained and/or improved.

$3.68 / 3.62 \quad 4.00 / 4.00$

Quality Performance

1. Collaborate with physicians to establish quality outcome indicators.

2. Collaborate with physicians to improve clinical

outcomes (e.g., c-section rates, decubiti incidence).

$3.78 / 3.92 \quad 4.00 / 4.00$

3. Sponsor hospital-wide continuous quality improvement teams. $\quad 3.50 / 3.36 \quad 3.00 / 3.00$

4. Implement data support systems to measure clinical pathway outcomes.

5. Implement outcome measurement to case manage across the continuum.

4=extremely important 3=important 2=somewhat important 1=important 
Table 4

Present-day and Future Role Expectations for CNEOs in IDSs in HMCMs ( $n=25)$

EXPECTATION IMPORTANCE RATINGS

M Mode

Present-day / Future

System/Organizational Improvement Expectations (continued)

Financial Performance

1. Develop, monitor, and ensure compliance with organizational budgets.

$3.84 / 3.83 \quad 4.00 / 4.00$

2. Reduce organizational operating expenses.

$3.72 / 3.75 \quad 4.00 / 4.00$

3. Implement productivity improvements.

$3.76 / 3.68 \quad 4.00 / 4.00$

Strategic Planning

1. Develop strategic plan which addresses future workforce needs, market share acquisition, and financial goal achievement.

$3.39 / 3.64 \quad 4.00 / 4.00$

2. Ensure that community health care needs are met.

$3.16 / 3.48 \quad 3.00 / 4.00$

3. Participate in setting the strategic vision for the organization.

$3.68 / 3.80 \quad 4.00 / 4.00$

4. Ensure that the organizations mission is met.

$3.80 / 3.84 \quad 4.00 / 4.00$

$4=$ extremely important $3=$ important $2=$ somewhat important $1=$ not important 


\section{Consensus between CNEOS and CNEO supervisors on present-day CNEO role}

expectations. Eighteen present-day CNEO role expectations were rated extremely important by $80 \%$ or more of the CNEO panelists. Twenty-two present-day CNEO role expectations were rated extremely important by $80 \%$ or more of the CNEO supervisor panelists. Fourteen present-day role expectations were identified by $80 \%$ or more of both CNEO and CNEO supervisor panel subgroups as extremely important. Table 5 lists each of the shared and non-shared extremely important present-day CNEO role expectations identified by panel sub-groups. Five of the 14 shared (consensus) extremely important CNEO/CNEO supervisor CNEO role expectations were were communication and relationship-building leadership expectations and three were nursing clinical expectations. The remaining six CNEO/CNEO supervisor shared (consensus) role expectations were widely dispersed across sub-categories.

Seventy-eight percent (14 of 18) of the CNEO panelist identified extremely important present-day role expectations and $64 \%$ (14 of 22) of the CNEO supervisor panelist identified extremely important present-day role expectations were shared extremely important CNEO role expectations. Figure 6 graphically illustrates the number of shared and non-shared extremely important present-day expectations for CNEO and CNEO supervisor panel members.

\section{Consensus between CNEOs and CNEO supervisors on future CNEO role expectations.} Eleven future CNEO role expectations were rated extremely important by $80 \%$ or more of the CNEO panelists. Twenty future CNEO role expectations were rated extremely important by $80 \%$ or more of the CNEO supervisor panelists. Eight future CNEO role expectations were identified by $80 \%$ or more of both CNEO and CNEO supervisor sub-groups as extremely important. Table 6 lists each of the shared and non-shared extremely important future CNEO role expectations identified by the panel sub-groups. The largest grouping of shared (consensus) extremely important future role expectations occurred in the communication/relationship-building leadership $(n=3)$ and the quality performance sub-category within the system/organizational improvement expectations category $(n=2)$. 
Table 5

Shared and Non-shared Extremely Important Present-day Role Expectations for CNEOs in IDSs in HMCMS ( $n=25$ )

EXPECTATION EXTREMELY IMPORTANT BY GROUP CNEOS CNEO Spvrs Both Groups

\section{Leadership Expectations}

Communication/Relationship Building

1. Communicate openly with nurses, physicians, and managers.

$x \quad x$

$x$

2. Conduct routine management meetings to

disseminate information and obtain input from subordinates.

$x$

3. Involve subordinates in decision-making processes. $X$

4. Develop, coach, and mentor subordinates. $\mathrm{X}$ $x$

$x \quad x$

5. Foster collegial relationships across disciplines. $X$

$x$

$x$

6. Acts as an organizational representative, internally and externally.

$x$

7. Produce highly effective work groups.

$\mathrm{X}$

$x$

$x$

Change Facilitation

1. Lead organizational change.

$x$

2. Ensure acceptance of organizational change.

$x$

3. Create an environment which breaks down barriers and support new ways of doing business.

$x$

$x$

$x$

(table continues) 
Table 5

Shared and Non-shared Extremely important Present-day Role Expectations for CNEOs in IDSs in HMCMs ( $n=25)$

\begin{tabular}{ll}
\hline EXPECTATION & EXTREMELY IMPORTANT BY GROUP \\
CNEOS CNEO Spvrs Both Groups
\end{tabular}

\section{Leadership Expectations}

System Integration

1. Participate in organizational right-sizing. $X$

2. Share 'best practices". X

\section{Clinical Expectations}

Nursing

1. Ensure delivery of safe, competent, costeffective nursing care.

$x$

$x$

$\times$

2. Establish nurse delivery models reflective of appropriate skill mix and staffing levels.

$\mathrm{X}$

$x \quad x$

3. Develop and maintain nursing standards of care. $X$

$x$

$x$

\section{Patient Care Redesign}

1. Redesign patient care delivery from a patient

focused, multi-disciplinary, continuum perspective.

$x$

2. Ensure patient care redesign projects improve

quality and reduce costs (e.g. multi-skilled workers, patient support associates).

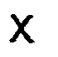

3. Involve physicians in patient care redesign.

$x$
$x \quad x$

$x$ 
Table 5

Shared and Non-shared Extremely Important Present-day Role Expectations for CNEOs in IDSs in HMCMs $(n=25)$

\begin{tabular}{ll}
\hline EXPECTATION & EXTREMELY IMPORTANT BY GROUP \\
CNEOS CNEO SpVIS Both Groups
\end{tabular}

\section{Clinical Expectations (continued)}

\section{Patient Care Redesign}

4. Demonstrate value of redesign efforts by enhancing

clinical, financial, and customer service outcomes.

$\mathrm{X}$

Clinical Innovation/Program Development

1. Integrate, coordinate, and facilitate clinical

programs and care across the continuum (e.g.,

in-patient and out-patient settings).

$x$

\section{System/Organizational Improvement Expectations}

\section{Customer Satisfaction}

1. Improve patient satisfaction survey scores.

$x$

$x$

$x$

2. Utilize patient satisfaction benchmarks (system

and national) to evaluate patient satisfaction

performance.

$x$

$x$

$x$

3. Ensure employee satisfaction levels are

maintained and/or improved.

$\mathrm{X}$

(table continues) 
Table 5

Shared and Non-shared Extremely Important Present-day Role Expectations for CNEOs in IDSs in HMCMs ( $n=25)$

\begin{tabular}{ll}
\hline EXPECTATION & EXTREMELY IMPORTANT BY GROUP \\
CNEOS CNEO SpVIS Both Groups
\end{tabular}

System/Oraanizational Improvement Expectations (continued)

Financial Performance

1. Develop, monitor, and ensure compliance with organizational budgets.

$\mathrm{X}$

$x$

$x$

2. Implement productivity improvements.

$x$

Strategic Planning

1. Ensure that the organization's mission is met.

$x$

$x$

$x$ 
Figure 6. Numerical breakdown of shared and non-shared extremely important present-day CNEO role expectations by CNEO and CNEO supervisor sub-groups.

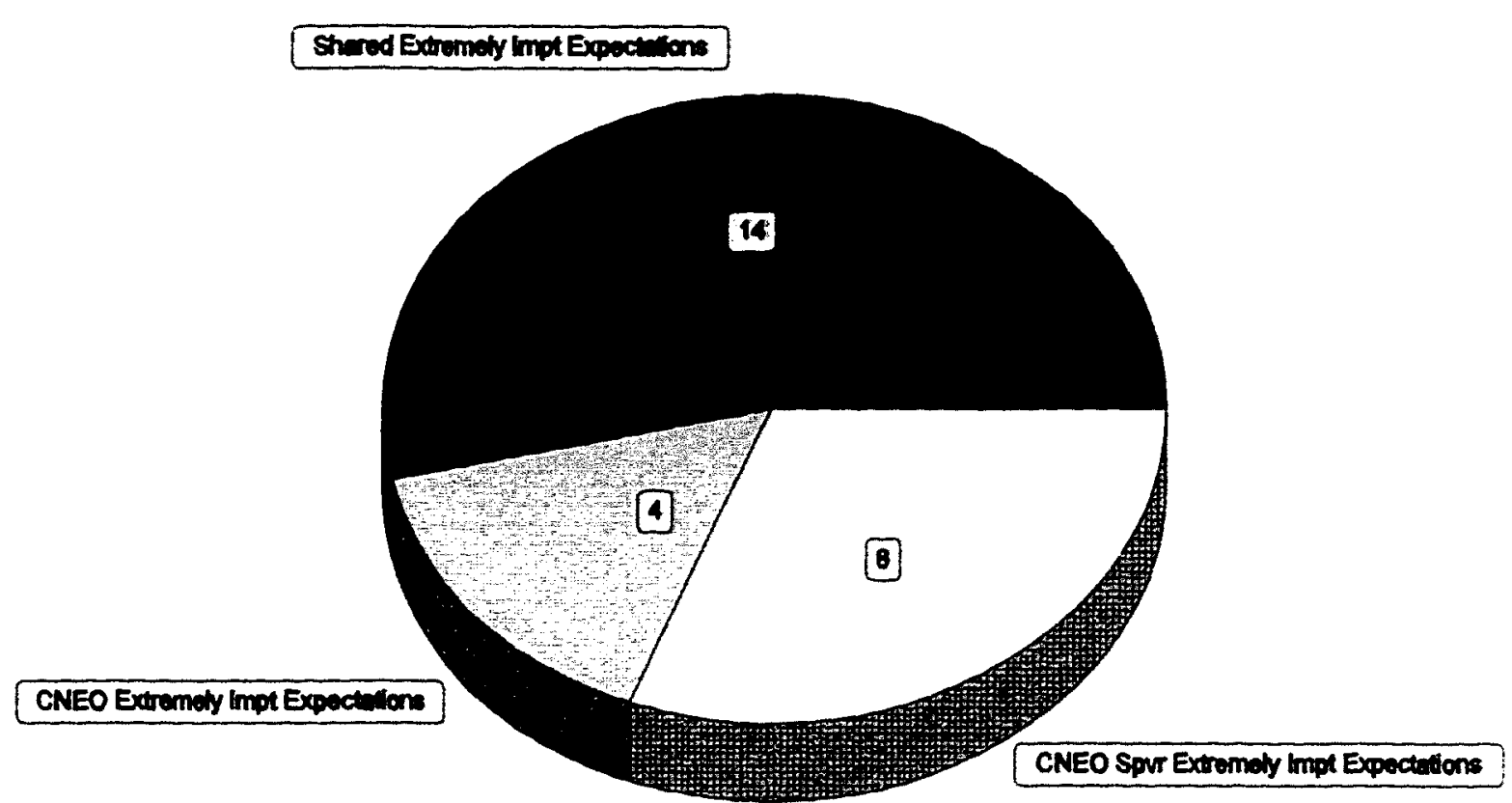


Table 6

Shared and Non-shared Extremely Important Future Role Expectations for CNEOs in IDSs in HMCMs $(n=25)$

\begin{tabular}{ll}
\hline EXPECTATION & EXTREMELY IMPORTANT BY GROUP \\
CNEOS CNEO Spvrs Both Groups
\end{tabular}

\section{Leadership Expectations}

Communication/Relationship-Building

1. Communicate openly with nurses, physicians,

and managers.

$x$

$x$

$x$

2. Conduct routine management meetings to

disseminate information and obtain input and

feedback from subordinates in decision-making

processes.

$x$

3. Involve subordinates in decision-making processes. $\mathrm{X}$

4. Develop, coach, and mentor subordinates.

$\mathrm{X}$

$\mathrm{X}$

$\mathrm{X}$

5. Foster collegial relationships across disciplines.

$x$

6. Produce highly effective work groups.

$x$

$x$

$x$

Change Facilitation

1. Lead organizational change.

$x$

2. Create an environment which breaks down barriers and supports new ways of doing business. $\quad X$

System Integration

1. Share "best practices." 
Table 6

Shared and Non-shared Extremely Important Future Role Expectations for CNEOs in IDSs in HMCMs $(n=25)$

EXPECTATION EXTREMELY IMPORTANT BY GROUP CNEOS CNEO Spvrs Both Groups

\section{Clinical Expectations}

Nursing

1. Ensure delivery of safe, competent, costeffective nursing care.

$x$

$x$

$x$

2. Establish nurse delivery models reflective of appropriate skill mix and staffing levels.

$\mathbf{x}$

Patient Care Redesign

1. Ensure patient care redesign projects improve quality and reduce costs (e.g., multi-skilled workers, patient support associates).

$\mathrm{X}$

$x$

$\mathrm{X}$

2. Involve physicians in patient care redesign efforts.

$x$

3. Demonstrate value of redesign efforts by enhancing

clinical, financial, and customer service outcomes.

$x$

\section{System/Oroanizational Improvement Expectations}

Customer Satisfaction

1. Improve patient satisfaction survey scores.

$x$

2. Ensure employee satisfaction levels are maintained and/or improved.

$x$

(table continues) 
Table 6

Shared and Non-shared Extremely Important Future Role Expectations for CNEOS in IDSs in HMCMs $(n=25)$

\begin{tabular}{ll}
\hline EXPECTATION & EXTREMELY IMPORTANT BY GROUP \\
CNEOS CNEO SpVIS Both Groups
\end{tabular}

System/Oroanizational Improvement Expectations (continued)

Quality Performance

1. Collaborate with physicians to establish quality

outcome indicators.

$x$

$X$

$\mathrm{X}$

2. Collaborate with physicians to improve clinical

outcomes (e.g., c-section rates, decubiti

incidence).

$\mathrm{X}$

$\mathrm{X}$

$\mathrm{X}$

Financial Performance

1. Develop, monitor, and ensure compliance with organizational budgets.

$\mathrm{X}$

2. Reduce organizational operating expenses. $X$

3. Implement productivity improvements. $\mathrm{X}$

Strategic Planning

1. Participate in setting the strategic vision for the organization.

$x$

$x$

$x$

2. Ensure that the organizations' mission is met. $X$ 
Seventy-three percent ( 8 of 11) of the CNEO panelist identified extremely important future role expectations and $40 \%$ ( 8 of 20 ) of the CNEO supervisor panelist identified extremely important future role expectations were shared (consensus) future role expectations. Figure 7 graphically illustrates the number of shared and non-shared extremely important future expectations for CNEO and CNEO supervisor panel members.

\section{Panelists' consensus on present-day and future CNEO role expecations by mean}

imoortance ratings. Table 7 lists in descending order, by mean mean importance rating, the 14 present-day CNEO role expectations which were rated by $80 \%$ or more of both CNEO and CNEO supervisor sub-groups as extremely important. Table 8 lists in descending order, by mean importance rating, the eight future CNEO role expectations which were rated by $80 \%$ or more of both CNEO and CNEO supervisor sub-groups as extremely important.

Future direction, importance, and evolution of the CNEO role. Fifty-six percent of the panelists responded to the open-ended question which addressed the future direction, importance, and evolution of the CNEO role. The following themes emerged from panelists' statements: a need for increased community awareness and involvement, a stronger continuum of care orientation, more physician and multi-disciplinary collaboration, the maintenance of standards of care and caring values, personal flexibility, mandate for quality outcomes, the development of new care delivery models, a call for vision and leadership, need for risk-taking, concerns regarding workload and pay, and increased board involvement.

Panelists stated that CNEOs will be increasingly called upon to "integrate nursing with other disciplines" and "collaborate with physicians in the development of new care delivery models" which are "continuum focused". CNEOs will need to be "more visible" in the community and "work with communities to determine needs and share resources". CNEOs must "ensure that consistent nursing standards and practices are carried out" and "produce quality outcomes". CNEOs will be called upon to be "highly flexible", "visionary", "risk-takers", who possess "excellent 
Fiqure 7. Numerical breakdown of shared and non-shared extremely important future CNEO role expectations by CNEO and CNEO supervisor sub-groups.

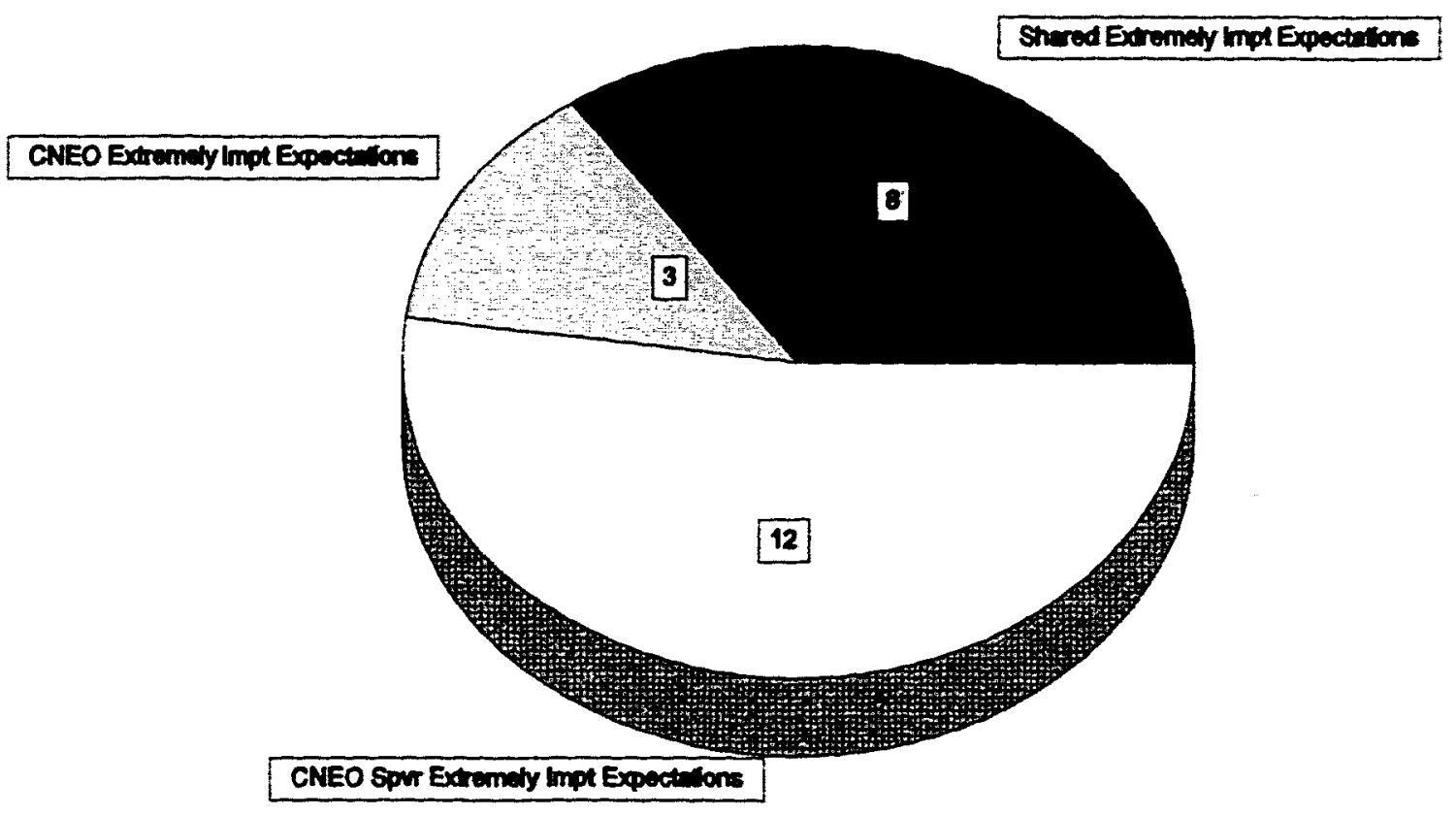


Table 7

Consensus Present-day Role Expectations for CNEOs in IDSs in HMCMs ( $n=25$ )

EXPECTATION M TYPE OF EXPECTATION

1. Communicate openly with nurses,

4.00 Leadership

physicians, and managers.

(Communication/Relationship Bldg)

2. Develop, coach, and mentor subordinates. 3.96 Leadership

(Communication/Relationship Bldg)

3. Produce highly effective work groups.

3.96 Leadership

(Communication/Relationship Bldg)

4. Ensure delivery of safe, competent,

3.96 Clinical

cost-effective nursing care.

(Nursing)

5. Create an environment which breaks

3.92 Leadership

down barriers and supports new ways

(Change facilitation)

of doing business.

6. Improve patient satisfaction survey scores. 3.88 System/Organizational Improvement

(Customer satisfaction)

7. Involve subordinates in decision-making

3.84 Leadership

processes.

(Communication/Relationship Bldg)

8. Foster collegial relationships across

3.84 Leadership

disciplines.

(Communication/Relationship Bldg)

9. Establish nurse delivery models reflective

3.84 Clinical

of appropriate skill mix and staffing levels.

(Nursing)

$4=$ extremely important $3=$ important $2=$ somewhat important $1=$ not important

(table continues) 
Table 7

Consensus Present-day Role Expectations for CNEOs in IDSs in HMCMs ( $n=25$ )

EXPECTATION M TYPE OF EXPECTATION

10. Involve physicians in patient care redesign. 3.84 Clinical

(Patient Care Redesign)

11. Develop, monitor, and ensure compliance 3.84 System/Organizational Improvement (Financial Performance)

12. Ensure that the organizations' mission

3.80 System/Organizational Improvement is met.

(Strategic Planning)

13. Utilize patient satisfaction benchmarks

3.80 System/Organizational Improvement (system and national) to evaluate (Customer Satisfaction) patient satisfaction performance.

14. Develop and maintain nursing standards 3.76 Clinical of care.

(Nursing)

4=extremely important $3=$ =important $2=$ somewhat important $1=$ not important 


\section{Table 8}

Consensus Future Role Expectations for CNEOs in IDSs in HMCMs ( $n=25$ )

EXPECTATION $M$ TYPE OF EXPECTATION

1. Communicate openly with nurses, physicians, and managers.

2. Ensure delivery of safe, competent, cost-effective care.

3. Collaborate with physicians to improve clinical outcomes (e.g., c-section rates, decubiti incidence).

4. Collaborate with physicians to establish quality outcome indicators.

5. Produce highly effective work groups.

6. Develop, coach, and mentor subordinates.

7. Participate in setting the strategic vision for the organization.

8. Ensure patient care redesign projects improve quality and reduce costs (e.g., multi-skilled workers, patient support associates.

\subsection{Leadership}

(Communication/Relationship Bldg)

3.92 Clinical

(Nursing)

3.92 System/Organizational Improvement (Quality Performance)

3.88 System/Organizational Improvement (Quality Performance)

3.88 Leadership

(Communication/Relationship Bldg)

Leadership

(Communication/Relationship Bldg)

3.80 System/Organizational Improvement (Strategic Planning)

3.56 Clinical

(Patient Care Redesign)

$4=$ extremely important $3=$ important $2=$ somewhat important $1=$ important 
leadership and management skills". As the CNEO role evolves, CNEOs must ensure that the "care values remain the same". One panelist believed, "the requirements of this job are overwhelming" and CNEOs need to be "paid consistent with other executive positions".

\section{Discussion of the Findings}

\section{Demegraphic Findings}

The personal, professional, and organizational demographic findings from this study were consistent with other investigations which have enlisted CNEOs and CEOs as research participants (Adams, 1994; Jaco, Price, \& Davidson, 1994; Kippenbrock, 1995; Kippenbrock \& May, 1995; Simms, Price, \& Pfoutz, 1985; Kippenbrock \& May 1994).The typical CNEO and CNEO supervisor panelist was employed in a not-for-profit organization which had a bed capacity greater than 300 , a mean age between $48-49$ years, possessed greater than 10 years of leadership experience, held a masters degree, and was employed in their current role for less than five years. The typical CNEO panel member was female and CNEO supervisor male.

This study revealed four unanticipated demographic findings. CNEO panel members reported an unusually high average number of years worked within IDSs and HMCMs (CNEOs- 6.5 years, CNEO supervisors-9.5 years) given IDSs and HMCMs have only proliferated within the last five to seven years (Coile, 1994). An average reported hospital occupancy rate of $70.3 \%$ was also higher than expected. HMCMs typically shift services from in-patient to out-patient settings which drop hospital occupancy rates (Dunn, 1996). Occupancy rates in southern Califomia have dropped up to $50 \%$ as a result of capitated managed care (Solovy, 1995). The third unanticipated finding was a reported $80 \%$ capitated managed care payor mix by one of the CNEO panel members. Capitated reimbursement rates in one of the most aggressive managed care markets, southern California, have not exceeded $35-40 \%$. Lastly, it was anticipated that many panel members would have multiple hospital responsibility. IDSs traditionally facilitate entity integration by creating 
leadership roles over multiple sites within systems (Shortell, 1995).

\section{Delphi Findings}

A three round panel member retention rate of $83 \%$ was greater than expected. The $17 \%$ panel member attrition rate for this study was much lower than the $30 \%$ to $50 \%$ attrition rates reported within the literature (Brower \& Crist, 1984; Lindeman, 1975; Vintura \& Waligora-Serafin, 1981; Williams \& Webb, 1994). Strong panel retention rate reduced the likelihood of subject bias and strengthened study findings (Williams \& Webb, 1994).

Consensus Present- day and Future CNEO Role Expectations.

The 59 present-day and future CNEO role expectations identified by panelists did not produce questionable findings. Panelist identified expectations were consistent with the CNEO expectations currently reported in the literature (see Chapter II). CNEO role expectation categories were consistant with AONE (1995) executive practice dimensions of clinical processes, leadership, and continuous improvement. The degree of importance placed upon expectations was understandable given the high consensus criterion that was required for expectation retention. Panelist consensus was reached on CNEO role expectations fairty quickly. Most likely, this was a result of the common work environment in which panelists were employed; IDSs located in HMCMs where "financial drivers" prevail. Additionally, panelists were all extremely busy executives who are accustomed to making decisions and having clarity of thought. Panelists did make numerous comments regarding their CNEO role expectation selections and the assigned importance ratings throughout each Round of the Delphi study.

Identical panel consensus on CNEO present-day and future role expectations was unanticipated. The study's methodology of asking the panelist to evaluate previously identified present-day CNEO role expectations with a futuristic orientation may have influenced identical future expectation identification. The alternative for identifying future CNEO role expectation would have been to have panelists start with an open listing or identification process. Most likely, that 
process would have been unsuccessful since panelists identified only three non-listed future CNEO role expectations when asked for additional future role expectations. Consensus evaluation and importance identification did not occur for the three identical additional future expectations. A Delphi Round Four was not conducted because of panel attrition concerns. Although panel attrition was low for this study, panel response time was long and follow-up prompting continuously required.

Leadership expectations. Forty percent of all panel identified role expectations fell into the leadership category. The emphasis panelists' placed upon leadership expectations was wellfounded as CNEOs, throughout the country, are assuming increased organizational leadership responsibilities (Porter-O'Grady, 1997), shifting their focus from management to leadership (Feldman, 1995). The panel identified leadership expectations related to the sub-categories of scope, communication-relationship building, change facilitation, and system integration.

Beyer (1994), Klakovich (1994), and Porter-O'Grady (1995) all address the scope of the CNEO role and report that CNEOs are increasingly moving away from single leadership roles and toward multi-disciplinary and continuum focused responsibilities. CNEOs are frequently accepting non-nursing service responsibilities such as pharmacy, laboratory, respiratory, and product and program development (McDonagh, 1991; Spitzer, 1991). Therefore, it was not surprising that the panel reached consensus on not retaining the CNEO role expectation, "responsible for only nursing services".

Fralic (1993) and McDonagh (1991) reinforce panel members identification of CNEO change facilitation expectations. Fralic and MCDonagh believe successful CNEOs must be skilled catalytic change agents who are comfortable dealing with conflict and ambiguity. CNEOs are leading organizational change through proactive and visionary responses versus traditional statusquo thinking (Smith, Parsons, Murray, Dwore, Vorderer, \& Okerlund, 1994). Positive CNEO led changes come by encouraging stakeholder involvement and cooperation in the change process 
(Klakovich, 1994) and reliance upon facilitation expertise (Matrone, 1996).

Panel members importance ratings were the highest in the sub-category of communication and relationship-building. Two of the expectations had mean importance ratings of 3.96. Also, the greatest number of identified expectations within a single sub-category also occurred within this group. Expectations in this sub-category related to the CNEO as facilitator, change agent, relationship-builder, producer of effective work groups, and involver of others in decision-making. Moore, Smith, Schumacher, \& Papke (1996) concur with panelists that the emerging role of the CNEO is one of facilitator, coach, and mentor. CNEOs are also called upon to build and manage relationships with varied constituents such as staff, physicians, board members, and communities (Brent, 1993; Borman, 1993, Fralic, 1992). Authors also believe organizational goal achievement is dependent upon a CNEO leader's ability to produce highly effective, motivated work groups (Mateo \& Meeker, 1992; Taylor-Dunham \& Klafehn; 1995). Redmond (1995), like panelists within this study, expects CNEOs to involve and empower others.

System integration expectations identified by panelists highlighted consolidating services, developing regional and health system alliances, sharing best practices across the system, and inter-entity cooperation within the system. As more and more hospitals merge and amalgamate into large IDSs, CNEOs are confronted with the challenge of successfully integrating services. Singleton \& Nail-Hall (1995) emphasized that CNEOs ultimately are responsible for operationalizing all service delivery aspects of system integration. Curran (1995) believed that inter-entity cooperation often takes place by "sharing best practices."

Clinical expectations. Clinically oriented CNEO role expectations fell into three subcategories: nursing, patient care re-design, and clinical innovation/program development. Nursing although not the singular focus of the CNEO role, continued to be highly valued. The highest mean importance score (3.96) for a clinical CNEO expectation was, "ensure delivery of safe, competent, cost-effective nursing care". The delivery of safe and competent care has long been a CNEO role 
expectation. What is new, is the "cost-effective" component of the expectation. Cost-effectiven nursing care is echoed throughout the literature (Jaco, Price \& Davidson, 1994; Sovie, 1995; Wyld, 1996). Innovation, maintaining nursing standards, and determining appropriate skill mixes and staffing levels are also CNEO role expectations substantiated within the nursing literature (Adams, 1994; Andrica, 1995; Smith et al., 1994). Interestingly, not found within the literature, were panelist identified CNEO role expectations which addressed CNEO organizational representation at statewide committees and boards and the creation of educational incentives for the nurse workforce.

Panelists identified seven CNEO role expectations specific to patient care redesign. The patient care redesign expectations were quite comprehensive. CNEO patient care expectations articulated who should be involved in the redesign process, what tools should be used to guide redesign, and what outcomes should be achieved by patient care redesign. Smith et al. (1995) stated that CNEOs must redefine, reassess, and reinvent patient care delivery models. Blouin \& Tonges (1996) believed that patient care redesign is one of the most popular administrative innovations in contemporary nursing and case management and clinical pathways are tools of the trade.

Clinical innovation and program development role expectations centered around development of clinical pathways, implementation of case management care models, and integration of clinical programs or departments. These role expectations are the hallmarks of today's healthcare organizations. Clinical innovation is necessary to meet the demands of the changing healthcare customer (Andrica, 1995). Clinical pathways and case management models are attempts to effectively reduce patient lengths of stay, labor and supply expenses, and unnecessary services, all survival imperatives in HMCMs (Stahl, 1996b).

System/Oroanizational improvement expectations. CNEO system/organizational improvement expectations were categorized into four groups: customer satisfaction, quality performance, financial performance, and strategic planning expectations. Sovie (1995) 
comprehensively reinforces panelists' selection of CNEO role expectations within this category. Sovie contended that as managed care evolves, CNEOs will focus on three imperatives: reduced hospital costs, improved clinical outcomes, and enhanced patient satisfaction.

Patient, physician, and employee customers were identified by panel members. Patient satisfaction is becoming increasingly important as managed health plans and health care providers are competing for enrollees (Coile, 1994; Shortell, 1995). Panelists' developed two CNEO role expectations specific to physicians and employees. Interestingly, the literature addresses the importance of physician collaboration (Smith et al., 1994) but does not address general or specific elements of physician satisfaction. Also, not found within the nursing literature are CNEO role expectations that address improving and/or maintaining employee satisfaction levels.

Panelist identified quality and financial performance expectations are well documented and supported within the literature (Porter-O'Grady, 1995; Sanford, 1994; Shortell, 1995; Sovie, 1995). Financial performance expectations all had mean importance ratings of 3.72 and greater and each had a mode of 4.00 indicating the high degree of importance placed upon these expectations. Given the very nature of HMCMs this was expected.

Panel members identified strategic planning expectations which focused on meeting the organization's mission, organizational survival and growth, and ensuring that community health care needs are met. The highest mean importance rating within this sub-category was for the CNEO role expectation related to ensuring that the organization's mission is met $(3.80)$ and the lowest was related to ensuring that the communities health care needs are met (3.16). This is somewhat incongruous in that organizational mission is typically tied to community need.

\section{Consensus Between CNEOs and CNEO Supervisors on Present-day and Future CNEO Role}

\section{Expectations}

The level of consensus between CNEO and CNEO supervisors was high on present-day CNEO role expectations and moderately high for future CNEO role expectations. Seventy-eight 
percent (14 of 18) of the CNEO panelist identified extremely important present-day role expectations and $64 \%$ (14 of 22 ) of the CNEO supervisor panelist identified extremely important expectations were shared (consensus) present-day extremely important role expectations, indicating a high level of consensus for present-day role expectations. Seventy-three percent of ( 8 of 11) the CNEO panelist identified extremely important future role expectations and $40 \%$ ( 8 of 20 ) of the CNEO supervisor panelist identified extremely important future role expectations were shared (consensus) future role expectations, indicating a moderately high level of consensus for future expectations. Forecasting the future is difficult and uncertain (Martino, 1982) therefore decreased consensus between CNEO and CNEO supervisor panel members on future CNEO role expectations was not surprising.

The greatest number of panelist identified extremely important present-day CNEO role expectations were in the categories of leadership and clinical expectations. Interestingly, the categories for the greatest number of panelist identified future CNEO role expectations changed to leadership and system/organizational improvement suggesting an increased future focus on customer satisfaction, quality and financial performance, and strategic planning. An important noted difference within system/organizational improvement expectation category was that the CNEO supervisor panelists identified all three of the financial performance expectations as extremely important future role expectations, CNEO panel members did not. The most frequently shared extremely important present-day CNEO role expectation were in the sub-categories of communication/relationship-building and nursing. The most frequently shared extremely important future role expectations were in the sub-categories of communication/relationship-building and quality performance indicating the future importance of outcome measurement and improvement.

\section{Future Direction. Importance, and Evolution of the CNEO Role}

Results of the open-ended question addressing the future direction, importance, and evolution of the CNEO role produced a few new findings and reinforced many of the earlier 
identified role expectations. Responses addressing the need for multi-disciplinary collaboration, development of new care delivery models, and a continuum of care perspective supported earlier identified CNEO role expectations. New findings were responses emphasizing CNEO risk-taking, flexibility, vision, workload, and pay expectations. Interestingly, panelists stressed the importance of community awareness and involvement, however the CNEO role expectation, "ensure that community health care needs are met" was not identified by the panel to be a future priority.

\section{Summany}

A three round Delphi study was conducted with a panel retention rate of $83 \%$. Twenty-five expert panelists completed all three Delphi rounds. Fifteen of the panelists were CNEOs and 10 were CNEO supervisors. Demographics revealed panel members were seasoned healthcare executives with significant IDS and HMCM experience. Panelists, through consensus measurement, identified 59 present-day and 59 identical future role expectations for CNEOS working in IDSs in HMCMs. Stratification of CNEO role expectations by panel sub-groups revealed a high level of consensus between CNEOs and CNEO supervisors on present-day CNEO role expectations and a moderately high level of consensus on future CNEO role expectations. 


\section{Chapter V}

\section{Summary, Conclusions, and Recommendations}

\section{Summary of the Study}

\section{Statement of the issue}

Today's healthcare industry is undergoing radical transformation. Traditional indemnity insurance and fee-for-service reimbursement strategies are becoming obsolete and managed health care is proliferating. Managed health care is controlling costs and service utilization, reducing health care provider profits, and threatening the very viability of hospitals. In response, health care organizations are seeking new ways of delivering health care, re-evaluating their core businesses, outsourcing non-clinical services, building new business partnerships and relationships, and shifting patient care services from in-patient to out-patient settings. Fundamental to the managed care market revolution and hospital survival is the restructuring of health care delivery systems into local and regional based alliances of providers, physicians, and payers (Fonner, 1996). By the year 2000, it is predicted that three out of every four hospitals will belong to multi-hospital networks, alliances, or integrated delivery systems (Coile, 1994).

The health care metamorphosis is placing new demands and expectations upon hospital leaders. Perhaps no individual is confronted more with new role expectations than the hospital Chief Nurse Executive Officer (CNEO). CNEOs are increasingly finding themselves in roles within complex integrated healthcare delivery systems (IDSs) located within highly managed care markets (HMCMs). As IDSs located within HMCMs have grown so has the anecdotal literature predicting CNEO role changes. Unfortunately, not found within the literature, are research investigations which address evolving CNEO role expectations. 


\section{Purpose of the Study}

The purpose of this study was to obtain expert opinion on CNEO role expectations within the growing context of IDSs in HMCMs. Present-day and future CNEO role expectations and the level of consensus between CNEO and CNEO supervisors on CNEO role expectations were examined. The following research questions were posed and answered:

1. What are the present-day role expectations for CNEOs employed in integrated healthcare systems in highly managed care markets?

2. What are future role expectations for CNEOs employed in integrated healthcare systems in highly managed care markets?

3. What is the level of consensus between CNEOs and CNEO supervisors on presentday role expectations for CNEOs employed in integrated healthcare systems in highly managed care markets?

4. What is the level of consensus between the CNEO and CNEO supervisors on future role expectations for CNEOs employed in integrated healthcare systems in highly managed care markets?

\section{Methodology}

The Delphi technique is a survey method for structuring group opinion and discussion for the purpose of solving complex problems, forecasting, consensus determination, and establishing priorities (Linstone \& Turoff, 1975). The Delphi method also allows experts from diverse locations to come together, for study purposes, without having to meet face-to-face. The lack of face-to-face identification minimizes peer pressure, intimidation, and undue influence from strong voices (Goodman, 1987; Lindeman, 1975).

This study was focused on both consensus determination and forecasting, making the Delphi method a logical choice. Additionally, input was needed from experts located in various parts of the country. From a financial and logistics perspective the expert panel physically could 
not have been brought together for data collection. The freedom of expression that comes without a face-to-face meeting was also believed to be advantageous for promoting honest opinion (Williams \& Webb, 1994). Lastly, this study drew heavily upon role theory literature. The Delphi method is conceptually congruent with that literature which reinforced the selection of the Delphi method. Role literature suggests that insight into role expectations is best obtained by expert role definers (e.g., the Delphi expert panel). Expert role definers are individuals who define (CNEO supervisors), perform (CNEOs), and evaluate (CNEO supervisors) role expectations (Bible \& McComas, 1966; Carey, Craighead, \& Netzel, 1988).

Several methodological limitations related to the Delphi method were identified within the literature (Dodge \& Clark, 1977; Duffield, 1993; Henry et al., 1996; Williams \& Webb, 1994). Four specific method limitations were considered for this study: consensus determination, loss of minority and extreme opinion, researcher bias, and subject bias secondary to panel attrition. Method limitations were considered during the design and safeguards taken during the implementation of the study (see Chapter III). None of the four limitations identified at the beginning of this study were felt to have influenced study outcomes.

\section{Results}

What are the present-day role expectations of CNEO employed in IDSs in HMCMs? Panelists reached consensus on 59 present-day role expectations for CNEOs employed in IDSs in HMCMs. Present-day CNEO role expectations were categorized into three major categories; $40 \%$ were leadership expectations, $32 \%$ clinical expectations, and $28 \%$ system/organizational improvement expectations. CNEO expectations were also categorized into sub-categories. Based upon mean importance ratings, all of the present-day CNEO role expectations were deemed important except for one which was evaluated as somewhat important. CNEO role expectations within the communication/relationship-building and financial sub-categories were found to have great importance. 
What are the future role expectations of CNEOs employed in IDS in HMCMs? Panelists obtained consensus on 59 future role expectations for CNEOs in IDSs in HMCMs. Three additional future CNEO role expectations were identified by expert panelists however they were not evaluated for consensus opinion or importance. The 59 future CNEO role expectations were categorized into three major categories; $40 \%$ leadership expectations, $32 \%$ clinical expectations, and $28 \%$ system/organizational improvement expectations. Based upon mean importance ratings, all of the present-day CNEO role expectations were considered important except for two which were evaluated as somewhat important.

What is the level of consensus between CNEOS and CNEO supervisors on present-day CNEO role expectations for CNEOs emploved in IDSs in HMCMs? Eighteen present-day CNEO role expectations were rated extremely important by $80 \%$ or more of the CNEO panelists and 22 expectations by $80 \%$ or more of the CNEO supervisor panelists. Fourteen of the present-day role expectations were identified by $80 \%$ or more of both CNEO and CNEO supervisor sub-groups as extremely important. Seventy-eight percent of the CNEO panelist identified extremely important present-day role expectations and $64 \%$ of the CNEO supervisor panelist identified extremely important present-day expectations were shared present-day role expectations, indicating a high level of consensus for priority present-day role expectations.

The leadership and clinical expectation categories had the highest number of shared panel identified extremely important present-day CNEO role expectations The greatest number of CNEO and CNEO supervisor shared present-day extremely important CNEO role expectations fell into the communication/relationship-building and nursing sub-categories.

What is the level of consensus between CNEOS and CNEO supervisors on future CNEO role expectations for CNEOS employed in IDSs in HMCMs? Eleven future CNEO role expectations were rated extremely important by $80 \%$ or more of the CNEO panelists and 20 expectations by $80 \%$ or more of the CNEO supervisor panelists. Eight future CNEO role 
expectations were identified by $80 \%$ or more of both CNEO and CNEO superviosr sub-groups as extremely important. Seventy-three percent of the CNEO panelist identified extremely important future role expectations and $40 \%$ of the CNEO supervisor panelist identified future role expectations were shared future role expectations, indicating a moderately high level of consensus for priority future expectations.

The leadership and system/organizational improvement categories had the highest number of panel identified consensus future CNEO role expectations. CNEO supervisors identified each of the financial expectations as future extremely important expectations; CNEOs did not. The greatest number of CNEO and CNEO supervisor shared future CNEO role expectations fell into the communication/relationship-building and quality sub-categories.

\section{Conclusions}

Present-day and future role expectations for CNEOs employed in IDSs located within HMCMs center around leadership, clinical, and system and organizational responsibilities. Presently, CNEOs and CNEO supervisors place great importance on leadership and clinical CNEO role expectations. Today's CNEOs are also moving away from roles with single discipline responsibility and toward multi-disciplinary roles that have increased program development responsibilities. Many of the present-day consensus leadership and clinical role expectations focus on communication and relationship-building, nursing care delivery, and patient care redesign activities. CNEOs and CNEO supervisors strongly agree on present-day consensus role expectations for CNEOs working in IDSs in HMCMs. CNEOs and CNEO supervisors expect CNEOs in IDSs and HMCMs to develop, coach, and mentor subordinates; communicate openly; foster collegial relationships; develop and maintain nursing standards, and ensure the delivery of safe, competent, cost-effective nursing care.

For the future, CNEOs and CNEO supervisors slightly shift their CNEO role expectation 
emphasis. Although leadership expectations prevail as extremely important, system and organizational role expectations take on increased significance. Customer satisfaction, quality and financial performance, and strategic planning CNEO role expectations are more frequently identified as extrememly important expectations. CNEO supervisors, unlike CNEOs, believe five years from today, that developing, monitoring, and ensuring compliance with organizational budgets; reducing organizational operating expenses; and increasing productivity will be extremely important expectations. CNEOs and CNEO supervisor only moderately agree on future consensus role expectations. In the future CNEOs and CNEO supervisors believe communication and relationship-building expectations and quality performance expectations relating to measuring and improving quality patient care will be important.

An interesting conversation is beginning to emerge within highly managed competition markets. Healthcare executives are articulating that IDSs are complex and require expensive organizational infrastructures which are cost prohibitive in capitated healthcare markets (e.g. Southem Califomia). If this belief becomes a realized reality, IDSs and multi-hospital systems and networks may dwindle and single entity providers re-emerge once again shifting CNEO role expectations.

\section{Implications of the Study}

Study findings have implications for CNEOS, CEOs, COO's and nurse educators. The insight gained from this study will assist CNEOs and CNEO supervisors to achieve CNEO role clarification. Role clarification based upon clearly defined, articulated, and shared CNEO role expectations minimize CNEO role ambiguity and conflict, power imbalances, inadequate role implementation, and job dissatisfaction (Biddle, 1979; Weaver, 1988). CNEO supervisors may also benefit by using study findings in the development of position descriptions and performance outcome criteria. Performance outcome criteria based upon well-defined role expectations 
strengthen the performance evaluation process and improves organizational performance. Professional nursing organizations such as the American Nurses Association (ANA) and American Organization of Nurse Executives (AONE) may also use the findings from this study to further support CNEO role expectation development. The AONE (1995) have identified dimensions and key processes of nurse executive practice but have not translated them into role expectations. The ANA (1995) scope and standards could be further refined and augmented using data from this study.

Educators may use the identified present-day and future role expectations to develop new graduate curricula or educational offerings. For example, the importance placed upon both present-day and future communication and relationship-building leadership expectations suggest that an educational emphasis be focused within this area. Addtionally, the empahsis placed upon the broadening multi-disciplinary scope of the CNEO supports educational and experiential learning in non-nursing clinical disciplines. Entrepreneurial nurse educators may find a unique opportunity to prepare CNEOs for this expanding role.

The moderate level of consensus between CNEOs and CNEO supervisors on future role expectations may also serve as a warning to CNEOs and CNEO supervisors that greater role expectation clarification is needed to avoid future role conflict, dissonance, and tumover (Adams, 1994; Kippenbrock, 1995). Exploration of the diffference of opinion between CNEO and CNEO supervisor panelists' regarding the future importance of CNEO financial role expectations may have great implication for reducing CNEO turnover. The very nature of HMCMs empahsize the importance of organizational financial importance, the disparate importance placed upon organizational financial performance is disturbing.

Panelists' identification of the future importance of CNEO community involvement signals that the CNEO role is moving from an internal focused role into one which is also externally (community) focused. Historically, CNEOs have not had community role expectations beyond that 
of the nursing community. Study findings also suggest that CNEOs must prepare themselves for roles which require flexibility, risk-taking, vision-setting, and overwhelming workload expectations. Finding's also have work implications for CNEOs related to the outsourcing of hospital services, ensuring employee job satisfaction, development of educational incentives and representation of nursing at state-wide committees.

\section{Recommendations for Further Research}

\section{Strengths of the Study}

Numerous study strengths are identified related to this investigation. The first strength was the studies' panel retention rate of $83 \%$. A strong panel retention rate lessened subject bias and loss of panel member opinion (Williams \& Webb, 1994). The investigations' short data collection period, five months, was also advantageous. A short data collection period decreased the likelihood that changing contextual variables altered panel member opinion (personal communication, February 15, 1995). The broad geographic representation of panelists also strengthened the investigation by minimizing regional and/or local panel bias. Another strength of the study was the use of a pre-established, high consensus criterion which supported retention of only valid CNEO role expectations (Grant, Kinney, \& Guzzetta, 1988). Lastly, the authentication of study findings with current nursing and healthcare literature reinforced the validity of study results.

\section{Weaknesses of the Study}

Several study weaknesses are recognized for this study. First, expert panel weakenesses were identified. The panel was small and had limited CNEO supervisor representation. A larger panel with stronger CNEO supervisor representation would have increased the statistical data analysis options and enhanced data interpretation and study conclusions. Terminating the study at the end of three rounds also weakened the study. A fourth Delphi round would have given panel members an opportunity to validate statistical prioritization of the present-day and future 
CNEO role expectations and allowed a more in-depth exploration of future CNEO role expectations. Unfortunately, a fourth Delphi round, most likely, would have increased panel member attrition which would have weakened the study. The use of the identified present-day CNEO role expectations to identify future CNEO role expectations was found to be a weakness of the study in that panel members were not stimulated to independently identify additional future expectations. The panel identified only three additional future expectations.

\section{Recommendations for Further Study}

Additional qualitative and/or quantitative studies are recommended to validate the present-day and future CNEO role expectations identified within this study. Validation of study findings using an ethnographic or focus group methodology are suggested. Duplicating this Delphi study, beginning Round One of the study with the presently identified CNEO role expectations would be another method of validating study findings. Using this studies' identified role expectations as the basis for a survey tool and conducting an investigation using a randomized CNEO and CNEO supervisor sample would be a quantitative approach to validating this studies' findings.

The future CNEO role expectations identified in this study need greater in-depth exploration. Additional, studies examining how the CNEO role expectations are communicated, operationalized, and evaluated within the work setting are recommended. Inquiry into specific relationships between CNEO role expectation consensus and job satisfaction, role performance, job tumover, and organizational financial and quality performance are also recommended. 


\section{REFERENCES}

Adams, C. (1988). Role expectations and role conflict of the army head nurse. Nursing Management $19(1), 45-50$.

Ahern, M. (1990). Nurses' an other experts' views of healthcare fraud and abuse. Nursing Economics, 14(1), 40-45.

American Hospital Association. (1990). Role function of the hospital nurse executive: Management advisory, 002-004.

American Hospital Assciation. (1995). 1995/1996 American Hospital Association Guide. Chicago, lllinois.

American Organization of Nurse Executives. (1995). The role and function of nurses in Executive practice. Chicago, Illinois.

American Nurses Association. (1995). Scope and standards for nurse administrators. Washington, D.C.: American Nurses Publishing.

Andrica, D. (1995). The 21st century executive: New competencies for sucess. Nursing Economics. 13(4), 287.

Barton, A. (1994). Data needs for decision support of chief nurse executives. Joumal of Nursing Administration, 24(4S), 19-25.

Bartu, A., Nelson, M., Ng, C., McGowan, S., \& Robertson, J. (1993). A delphi survey of clinical nursing research priorities in Westem Austrailia. Australian Joumal of Advanced Nursing. $\underline{8}(3), 29-33$.

Beyer, M. (1994). Is the nurse executive role expanding of contracting? Joumal of Nursing Administration, 24(11), 8-9. 
Bible, B., \& McComas, J. (1966). Role consensus and teacher effectiveness. Social Forces. 42, 225-236.

Biddle, B. (1961). The present status of role theory Columbia, Missouri: University of Missouri Press.

Biddle, B. (1979). Role theory: Expectations, identities, and behaviors. New York: Academic Press. Annual review of sociology. 12, 67-92.

Biddle, B. (1986). Recent development in role theory. Annual review of sociologr, 12, 67 92.

Biddle, B., \& Thomas, E. (1966). Role theory: Concepts and research. New York: Wiley.

Blouin, A., \& Brent, N. (1993). The chief nurse officer as a board member: An overview. Joumal of Nursing Administration, 23(3), 14-15.

Blouin, A., \& Tonges, R. (1996). The content/context imperative. Joumal of Nursing Administration, 26(3), 38-45.

Bostrum, J. (1995). Multiple health care contracts: Changing the rules for hospital staff and systems. Nursing Economics. 13(2), 99-103.

Brower, H., \& Crist, M. (1985). Research priorities in gerontological nursing for long-term care. Image: The Joumal of Nursing Scholarship. 17(1), 22-27.

Bunsey, S., De Fazio, M., Pierce, L., \& Jones, S. (1991). Nurse managers: Role expectations and job satisfaction. Applied Nursing Research 4(1), 7-13.

Cadmus, N. (1903). The duties of the executive head nurse of a small hospital. American Joumal of Nursing. $3(8), 621-624$.

Campbell, R. (1966). A methodological study of the utilization of experts in business forecasting. An unpublished doctoral dissertation, Univeristy of California at Los Angeles, California. 
Carey, S., Craighead, P., \& Netzel, C. (1988). Conflicting role expectations for the director of nursing position: A new standard. Nursing Administration Quarterty, 12(2), 32-44.

Carter, B., \& Axford, R. (1993). Assessment of computer leaming needs and priorities of registered nurses practicing in hospitals. Computers in Nursing. 11(3), 122-125.

Chapman, B. (1977). An analysis of mutual role expectations of nurse educators and head nurses. Dissertation Abstracts International. 20 (1693). (University microfilms No. C-767).

Cicarelli, J. (1994). The future of economics. Technological forecasting and social change, $25,139-157$.

Clark, K. (1991). Building creative organizations: the nurse executive's role. Aspens Advisor for Nurse Executives. 6(9), 5-6.

"Clinical Maneuvers". (1995). Hospitals \& Health Networks, January 5, 52

Clyde, R., \& Westbury, S. (1985). Survey advises CEO's to re-examine traditional goals. Health Progress. (66), 26-29.

Coile, R. (1994). The new govemance: Strategies for an era of health reform. Health Administration Press: Ann Arbor, Michigan.

Couper, M. (1984). The delphi technique: Characteristics and sequence model. Advances in Nursing Science. $7(1), 72-77$.

Curran, C. (1995). IDN core competencies: Nursings role. Nursing Economics, 13(4), $192-193$.

Dalkey, N. (1969). The delphi method: An experimental study of group opinion, Santa Monica, Califomia: RAND Corporation.

Davidson, D. (1996). The role of the nure executive: In the corporatization of health care. Nursing Administration Quarterty, 20(2), 49-53.

Deux, K. (1984). From individual differences to social categories: Analysis of a decades's research on gender. American Psychology, 39, 105-116. 
Dodge, B., \& Clarke, R. (1977). Research on the delphi technique: Reserach briefing. Educational Technology, April. 58-60/

Duffield, C. (1993). The delphi technique: A comparison of results obtained using two expert panels. International Journal of Nursing Studies, 30(3), 227-237.

Dunn, D. (1996). Health care 1999: A national bellweather. Joumal of Health Care Finance, 22(3), 23-27.

Emden, C., \& Young, W. (1981). Theory development in nursing: Austrailian nurses advance global debate. Australian Joumal of Advanced Nursing. 4(3), 22-40.

Enzer, S. (1969). A case study using forecasting as a decision-making aid. Madison, Wisconsin: The Institute for the Future.

Erickson, E. (1980). The nursing service director, 1880-1980. Joumal of Nursing Administration, April, 6-13.

Feldman, H. (1995). Preparing the nurse executive of the future. Nursing Leadership Forum. 1(1), 18-22.

Flarey, D. (1990). Physician bonding: The role of the nurse executive. Journal of Nursing Administration, 20(12), 23-27.

Fonner, E. (1996). Identifying comets on the road to integration. Journal of Health Care Finance. 22(3), 28-33.

Fralic, M. (1992). Nurse executive practice-into the next millennium: From limbo dancer to pole vaulter. Joumal of Nursing Administration, 22(2), 15-16.

Fralic, M. (1993). The new era nurse executive: Centerpiece characteristics. Journal of Nursing Administration. 23(1), 7-8.

Gallivan, M. (1986). AONE study finds nurse-executive field in transition. Hospitals. September, 94. 
Gilmartin, M. (1996). Creating the vision: The role of the CNE in bringing innovations to client care service delivery. Nursing Administration Quarterty, 21(1), 14-23.

Gladwin, M. (1907). Superintendents of small hospitals. American Joumal of Nursing. May, 622-623.

Goodman, C. (1987). The Delphi technique: A critique. Journal of Advanced Nursing 12, 729-734.

Goodrich, N. (1982). A profile of the competent nursing administrator. Ann Arbour Research: Maine.

Gordon, T., \& Helmer, O. (1964). Report on a long-range forecasting study. Santa Monica, California: The Rand Corporation.

Grant, A. (1992). Entrepreneurial leadership: A delphi study of new venture success factors. An unpublished doctoral dissertation, University of San Diego, California.

Grant, J., Kinney, M., \& Guzzetta, C. (1990). A methodology for validating nursing diagnoses. Advances in Nursing Science. 12(3), 65-73.

Grimaldi, P. (1995). Medicaid switching to managed care. Nursing Management, 26(7), 12-18.

Grimaldi, P. (1996). Managed care authorizations to manage care. Nursing Management. $27(4), 49-50$.

Gross, N., Mason, W., \& MacEachem, A. (1958). Explorations in role analysis: Studies in the school superintendency role. New York, New York: Wiley.

Hamil, E. (1969). The changing director of nursing service. Nursing Outlook, 7. 64-65.

Hardy, M., \& Conway, M. (1988). Role theory: Perspectives for health professionals. Norwalk, Connecticut: Appleton \& Lange.

Heath, A., Neimeyer, G., \& Pederson, P. (1988). The future of cross-cultural counseling: A delphi poll. Joumal of Counseling and Development. 67(9), 27-30. 
Heimer, O. (1983). Looking forward: A quide to futures research. Beverty Hills, California: Sage Publications.

Henney, C., Chrissafis, I., McFarlane, J., \& Crooks, J. (1979). A method of estimating nursing workload. Joumal of Advanced Nursing. 7(4), 319-325.

Henry, B. (1991). Attributes of service-based nursing research programs useful for decision-making. Nursing Administration Quarterly, 15(4), 82-84.

Henry, B., Moody, L., Pendergast, J., Odonnell, J., Hutchinson, S., \& Scully, S. (1987). Delineation of nursing administration research priorities. Nursing Research, 36(5), 309-314.

Hollandar, E. (1985). Leadership and power. In C. Lindzey \& E. Aronson (Eds.), Handbook of social psychology (pp. 265-281). New York, New York: Random House.

"How Markets Evolve". (1995). Hospitals \& Health Networks, March 5, 48.

Ikle, A. (1976). Administrator must work to find a nursing director with superior management ability. Modem Healthcare, October, 1967.

Irurita, V. (1994). Optimism, values, and commitment as forces in nursing leadership. The Joumal of Nursing Administration. 24(9), 61-71.

Issac, S., \& Michael, W. (1972). Handbook in research and evaluation. San Diego, Califomia: Robert K. Knapp.

Jaco, P., Price, S., \& Davidson, A. (1994). The nurse executive in the public sector. Joumal of Nursing Administration. 24(3), 55-62.

Johns, J. (1996). Trust: Key to acculturation in corporatized health care environments. Nursing Administration Quarterly. 20(2), 13-24.

Johnson, L. (1990). Strategic management: A new dimension of the nurse executive's role. Joumal of Nursing Administration, 20(9), 7-10.

Joint Commission on Accreditation of Healthcare Organizations (1993). Accreditation manual for hospitals: Volume 1(93-78938). Oak brook Terrace, Illinois. 
Judd, R. (1972). Forecasting to consensus gathering: Delphi grows up to college needs. College and University Business, 53(35-43).

Kahn, R., Wolfe, D., \& Quinn, R. (1964). Organizational stress: studies in role conflict and ambiquity. New York, New York: Wiley.

Kippenbrock, T. (1995). Turnover of hospital chief nurse officers. Nursing Economics. $13(6), 330-336$.

Kippenbrock, T., \& May, F. (1994). Turnover at the top: CNOs and hospital characteristics. Nursing Management. 25(9), 54-57

Kippendorff, K. (1980). Content analysis: An introduction to its methodology. Beverly Hills, CA: Sage Publications.

Klakovich, M. (1994). Connective leadership for the 21st century: A historical perspective and future directions. Advances in Nursing Science. 16(4), 42-54.

Leininger, M. (1974). The leadership crisis in nursing: A critical problem and challenge. Journal of Nursing Administration, March-April, 28-34.

Lennon, M. (1987). Sex differences in distress: The impact of gender and work roles. Journal of Health \& Social Behavior, 28(3), 290-305.

Lewandowski, L., \& Kositsky, A. (1983). Research priorities for critical care nursing: A study by the American Association of Critical Care Nurses. Heart \& Lung 12(1), 35-44.

Lindeman, C. (1975). Delphi survey of priorities in clinical nursing research. Nursing Research. 24(6), 434-441.

Linstone, H., \& Turoff, M. (1985). The Delphi method: Techniques and applications. Addison-Wesley: Reading, Massachusetts.

Mark, B., \& Turner, J. (1990). Economic trends influencing the nurse executive's role. Aspens's Advisor, 5(5), 5-9. 
Martino, J. (1982). Technological forecasting for decision-making. North Holland: New York, New York.

Mateo, M., \& Meeker, M. (1992). Publication skill development in nurses. A vital role of nurse executives. Joumal of Nursing Administration, 22(4), 64-66.

Matrone, J. (1996). How to move into the next era of health care. Nursing Administration Quarterty, 21(1), 1-6.

McDonagh, K. (1991). Nurse executives: Future leaders of our healthcare system. Aspen Advisor for Nurse Executives, 6(10), 6-8.

McGoldrick, T., Jablonski, R., \& Wolfe, Z. (1994). Needs Assessment for a patient education program in a nursing department. Joumal of Nursing Staff Development. 10(3), 123 130.

McKenna, $H$. (1989). The selection by ward managers of an appropriate nursing model. Journal of Advanced Nursing. 14, 762-775.

McKenna, H. (1994). The delphi technique: A worthwhile research approach for nursing? Joumal of Advanced Nursing. 19, 1221-1225.

McMurray, A. (1994). Three decision-making aids. Joumal of Nursing Staff Development. March/April, 62-65.

Mead, G. (1934). Mind. self. and society. Chicago, Illinois: University of Chicago Press.

Monahan, S. (1968). A study of the perceptions of the perceptions of director of nursing service concerning functions and problems of nursing administration. (Unpublished doctoral dissertation, New York University).

Moore, B., Smith, S., Schumacher, L., \& Papke, R. (1996). Patient care leadership within an emerging integrated delivery network. Nursing Administration Quarterly. 20(2), 54-64.

Moreno, J. (1934). Who shall survive? New York, New York: Beacon House. 
Murray, J. (1967). The development and test of a concept and methodology for longrange forecasting. An unpublished doctoral dissertation, University of Colorado, Colorado.

Oberst, M. (1978). Priorities in cancer nursing research. Cancer Nursing. 1(4), 281-290.

O'Neal, W. (1990). The knowledgeable and competent acute care hospital nurse executive of the future: Perceptions of practicing chief executive officers and nurse executives. Unpublished doctoral dissertation, Kansas State University, Kansas.

Orton, H. (1981). Ward leaming climate and student nurse response. Unpublished masters thesis, Sheffield City Polytechnic College, Sheffield.

Pappas, C. (1991). The nurse executive: Creator and innovator. Aspens Advisor for Nurse Executives. 7(7), 7-8.

Polit, D., \& Hungler, B. (1995). Nursing research: Priniciples and methods. Philadelphia: J.B. Lippincott.

Porter-O'Grady, T. (1995). Shifting tides: The new role of the nurse executive. Aspens Advisor for Nurse Executives, 10(8), 1-4.

Porter-O'Grady, T. (1997). Quantum mechanics and the future of healthcare. Joumal of Nursing Administration. 27(1), 15-20.

Poulin, M. (1984). The nurse executive role: A structural and functional analysis. The Journal of Nursing Administration. February, 9-14.

Preble, J. (1984). The selection of delphi paneis for strategic planning purposes. Strategic Management Joumal. 5, 157-170.

Princeton, J. (1993). Education for executive nurse administrators: A databased curricular model for doctoral (PhD) programs. Joumal of Nursing Educational. 32(2), 59-63.

Quade, E. (1967). Cost-effectiveness: Some trends in analysis. Santa Monica: Rand Corporation.

Rasp, A. (1973). Delphi: A decision-maker's dream. Nation's School.1, 29-32. 
Reid, N. (1988). The Delphi technique, its contribution to the evaluation of professional practice. In R. Ellis (Ed.), Professional competence and quality assurance in the caring professions (pp. 300-330). Croom Helm: Beckenham, Kent.

Redmond, G. (1995). "We don't make widgets here": Voices of chief nurse executives. The Joumal of Nursing Administration. 25(2), 63-69.

Richards, L. (1929). Reminiscences of Linda Richards: America's first nurse. Boston, Massachusetts: M. Barrows \& Company.

Rizzo, J., House, R, \& Litzman, S. (1970). Role conflict and ambiguity in complex organizations. Administrative Science Quarterty, 15, 150.

Rotter, J. (1954). Social leaming and clinical psychology. Englewood, New Jersey: Prentice-Hall.

Rowland, H., \& Rowland, B. (1985). Nursing administration handbook. Rockville, Maryland: Aspen Publications.

Sackman, H. (1975). Delphi critique. Lexington Books: Lexington, Massachusetts.

Sanford, K. (1994). Future education: What do nurse executives need? Nursing Economics. 12(3), 126-130.

Santee, R., \& VanDerPol, T. (1976). Actor's status and conformity to norms: A study of students' evaluations of instructors. Sociological Quarterly, 17,378-388.

Sarbin, T., \& Allen, V. (1968). Role theory. In C. Lindzey \& E. Aronson (Eds.), Handbook of social psychology (pp. 497-506). New York, New York: Random.

Scovil, E. (1901). The problem of the superintendent. American Joumal of Nursing. March, 507. 
Shaw, W. (Ed.). (1995). Market evolution. In Managing integration and operations: A quide to quality health care systems (pp. 11-15). New York, New York: Thompson Publishing Group.

Shepardson, R. (1972). Survey to assess and objectively display the arguments for and against developing a performance based teacher education program. Joumal of Teacher Education, XXIII, 166-168.

Sherif, M. (1936). The psychology of social norms. New York, New York: Harper.

Shortell, S. (1985). High-performing healthcare organizations: Guidelines for the pursuit of excellence. Hospital \& Health Services Administration, July 7-35.

Shortell, S. (1993). Creating organized delivery systems: The bariers and facilitators. Hospital \& Health Services Administration. 38(4), 451-466.

Shortell, S., Anderson, D., \& Gillies, R. (1993). The holographic organization. Healthcare Forum Journal, March/April, $20-26$.

Shortell, S. (1995). Watch for flying phrases. Hospitals \& Health Neworks, June 20, $79-$ 82.

Simms, L., Price, S., \& Pfoutz. (1985). Nurse executives: Functions and Priorities. Nursing Economics, 3, 238-244.

Singleton, E., \& Nail, F. (1988). Nursing leadership: The effects of organizational structure. Joumal of Nursing Administration. 18(10), 10-14.

Singleton, E., \& Nail-Hail, F. (1995). Charting the course for merger. The Journal of Nursing Administration. 25(5), 47-49.

Smith, V. (1947). A century of service: Rochester General Hospital 18471947. New York, New York: G. P. Putnam's Sons. 
Smith, P., Parsons, R., Murray, B., Dwore, R., Lawrenc, V., \& Okertund, V. (1994). Joumal of Nursing Administration. 24(11), 56-62.

Solovy, A. (1995). Predicting the unpredictable. Hospital and Health Networks, 69(1), 2629.

Sovie, M. (1995). tailoring hospitals for managed care and integrated health systems. Nursing Economics, $13(2), 72-83$.

Special course in economics (1904). American Joumal of Nursing. 4(9), 687690.

Spengler, C. (1989). The evolution of the nurse executive role from one perspective. Nursing Administration Quarterty, 13(2), 51-55.

Spitzer, R. (1991). The role of chief nursing executive in a true product-line environment. Nursing Administration Quarterty, 15(2), vii-viii.

Stachura, C. (Ed.). (1995). From increasing revenues to controlling costs: Benchmark data for strategic planning. Westchester, Illinois: Healthcare Financial Management Association.

Stahl, D. (1995). Merger mania, alliances and subacute care. Nursing Management. 26(11). 16-19.

Stahl, D. (1996a). The phases of managed care: Where does subacute fit? Nursing Management Supplement, October, 8-9.

Stahl, D. (1996b). The pulse of managed care in 1996 and beyond. Nursing Management. 27(4), 16-17.

Strauss, A. \& Corbin, J. (1990). Basics of qualitative research. Newbury Park, CA: Sage Publications.

Strauss, H., \& Zeigler, L. (1975). The delphi technique and its uses in social science research. Joumal of Creative Behavior. IX, 253-59.

Stodgill, R. (1974). Handbook of leadership. New York: The Free Press. 
Sullivan, E., \& Byre, C. (1983). Use of the delphi technique for curriculum planning. Joumal of Nursing Education, 22(5), 187-189.

Taylor-Dunham, J., \& Klafehn, K. (1995). Identifying the best in executive leadership. Joumal of Nursing Administration, 25(6), 68-70.

Tubbesing, B. (1977). Perceptions of the director of nursing role in hospitals. Dissertation Abstracts International, (University Microfilms No. C-797).

Uhl, N. (1971). Identifying institutional goals. Durham, North Carolina: National Laboratory for Higher Education.

Vela, N. (1989). A delphi study of califomia community college counselors' responsibilities and competencies for the 1990's as perceived by chief student services administrators. Unpublished doctoral dissertation, University of San Diego, California.

Ventura, M., \& Waligora-Serafin, B. (1981). Study priorities identified by nurses in mental health settings. International Joumal of Nursing Studies, 18, 41-46.

Wangsness, S. (1991). A study of decision-making activities of nurse executives in acute care Pennsylvania hospitals. Unpublished doctoral dissertation, Pennsylvania State University, Pennsylvania.

Waltz, C., Strickland, O. \& Lentz, E. (1991). Measurement in nursing research. Philadelphia: F.A. Davis.

"Watch for Flying Phrases". (1995). Hospitals \& Health Networks. March 20, 79-80.

Weaver, C (1988). Nurse executive turnover. Nursina Economics. 6(6), 283-286.

Whitman, N. (1990). The committee meeting alternative: Using the Delphi technique. Joumal of Nurse Administration. 20(7/8), 30-36.

Williams, J. (1992). Guidelines for managing integration. Healthcare Forum Joumal. March/April, 39. 
Williams, P. \& Webb, C. (1994). The delphi technique: A methodological discussion. Joumal of Advanced Nursing. 19, 180-186.

Wright, L. (1995). Avoiding services marketing myopia. In W. Glynn and J. Barnes (Eds.), Understanding Services Management (pp. 33-56). West Sussex, England: John Wiley \& Sons.

Wyld, D. (1996). The capitation revolution in health care: Implications for the field of nursing. Nursing Administration Quarterty. 20(2), 1-11. 


\title{
APPENDIX A
}

\section{INVITATION TO PARTICIPATE IN STUDY}

October 4, 1996

\author{
Mr. John Doe \\ Chief Executive Officer \\ Mercy Hospital \\ 1111 Frost Street \\ San Francisco, CA 12121
}

Dear Mr. Doe:

I am currently conducting a Delphi study addressing Chief Nurse Executive Officer (CNEO) role expectations in integrated healthcare delivery systems located within highly managed care markets (Stage III and IV). I am currently a doctoral student at the University of San Diego and this study will serve as my doctoral dissertation. The study will seek to identify and prioritize present-day and future CNEO role expectations. Currently, only anecdotal literature addresses this topic therefore this qualitative research study is extremely timely. Findings will be used to help clarify and communicate CNEO role expectations and performance outcomes to CNEOs, CEOs, COOs, and educators during a time of tremendous CNEO role transformation. I believe study findings will also support CNEO role preparation, role transition, role enactment, retention, and ultimately organizational success and viability.

The first step of this study is to develop an expert panel. Panel members will be CNEOs of acute care hospitals and CNEO immediate supervisors (CEOs/COOs). Expert panel members will need to have worked within integrated delivery systems in highly managed care markets (Stage III or IV) for a minimum of two years. Your organization, for study purposes, has been identified to be part of an integrated healthcare system in a highly managed care market. Panel members and their responses will remain anonymous throughout and after the study unless panelists choose to be identified. Panelists will be required to complete three surveys over a two-three month period. Each survey administration will require approximately 15 minutes. Surveys will require expert panel members to make decisions on item retention, item importance, and share opinions with fellow panel members.

Panel participation and attrition is extremely critical in this particular study as the number of potential panelists is quite small. Therefore, I hope that you can please find time to assist me in this research and complete the entire study. If you have any questions regarding this study prior to committing to participation please do not hesitate to call me at 619-541-4082.

Enclosed you will find: 1) a demographic questionnaire, 2) the Delphi instrument: Round 1,3) two consent letters for study participation (one copy to be kept for your file), and 4) a selfaddressed envelope. 
Please retum to me within 5-10 days: 1) one consent letter and 2) completed Demographic and Delphi: Round 1 questionnaires. Thank-you in advance for assisting me with this study.

Respectfully,

Daniel L. Gross, DNSc (c), RN

ㅁ Please check here if you would prefer future study information/questionnaire emailed to you for completion as opposed to traditional mail service. E-Mail Address: 


\section{APPENDIX B}

\section{DEMOGRAPHIC QUESTIONNAIRE}

\section{ROLE EXPECTATIONS OF CNEOS IN INTEGRATED HEALTHCARE DELIVERY SYSTEMS IN HIGHLY MANAGED CARE MARKETS}

Directions: Please complete the following questions by either checking a response or filling in the blank. Your responses will be used to complete a general panel profile for this study. Individual data will not be shared or published.

\section{Personal Background}

1. What is your age?

2. What is your gender?

$\square$ Female $\square$ Male

3. What academic degrees have you obtained?

\section{Professional Background}

1. What is your current position title?

2. How many years have you been in your current role?

3. How many years have you been in an administrative/leadership role?

4. How many years have you worked in an integrated delivery system located in a highly managed care market?

5. CNEO's, what is your immediate supervisors titte?

6. Do you have role responsibility for more than one hospital?

$\square$ Yes $\square$ No

7. Do you have role responsibilities that transcend inpatient hospital care?

$\square$ Yes $\square$ No

If yes, please list.

\section{Organizational Background}

1. Is your organization not-for-profit?

$\square$ Yes $\square$ No

2. What is the bed size of your hospital?

$\square<150$
$\square>501$

ㅁ $151-300$

ㄷ 301-500

3. What is your average occupancy rate?

4. What percent of your hospitals' revenue is considered to be contracted managed care? (Exclude medicare unless HMO. Include capitated, case rate, discount, per diems)

4. What percent of your hospitals' revenue is considered to be capitated managed care? 
5. What continuum of care services does your integrated healthcare delivery system provide or arrange to provide via contract or affiliation? Acute $\square$ Yes $\square$ No Rehab $\square$ Yes $\square$ No Subacute $\square$ Yes $\square$ No Home Health $\square$ Yes $\square$ No Other: 
DELPHI ROUND 1: QUESTIONNAIRE

ID\#

\section{ROLE EXPECTATIONS OF CHIEE NURSE EXECUTIVE OFFICERS IN INTEGRATED HEALTHCARE SYSTEMS LOCATED IN HIGHLY MANAGED CARE MARKETS: A DELPHI STUDY}

Qverview of Instrument: The goal of this instrument is to identify five priority present-day CNEO role expectations for CNEOs in integrated health care delivery systems in highly managed care markets.

Defintitions:

Chief Nurse Executive Officer-

A licensed registered nurse assigned responsibility for directing nursing services within an acute care hospital. Present-day CNEO Role ExpectationsIntegrated Healthcare Dellvery Sustem.

Hiahly Managed Care Market-

Current behavioral expectations required of CNEOs; duties and obligations.

a network of organizations that provides or arranges to provide a coordinated continuum of services to a defined population.

Stage III or IV managed care markets where HMO plans conlrol $31 \%$ or more of hospltals Inpatient admissions.

\section{PRIORITY PRESENT-DAY CNEOROLEEXPECTATIONS}

Directions: Please identify five priority present-day CNEO role expectations for CNEOs employed in acute care hospitals within integrated healthcare delivery systems located in highly maneged care markets. Place your priority role expectations in the space provided. If you have additional role expectations that you would like to identify please feal free to do so. To assist you in ldentitying CNEO prionity role expectations you may want to reflect upon your organizations CNEO position description, performance standards/appraisal, work schedule. meetings, andior work requests. CNEO roxe expectations may represent clinicol processes (e. clinical integretion, patient cere redesian/delivenyfinnovetion, program development).

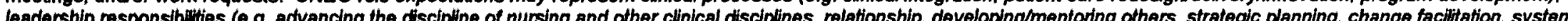

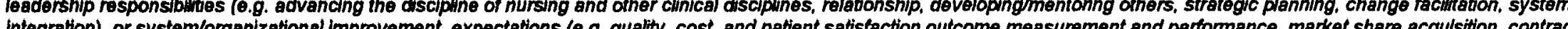
integration), or systemvorganizational mprovement expectations (e.g. quality, cost, and patient satisfaction outcome measurement and pertormance, market share acqulsition, contract
negotation, workforce planning/acquisition). Pleese be specific. ENE PRIORITY PRESENT-DAY CNEO ROLE EXPECTATIONS

1.

2.

3.

4.

5. 


\title{
APENDIX D \\ CONSENT FOR STUDY PARTICIPATION
}

October 4, 1996

\author{
Mr. John Doe \\ Chief Executive Officer \\ Mercy Hospital \\ 1111 Frost Street \\ San Francisco, CA 12121
}

Dear Mr Doe:

Thank you for your participation in this study. As you will recall, this Delphi study addresses Chief Nurse Executive Officer (CNEO) role expectations in integrated healthcare delivery systems located within highly managed care markets. You have been selected to participate in the study because of your work history and expertise. The benefit of this study is to help clarify and communicate CNEO role expectations to CNEOs, CEOs, COOs, and educators during a time of tremendous CNEO role transformation. Study findings will support CNEO role preparation, role transition, role enactment, retention, and ultimately organizational success and viability.

Your participation in this study is voluntary and you may withdraw from participation at any time without penalty or consequence. Your responses will be recorded and reported without identifying you. Research publications and presentations may result from this study. There are no anticipated physical, social, or psychological risks involved in this study. You will not receive any compensation for participation. Your participation and responses will be kept anonymous at all times.

You will find enclosed: 1) a demographic questionnaire, 2) the Delphi instrument Round 1,3) an additional copy of this letter for your files, and 4) a self-addressed, stamped envelope. Both the demographic and Delphi questionnaires have complete instructions listed at the top of each instrument. It will take approximately 15 minutes to complete the questionnaires.

Please return to me within 5-10 days: 1) a copy of this letter with your signature and 2) completed Demographic and Delphi (Round 1) questionnaires. This letter serves no purpose beyond consent for study participation and clarification of enclosed research materials. Your signature at the bottom of this letter signifies your agreement to voluntarily participate in this study. In approximately one month you will receive Round 2 of this Delphi study. The entire study will most likely include a total of three rounds 
requiring 15 minutes of your time for each round. If you have any questions regarding the study or the enclosed materials please do not hesitate to contact me at 619-541-4082.

Respectfully,

Daniel L. Gross, DNSc (c), RN 


\title{
APPENDIX E
}

\section{FOLLOW-UP INVITATION TO PARTICIPATE IN STUDY}

October 25,1996

\author{
Mr. John Doe \\ Chief Executive Officer \\ Mercy Hospital \\ 1111 Frost Street \\ San Francisco, CA 12121
}

Dear Mr. Doe:

Recently you received a copy of the enclosed demographic and Delphi questionnaires requesting your participation in a study seeking to identify and prioritize present-day and future CNEO role expectations in integrated health care delivery systems located within highly managed care markets (Stage III and IV). As mentioned in my initial letter, secondary to a small number of potential panelists, your participation is extremely critical. Therefore, I hope that you can please find time to participate in this study.

Originally, I had requested that study participants have a minimum of two years experience in integrated delivery systems and highly managed care markets. If you have only one year experience in the aforementioned market I would also like your participation. If you feel this study has been directed to you incorrectly I would appreciate your forwarding it to the appropriate executive in your organization.

Again, your participation and timely response would be greatly appreciated. Please feel free to contact me at 619-541-4082 if you have questions.

Respectfully,

Daniel L. Gross, DNSc (c), RN 


\title{
APPENDIX F
}

\section{COVER LETTER: ROUND TWO}

December 11, 1996

\author{
Mr. John Doe \\ Chief Executive Officer \\ Mercy Hospital \\ 1111 Frost Street \\ San Francisco, California 12121
}

Dear Mr Doe:

Thank you for serving as an expert panelist on my doctoral research study addressing Chief Nurse Executive Officer (CNEO) role expectations in integrated health care delivery systems located within highly managed care markets. Thirty individuals, 19 CNEO's and 11 CEO's/COO's, agreed to participate. I have completed content analysis of Round One data and have enclosed the Delphi Questionnaire: Round Two for your completion. The Delphi Questionnaire: Round Two will take approximately 10 minutes to complete.

Please complete and retum the questionnaire as soon as possible. I hope to receive Round Two data from you by the end of December and at the latest by January 6th; the earlier the better. If you have any questions please do not hesitate to call me at $619-541-4082$. Your participation is invaluable to me, there are very few experts available to assist in such contemporary research. I thank you for your time and wish you and your family the happiest of holidays. Please accept the enclosed Starbucks coffee certificate as a very small token of my appreciation for you taking time from your busy schedule to assist me in this research.

Respectfully,

Daniel L. Gross, DNSc(c), RN 


\title{
ROLE EXPECTATIONS OF CHIEF NURSE EXECUTIVE OFFICERS IN INTEGRATED HEALTH CARE SYSTEMS
} LOCATED IN HIGHLY MANAGED CARE MARKETS: A DELPHI STUDY

\begin{abstract}
Overview of instrument:
The goal of this questionnaire is to have expert panelists determine if expectations should be retained, rate the importance of each expectation, and make comments or clarfifications on priority present-day CNEO role expectations for CNEOs in integrated health care delivery systems in highly managed care markets.

Definitions:

Chief Nurse Executive Officer:

A licensed registered nurse assigned responsibilly for directing nursing services within an acute care hospltal.

Present-dav CNEO Role Expectations: Current behavioral expectations required of CNEOs; dutles and obligations. Inlegrated Health Care Dellvery Systems: A network

Hlahlv Managed Care Market: $\quad$ Stage III or IV managed care markets where HMO plans control $31 \%$ or more of hospitals inpatient admissions.
\end{abstract}

Importance Level-Scale:

Not Important-1 Somewhat Important:-2

Important-3

Extremely Important--4

DIRECTIONS: Signify whather each item should be retained by circling yes or no. Please rate each expectation by circling an importance value of 1,2.3, or 4. On each item make comments that will promote clarity and understanding of your opinion or thoughts regarding the expectation. Please feel free to modity the expectation. Additionally, add any present-day priority CNEO expectations that you feel are missing.

\section{LEADERSHIP EXPECTATIONS




\section{Communication/Relationhsip-Bullaing}

Involve subordinates in decision-making processes.

Yes No

Develop, coach, and mentor subordinates.

Foster collegial relationships across disciplines.

Produce highly elfective work groups.

Acts as an organizational representative, internally and externally.

10.

\section{Change Facilitation}

1. Lead organizational change.

Yes No

Ensure acceptance of organizational change.

Yes No

Act as an organizational cheerleader.

Intervene in organizational crises.

Yes No

Yes No

Create an environment which breaks down barriers and supports

Yes No

new ways of doing business.

7.

9.

\section{System Integration}

1. Participate in consolidating services across the health care system.

Particlpate in organizational right-sizing.

Ensure that entify culture is recognized within the system.

Cooperate with all entities within the system.

Assist in integrating diverse organizations within the system.

Assist in integrating diverse organizations within the

Share "best practices".
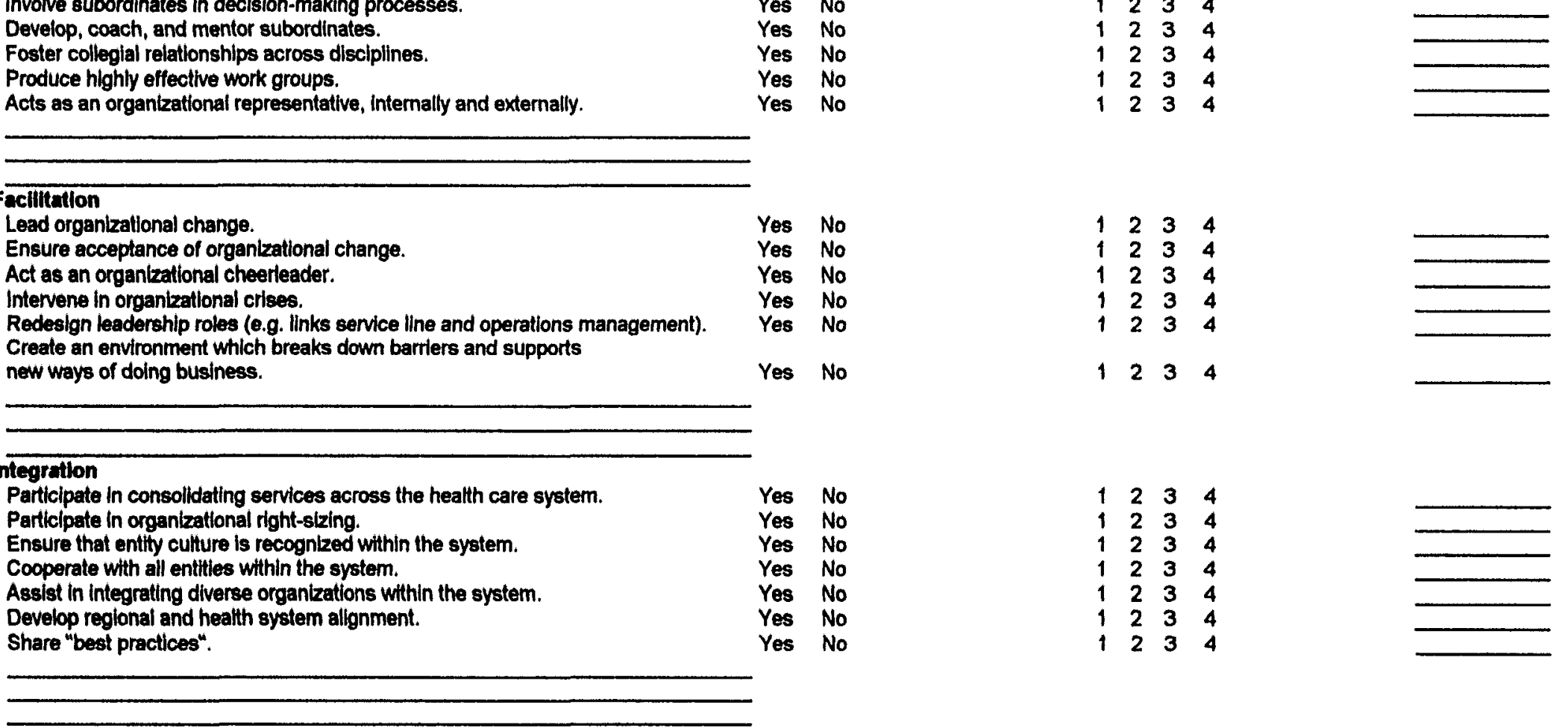
Nursing

1. Ensure delivery of safe, competent, cost-effective nursing care.

2. Establish nurse delivery models reflective of appropriate skill mix

and staffing levels.

Advance the discipline of nursing (e.g., implementation of shared

governance, role maximization, professional practice).

Develop and maintain nursing standards of care.

Represent the organization at state-wide nursing committees and boards.

Create education incentives for the nurse workforce.

implement systems which support patient billing for nursing services.
Yes No

Yes No

Yes No

Yes No

Yes No

Yes $\mathrm{No}$

10.

\section{Patient Care Redesign}

1. Redesign patient care delvery from a patient focused,

multi-disciplinary, continuum perspective.

Esnure petlent care redesign projects improve quality and reduces costs

Yes No

(e.g., multi-skilled workers, patient support associales).

Involve physiclans in patient care redesign efforts.

4. Use information systems to gulde patient care redesign.

6.

Clinical Innovation/Program Development

1. Design and implement clinical pathways. $\quad$ Yes No

Design and Implement case management care models.

Yes No

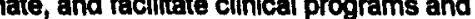

Yes No

care across the continuum (e.g. in-patient and out-patient settings).

and care guidellines across system.

Yes No

Advance inter-disciplinaly prectice (e.0., dally patient rounds).

Yes No

Merge clinical departments under an Integrated leadership team.

$\begin{array}{llll}1 & 2 & 3 & 4\end{array}$

$\begin{array}{llll}1 & 2 & 3 & 4\end{array}$

$1 \begin{array}{llll}1 & 2 & 3 & 4 \\ 1 & 2 & 3 & 4\end{array}$

$\begin{array}{lllll}1 & 2 & 3 & 4\end{array}$

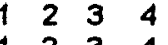

$\begin{array}{lllll}1 & 2 & 3 & 4\end{array}$

$\begin{array}{llll}1 & 2 & 3 & 4\end{array}$

$\begin{array}{llll}1 & 2 & 3 & 4\end{array}$

$\begin{array}{llll}1 & 2 & 3 & 4\end{array}$

$\begin{array}{llll}1 & 2 & 3 & 4\end{array}$

$\begin{array}{llll}1 & 2 & 3 & 4 \\ 1 & 2 & 3 & 4\end{array}$

1234

$\begin{array}{llll}1 & 2 & 3 & 4 \\ 1 & 2 & 3 & 4\end{array}$

$\begin{array}{llll}1 & 2 & 3 & 4 \\ 1 & 2 & 3 & 4\end{array}$

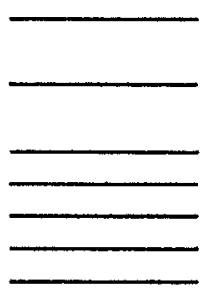

8.
8.

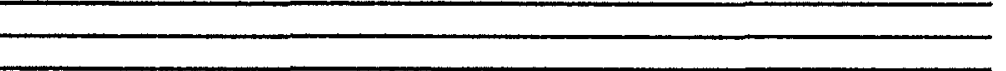

Yes No

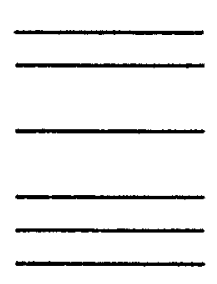


Customer Satisfaction

1. Improve patient satisfaction survey scores.

Utillze patient satisfaction benchmarks (system and national) to

evaluate patient satisfaction performance.

Yes No

$\begin{array}{llll}1 & 2 & 3 & 4\end{array}$

Yes No

Ensure physician satisfaction with patlent care dellvery processes.

$\begin{array}{llll}1 & 2 & 3 & 4\end{array}$

$\begin{array}{llll}1 & 2 & 3 & 4\end{array}$

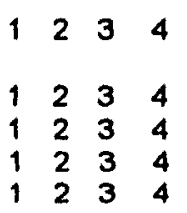

Collaborale with physicians to establish quality outcome indicators.

Yes No

Collaborate with physiclans to improve clinical

Yes

Yes No

outcomes (e.g. c-section rates, decublit incidence).

Yes No

Yes No

implernent data support systems to measure clinical pathway outcomes.

$\begin{array}{ll}5 . & \text { Implement outcome measurement to case manage across the continuum. } \\ 6 . & \end{array}$

Yes No

7.

\section{Financlal Performance}

1. Develop, monitor, and ensure compliance with organizational budgets. Reduce organizational operating expenses.

implement productlvity improvements.

Yes No

Participate in clinical contract negotiations (e.g., insurance, MD, and
state agencles).

Yes No

Negotiate physiclan salarles and productlvity levels.

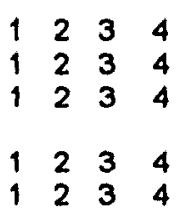

$\begin{array}{llll}1 & 2 & 3 & 4\end{array}$

$\begin{array}{llll}1 & 2 & 3 & 4 \\ 1 & 2 & 3 & 4\end{array}$

$\begin{array}{llll}1 & 2 & 3 & 4 \\ 1 & 2 & 3 & 4\end{array}$

Ensure that community health care needs are met.

Participate in setting the strategic vision for the organization.

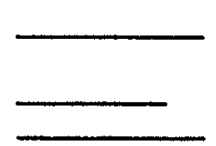




\title{
APPENDIX H
}

\section{COVER LETTER: ROUND THREE}

February 5, 1997

\author{
Mr. John Doe \\ Chief Executive Officer \\ Mercy Hospital \\ 1111 Frost Street \\ San Francisco, CA 12121
}

Dear Mr. Doe,

Thank-youl! I greatly appreciate you taking time from your busy schedule last month to complete Round II of this Delphi study. The data provided by expert panelists has been thought provoking and interesting. I've valued the information you've provided and I am extremely pleased with the comments many of you have made regarding the personal benefit gained from participating in this study.

Enclosed is a questionnaire addressing Round III, the last round, of this doctoral study. The questionnaire should take approximately 15 minutes to complete. Unfortunately, five panelists were unable to complete Round II, making it critical that I retain the remaining 25 panelists to complete this study. I know you are exceedingly busy but I hope you will be able to complete one more questionnaire.

Please complete the questionnaire over the next 5-10 days. To facilitate a timely return feel free to fax your completed questionnaire to me at $619-541-5419$ or mail it in the self addressed, stamped envelope.

Upon completion of my data analysis and subsequent doctoral defense I will mail you a summary of my findings and recommendations. Hopefully, you will find the study conclusions to be beneficial in providing CNEO role clarification, implementation, preparation, and performance evaluation.

Respectfully,

Daniel L. Gross, DNSc (c), RN 


\section{ROLE EXPECTATIONS OF CHIEF NURSE EXECUTIVE OFFICERS IN INTEGRATED HEALTH CARE DELIVERY SYSTEMS LOCATED IN HIGHLY MANAGED CARE MARKETS: A DELPHI STUDY}

Qverview of Instrument:

Definitions:

PARTI
This instrument has two parts. Part/ contains five present-day CNEO role expectations that panelists did not reach consensus (80\%) on and seven new CNEO role expectations generated during Round II. After reviewing individual and group response data, panellsts are asked to re-evaluate whether or not each of the non-consensus role expectations should be retained and rate lit's importance. Panelis's are also asked to determine if the newly identified expectations should be retained and their importance. Part $\|$ contains all 65 role expectations and panelists are asked to make a judgement as to whether or not each of the CNEO role expectations will exist five vears from todav and their anticlpated importance at that time.

Chief Nurse Executive Officer (CNEO): A licensed registered nurse assigned responsibillty for directing nursing services within an acute care hospital. Present-day CNEO Role Expectations: Current behavioral expectations required of CNEOs; duties and obligations. Euture CNEO Role Expectations: Behavior expectations required of CNEOs five years from today; dutles and obligations.

Inlegrated Health Care Dellvery Systems: A network of organlzations that provides or arranges to provide a coordinated continuum of services to a defined

Hiahly Managed Care Market: $\quad$ Stage III or IV managed care markets where HMO plans control 31\% or more of hospltals inpatient admissions.

DIRECTIONS: Plapse reviow esch of the five CNEO role expectations that panellsts did not reach consensus on by rovlowing your earller oplnion along with aggregate panel data. Individual panellst comments, if made, are ilsted below each expectation to ass/st you in ro-evaluating your opinion. For each of the five expectations as well as the soven newly identified CNEO role expectattons slgnify whether each ltem should be retalned by circling yes or no. Paese rate each expectation by circling an importance value of 1 (noc important), 2 (somewhat important), 3 (important), or 4 (extremely important).

\section{NON-CONSENSUS CNEO ROLEEXPECTATIONS}

1.

Responsible for only nursing services

Comments:

Do not retain, CNEO role addresses more than one discipline.

Coordination of continuum services requires accounlabillty beyond nursing.

If done well, nursing service responsibility is more than enough.

Most CNEOs have broader responsibilitles than Just nursing.

Job is much more than just nursing.

Acute care services are interdependent on all disciplines.

Nursing services need to identify with CNEO, but that does not preclude additional responsibiltties.

The CNEO is the expert clinician who can best represent all non-physician clinical services at the executive level.

CNEO role must exlst but can have other accountabilities for product lines and clinical services.

NON-CONSENSUS CNEO ROLE EXPECTATIONS

\section{RETAN ITEM: YES ORNO}

Yes No

Your previous opinion:

Aggregate opinion: $32 \%$ (yes)

$56 \%$ (no)

$12 \%$ (no opinion)
IMPORTANCE RATING

1234

Your previous rating:

Mean Score: 3.18 
Comments:

Not In managed care; cannot implement separate billing systems.

Your previous opinion:

Your previous rating

Billing is a non-lssue in managed care; value added is the focus

Immalerial in a cost-based system.

Aggregate opinion: $48 \%$ (res)

Mean Score: 2.21

Nursing seen as a cost center not a revenue center; need to know your costs.

Aggregate opinion: $48 \%$ (yes)
$48 \%$ (no)

$48 \%$ (no)
$4 \%$ (no opinion)

Doesn't matter in a capitated in environment.
Billing for individual services unimportant; cost of service per case type or population is important.

Design and implement clinical pathways.

Yes No

$\begin{array}{llll}1 & 2 & 3 & 4\end{array}$

Comments:

Nursing plays a strong supporting role in thls area but shouldn't be the lead.

Your prevlous opinion:

Your prevlous rating:

\section{Delegate but provide leadership.}

Best developed by those who deliver the care.

Develop with a multi-disciplinary team.

Aggregale opinion: $76 \%$ (yes)

$24 \%(\mathrm{no})$

Develop for unpredictable patient populations; don't overprocess or overmanage.

4. Participate in clinical contract negotiations (e.g., Insurance, MD, and state agencies).

Yes No

$\begin{array}{llll}1 & 2 & 3 & 4\end{array}$

Comments:

Others do that.

Your previous opinion:

Your previous rating:

As it relates to service line responsibilitites.

Input is given to responsible person.

Aggregate opinion: $56 \%$ (yes)

Service line VP responsibility.

Aggregate opinion: $56 \%$ (yes)
$44 \%$ (no)

Mean Score: 2.72

This is critical for the CNEO to assist with; outcomes will effect organizational financial performance. 


\section{NEWROUND II IDENTIFIED GNEO ROLE EXPECTATIONS}

1. Responsible for oversight of the organizations quality program.

2. Ensure nursing and administration visiblity through "ceremonial" activities.

3. Develop electronic medical records and documentation systems.

4. Utilize health services research principles in patient care redesign efforts.

5. Use technology to complement redesign efforts.

6. Demonstrate value of redesign efforts by enhancing clinical, financial, and customer service outcomes.

7. Ensure employee satlsfaction levels are malntained and /or improved.

\section{RETAIN ITEM: YES OR NO}

Yes No

Yes No

Yes No

Yes No

Yes No

Yes No

Yes No
IMPORTANCE RATING

$\begin{array}{llll}1 & 2 & 3 & 4\end{array}$

$\begin{array}{llll}1 & 2 & 3 & 4\end{array}$

1234

1234

$\begin{array}{llll}1 & 2 & 3 & 4\end{array}$

$\begin{array}{llll}1 & 2 & 3 & 4\end{array}$

$\begin{array}{llll}1 & 2 & 3 & 4\end{array}$ 


\section{LEADERSHIP EXPECTATIONS}

Scope

Responsible for only nursing services.

2. Responsible for multiple clinical services (e.g., lab)

3. Responsible for product and service lines.

4. Responsible for program and project design and implementation

5. Responsible for oversight of the organizations quality program.

Communication/Relationshlp-Bullding

6. Communicate openly with nurses, physiclans, and managers.

7. Conduct routine management meetings to disseminate information and

obtain input and feedback from subordinates.

Involve subordinates in decision-making processes.

Develop, coach, and mentor subordinates.

Foster collegial relationships across disciplines.

Produce highty effective work groups.

Act as an organizational representative, Internally and externally.

Ensure nursing and administration visibility through "ceremonial" activities.

\section{Change Facilitation}

14. Lead organizational change.

15. Ensure acceptance of organizational change.

16. Act as an organizational cheerleader.

17. Intervene in organizational crises.

18. Redesign leadership roles (e.g. links service line and operations management).

19. Create an environment which breaks down barriers and support new ways of doing business System Integration

20. Participale in consolidating services across the health care system.

Participate in organizational right-sizing.

Ensure that entity culture is recognized within the system.

Cooperate with all entilies within the system.

Assist in integrating diverse organizations within the system.

Develop regional and health system alignment.

Share "best practices".

\section{RETAIN ITEM: YES OR NO IMPORTANCERATING}

\begin{tabular}{|c|c|c|c|c|c|}
\hline Yes & No & 1 & 2 & 3 & 4 \\
\hline Yes & No & 1 & 2 & 3 & 4 \\
\hline Yes & No & 1 & 2 & 3 & 4 \\
\hline Yes & No & 1 & 2 & 3 & 4 \\
\hline Yes & No & 1 & 2 & 3 & 4 \\
\hline Yes & No & 1 & 2 & 3 & 4 \\
\hline Yes & No & 1 & 2 & 3 & 4 \\
\hline Yes & No & 1 & 2 & 3 & 4 \\
\hline Yes & No & 1 & 2 & 3 & 4 \\
\hline Yes & No & 1 & 2 & 3 & 4 \\
\hline Yes & No & 1 & 2 & 3 & 4 \\
\hline Yes & No & 1 & 2 & 3 & 4 \\
\hline Yes & No & 1 & 2 & 3 & 4 \\
\hline Yes & No & 1 & 2 & 3 & 4 \\
\hline Yes & No & 1 & 2 & 3 & 4 \\
\hline Yes & No & 1 & 2 & 3 & 4 \\
\hline Yes & No & 1 & 2 & 3 & 4 \\
\hline Yes & No & 1 & 2 & 3 & 4 \\
\hline Yes & No & 1 & 2 & 3 & 4 \\
\hline RETAN ITEM: & YES ORNO & IMPOF & IAN & CEF & ATING \\
\hline Yes & No & 1 & 2 & 3 & 4 \\
\hline Yes & No & 1 & 2 & 3 & 4 \\
\hline Yes & No & 1 & 2 & 3 & 4 \\
\hline Yes & No & 1 & 2 & 3 & 4 \\
\hline Yes & No & 1 & 2 & 3 & 4 \\
\hline Yes & No & 1 & 2 & 3 & 4 \\
\hline Yes & No & 1 & 2 & 3 & 4 \\
\hline
\end{tabular}




\section{$\infty$ II. CLINICAL EXPECTATIONS}

\section{Nursing}

27. Ensure delivery of safe, competent, cost-effective nursing care.

Yes No

Establish nurse delivery models reflective of appropriate skill mix

and stafing levels.

Yes No

Advance the discipline of nursing (e.g. implementation of shared

Yes No

.

30. Develop and maintain nursing standards of care.

31. Represent the organization at state-wide nursing committees and boards.

Yes No

Create educalion incentives for the nurse workforce.

implement systems which support patient billing for nursing services.

Develop electronic medical records and documentation systems.

Yes No

Yes No

Yes No

Yes No

\section{Pattent Care Redesign}

35. Redesign patient care delivery from a patient focused, multi-disciplinary, continuum perspective.

36. Ensure palient care redesign projects improve quality and reduces costs

(e.g., multi-skilled workers, patient support assoclates).

Involve physicians in patient care redesign efforts.

Use information systems to gulde patlent care redesign.

Utilize health services research principles in patient care redesign elforts.

Use technology to compliment redesign efforts.

41. Demonstrate value of redesign efforts by enhancing clinical, financial, and customer service outcomes.

\section{Clinical innovation/Program Development}

42. Design and implement clinical pathways.

43. Design and implement case management care models.

44. Integrate, coordinate, and faciltate clinical programs and

care across the continuum (e.g., In-patient and out-patient settings)

45. Standardize policies and procedures, clinical protocols.

and care guidelines across system.

46. Advance inter-disciplinary practice (e.g., daily patient rounds).

47. Merge clinical departments under an Integrated leadership leam.

Yes No

Yes No

Yes No

Yes No

Yes No

Yes No

Yes No

Yes No

Yes No

Yes No

Yes No

Yes No $\begin{array}{llll}1 & 2 & 3 & 4\end{array}$

$\begin{array}{llll}1 & 2 & 3 & 4\end{array}$

$\begin{array}{llll}1 & 2 & 3 & 4\end{array}$

1234

$\begin{array}{llll}1 & 2 & 3 & 4\end{array}$

$\begin{array}{llll}1 & 2 & 3 & 4\end{array}$

$\begin{array}{llll}1 & 2 & 3 & 4\end{array}$

$\begin{array}{llll}1 & 2 & 3 & 4\end{array}$

$\begin{array}{llll}1 & 2 & 3 & 4\end{array}$

$\begin{array}{llll}1 & 2 & 3 & 4\end{array}$

$\begin{array}{llll}1 & 2 & 3 & 4\end{array}$

$\begin{array}{llll}1 & 2 & 3 & 4\end{array}$

$\begin{array}{llll}1 & 2 & 3 & 4\end{array}$

$\begin{array}{llll}1 & 2 & 3 & 4\end{array}$

1234

1234

1234

$\begin{array}{llll}1 & 2 & 3 & 4\end{array}$

1234 


\section{O) III. SYSTEMIORGANIZATIONALIMPROVEMENT EXPECTATIONS}

Customer Satisfaction

48. Improve patient satisfaction survey scores.

49. Utilize patient satisfaction benchmarks (system and national) to

evaluate patient satisfaction performance.

50. Ensure physiclan satisfaction with patient care delivery processes.

51. Ensure employee satisfaction levels are maintained and/or Improved. Quality Performance

52. Collaborate with physiclans to establish quality outcome indicators.

53. Collaborate with physicians to improve clinical

outcomes (e.g., c-section rates, decubitt incidence).

54. Sponsor hospltal-wide continuous quality improvement teams.

56. Implement data support systems to measure clinical pathway outcomes.

56. Implement outcome measurement to case manage across the continuum

\section{Financial Performance}

57. Develop, monitor, and ensure compliance with organizational budgets.

58. Reduce organizational operating expenses.

59. Implement productivity improvements.

6. Participate in clinical contract negotiations (e.g., insurance, MD, and state agencies).

61. Negotiate physiclan salaries and productivity levels.

\section{Strategic Pianning}

62. Develop strategic plan which addresses future workforce needs,

market share acquistion, and financlal goal achievement.

6. Ensure that community health care needs are met.

64. Participate in setting the strategic vision for the organization.

65. Ensure that the organizations mission is met.

\section{RETAINITEM: YES OR NO}

Yes No

Yes No

Yes No

Yes No

Yes No

Yes No

Yes No

Yes No

Yes No

Yes No

Yes No

Yes No

Yes No

Yes No

Yes No

Yes No

Yes No

Yes No
IMPORTANCE RATING

$\begin{array}{llll}1 & 2 & 4\end{array}$

$\begin{array}{llll}1 & 2 & 3 & 4\end{array}$

$\begin{array}{llll}1 & 2 & 3 & 4\end{array}$

$\begin{array}{llll}1 & 2 & 3 & 4\end{array}$

$\begin{array}{llll}1 & 2 & 3 & 4\end{array}$

1234

$\begin{array}{llll}1 & 2 & 3 & 4\end{array}$

$\begin{array}{llll}1 & 2 & 3 & 4\end{array}$

1234

$\begin{array}{llll}1 & 2 & 3 & 4\end{array}$

$\begin{array}{llll}1 & 2 & 3 & 4\end{array}$

$\begin{array}{llll}1 & 2 & 3 & 4\end{array}$

1234

$\begin{array}{llll}1 & 2 & 3 & 4\end{array}$

$\begin{array}{llll}1 & 2 & 3 & 4\end{array}$

1234

$\begin{array}{llll}1 & 2 & 3 & 4\end{array}$

1234

\section{Additional Future CNEO Role Expectations}


Please make comment regarding the future direction, Importance, or evolution of the Chlef Nurse Executive Officer role in integrated healcare dellvery systems in highly managed care markets.

THANK YOU II 